\title{
Numerical Simulation of Inter-basin Groundwater Flow into Northern Yucca Flat, Nevada National Security Site, Using the Death Valley Regional Flow System Model
}

\author{
prepared by \\ Karl Pohlmann and Ming Ye \\ submitted to \\ Nevada Site Office \\ National Nuclear Security Administration \\ U.S. Department of Energy \\ Las Vegas, Nevada
}

March 2012

PUBLICATION \#45235 
Reference herein to any specific commercial product, process, or service by trade name, trademark, manufacturer, or otherwise, does not necessarily constitute or imply its endorsement, recommendation, or favoring by the United States Government or any agency thereof or its contractors or subcontractors.

Available for sale to the public from:

U.S. Department of Commerce

National Technical Information Service

5301 Shawnee Road

Alexandria, VA 22312

Phone: 800.553.6847

Fax: 703.605.6900

Email: orders@ntis.gov

Online ordering: http://www.osti.gov/ordering.htm

Available electronically at http://www.osti.gov/bridge

Available for a processing fee to the U.S. Department of Energy and its contractors, in paper, from:

U.S. Department of Energy

Office of Scientific and Technical Information

P.O. Box 62

Oak Ridge, TN 37831-0062

Phone: 865.576.8401

Fax: 865.576.5728

Email: reports@adonis.osti.gov 


\title{
Numerical Simulation of Inter-basin Groundwater Flow into Northern Yucca Flat, Nevada National Security Site, Using the Death Valley Regional Flow System Model
}

\author{
prepared by \\ Karl Pohlmann and Ming Ye \\ Division of Hydrologic Sciences, Desert Research Institute \\ Nevada System of Higher Education
}

Publication No. 45235

submitted to

Nevada Site Office

National Nuclear Security Administration

U.S. Department of Energy

Las Vegas, Nevada

March 2012

The work upon which this report is based was supported by the U.S. Department of Energy under Contract \#DE-AC52-06NA26383. Approved for public release; further dissemination unlimited. 
THIS PAGE INTENTIONALLY LEFT BLANK 


\section{EXECUTIVE SUMMARY}

Models of groundwater flow for the Yucca Flat area of the Nevada National Security Site (NNSS) are under development by the U.S. Department of Energy (DOE) for corrective action investigations of the Yucca Flat-Climax Mine Corrective Action Unit (CAU). One important aspect of these models is the quantity of inter-basin groundwater flow from regional systems to the north. This component of flow, together with its uncertainty, must be properly accounted for in the CAU flow models to provide a defensible regional framework for calculations of radionuclide transport that will support determinations of the Yucca FlatClimax Mine contaminant boundary. Because characterizing flow boundary conditions in northern Yucca Flat requires evaluation to a higher level of detail than the scale of the Yucca Flat-Climax Mine CAU model can efficiently provide, a study more focused on this aspect of the model was required.

The Climax Mine sub-CAU flow model was developed for DOE's Underground Test Area (UGTA) program to predict groundwater flow rates for the northern boundaries of Yucca Flat-Climax Mine CAU model while incorporating alternative conceptualizations of the hydrogeologic system (five groundwater recharge models and five subsurface hydrostratigraphic models) and the uncertainty associated with these multiple conceptual models (Pohlmann et al., 2007). Though the models honor regional and local measurements of hydraulic head and groundwater flow through the model calibration process, the range of uncertainty in simulated inter-basin flows to northern Yucca Flat did not fully encompass low flows estimated by other means. Flows simulated by individual calibrated sub-CAU models exceed $44,400 \mathrm{~m}^{3} / \mathrm{d}$, flows simulated by other numerical models are less than about $25,000 \mathrm{~m}^{3} / \mathrm{d}$, and flows estimated through regional water-balance calculations are about 1,200 $\mathrm{m}^{3} / \mathrm{d}$ (Winograd and Thordarson, 1975). Differences between these estimates reflect uncertainty in methodology, model parameters, and model conceptualization.

It is the objective of this study to determine whether the Climax Mine sub-CAU flow model can simulate inter-basin flows into northern Yucca Flat, denoted as $Q_{y}$, that are on the order of other estimates given available hydrogeologic models and revised model parameters considered in this study. The analysis is not restricted to the regional lower carbonate aquifer through which the vast majority of flow occurs; all hydrostratigraphic units that may affect inter-basin flow are considered including all sensitive parameters. The goal is to minimize $\mathrm{Q}_{\mathrm{y}}$ while maintaining acceptable model goodness-of-fit (through minimizing the sum of squared weighted residuals, or SSWR, between simulated values and observations). The evaluation is accomplished through revisions to the Climax Mine sub-CAU model with particular emphasis placed on evaluation of parameters, particularly hydraulic conductivity and drain conductance, critical to inter-basin flow to northern Yucca Flat. Given that up to 50 parameters are chosen for calibration, the task of identifying which parameters are the most critical to estimation of $\mathrm{Q}_{\mathrm{y}}$ is accomplished using the Morris method (Morris, 1991) as a screening tool. Once identified, these critical parameters are varied through their uncertainty ranges in Monte Carlo simulations to produce multiple realizations of the model from which optimal combinations of $\mathrm{Q}_{\mathrm{y}}$ and SSWR can be selected and analyzed.

The regional groundwater flow context for the sub-CAU model is provided through the use of the Death Valley Regional Flow System (DVRFS) model framework (Belcher et al., 2004), which is the most complete and up-to-date regional model encompassing Yucca Flat. 
The revised sub-CAU model is converted to steady-state from the original transient state to reduce simulation times, thereby making more efficient use of computational resources. Existing hydrostratigraphic framework and recharge models in the sub-CAU model are utilized unmodified as these are assumed to fully represent conceptual model uncertainty. Only those models found to be most plausible in the sub-CAU model (Pohlmann et al., 2007) are incorporated here. These include three hydrostratigraphic framework models (DVRFS, UGTA Base, and UGTA CP-Thrust) and two recharge models (net infiltration with runonrunoff and chloride mass-balance with alluvial and elevation masks). Thus, six combinations of conceptual models are included in this analysis. Limited analysis of estimated perimeter boundary flow volumes and their observation weights are also conducted to address their impacts on Yucca Flat flow. Other aspects of the DVRFS model are not tested because the USGS is currently making major updates and revisions to the model to address some of these same issues, among others.

Six to nine (depending on the model) of the nearly 50 calibration parameters considered are identified as critical to simulation of $\mathrm{Q}_{\mathrm{y}}$. As expected, five of these are parameters that specify hydraulic conductivity values in zones of the lower carbonate aquifer that define a regional flow path extending from the northern DVRFS south through Yucca Flat. Also critical are three hydraulic conductivity parameters in volcanic and intrusive units and one drain parameter. These parameters are also associated with the same regional flow path and play a role in the volume of flow that is simulated through the Yucca Flat flow system.

Only a small percentage of the Monte Carlo realizations for each conceptual model combination are found to meet the constraint that $\mathrm{Q}_{\mathrm{y}}$ be less than 25,000 $\mathrm{m}^{3} / \mathrm{d}$ (a value chosen to be consistent with the independent estimates). Of these, the realization with the lowest SSWR is selected for each of the six model combinations. Results show that interbasin flows ranging from 19,000 to $25,000 \mathrm{~m}^{3} / \mathrm{d}$ can be simulated with acceptable goodnessof-fit to observation data, although the goodness-of-fit is not as high as for their associated calibrated models. Examination of water budgets, statistics of the simulated values, residuals, and spatial distributions of the residuals indicates that the simulation results for the six selected realizations are reasonable and consistent with the DVRFS model.

Three factors contribute to lower inter-basin flows into Yucca Flat as compared to the DVRFS and 2007 sub-CAU models. First and most important, boundary inflow simulated at the Stone Cabin-Railroad segment is significantly reduced as a result of reduction in the hydraulic conductivity values of K221_LCA and K422LNEVSU, which both extend from northern Yucca Flat to the northern part of the domain. Second, changes in drain discharge (representing springs and evapotranspiration) occur upgradient of Yucca Flat in Penoyer Valley where increased heads in the area increase evapotranspiration and thus reduce flow toward Yucca Flat. Third and least important, is the redistribution of a portion of flow through flow systems that circumvent Yucca Flat.

Several aspects of the DVRFS modeling framework limit further reduction of simulated inter-basin flow rate into northern Yucca Flat. First, the volume of discharge simulated in Ash Meadows is strongly linked to high flow rates simulated further north in the Ash Meadows flow system that includes Yucca Flat. Routing flow in this system around Yucca Flat (to reduce flow into Yucca Flat while maintaining discharge volume in Ash Meadows) would be feasible only if subsurface data support reducing the extent, continuity, 
and/or hydraulic conductivity values of the lower carbonate aquifer north of Yucca Flat. Second, large uncertainties associated with estimates of flow through outer perimeter constant-head boundaries allow some segments to simulate flow rates that are very different from estimates. This is particularly an issue at the critical Stone Cabin-Railroad segment where simulated flow is almost seven times greater than the estimate. Third, inter-basin flow rates are not used as calibration targets to better constrain internal flow rates. Though direct measurements of these flows are unavailable, reasonable estimates can be based on regional water budgets (Harrill et al., 1988) and isotope mixing models (Carroll et al., 2008). Finally, head observations dominate the objective function in terms of both numbers and their relative weights, though boundary flow and discharge observations have a more direct relationship to simulated flows. Declustering head observations or reducing their weights in the objective function would allow boundary flow and discharge to play a more significant role in calibration. These limitations are related and a systematic investigation to address them would lead to improved performance and applicability of the DVRFS modeling framework.

A preliminary test of the boundary-flow aspect was performed by constraining flow through the Stone Cabin-Railroad segment to a value closer to the estimated value in a revised calibration run of model G3R2. Though the results show that simulated flow into northern Yucca Flat can be reduced through this mechanism, goodness-of-fit to observations of discharge and constant-head boundary flows deteriorated. A comprehensive analysis of the DVRFS modeling framework is suggested to address whether other components of the model can be revised to improve fit and whether further reduction of simulated flow into northern Yucca Flat to conceptualized values is feasible.

The models developed in this study are more consistent than the 2007 Climax Mine sub-CAU model in terms of matching estimated inflow along the northern DVRFS model boundaries and matching measured discharge values. Though these models simulate interbasin flows into northern Yucca Flat that are lower than those simulated by the DVRFS model and the 2007 sub-CAU model, relatively few realizations of the multiple conceptual models are capable of simulating flows less than $25,000 \mathrm{~m}^{3} / \mathrm{d}$. These lower flows were obtained by systematic adjustment of model parameterization. Further reductions may only be possible by substantial modifications to other aspects of the model such as reducing the extent, continuity, or hydraulic conductivity of the lower carbonate aquifer north of Yucca Flat, increasing the weights of boundary flow observations, and revising selected boundary flow estimates. With regard to the carbonate system, it should be noted that USGS and UGTA geologists agree on the general distribution of the LCA north of Yucca Flat as it is represented in the DVRFS model. In any case, consideration must be given to the challenges inherent to estimating subsurface flow volumes where direct measurement of inflow to northern Yucca Flat is not possible and large uncertainties remain in the conceptualization of the system. 


\section{ACKNOWLEDGEMENTS}

The authors thank Tiraz Birdie (N-I), Ed Kwicklis (LANL) and Robert Andrews (N-I) for informative discussions regarding the configuration and status of the Yucca Flat CAU flow models and for their reviews of this report, Rick Waddell (GeoTrans, Inc.) for ongoing conversations about boundary conditions in the DVRFS model, and Claudia Faunt (USGS) for instructive consultations on the configuration of the DVRFS model. We also acknowledge the insightful comments provided by the Preemptive Review Committee for the Yucca Flat Flow and Transport Model chaired by Andy Tompson (LLNL), and consisting of Bruce Crowe (N-I), Keith Halford (USGS), Gayle Pawloski (LLNL), Greg Pohll (DRI), Chuck Russell (DRI), Rick Waddell (GeoTrans, Inc.), Vefa Yucel (NSTec), and Mavrik Zavarin (LLNL). 


\section{CONTENTS}

Executive Summary ………………............................................................................... ii

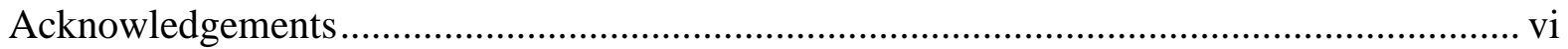

List of Figures ................................................................................................................

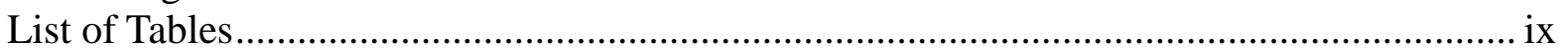

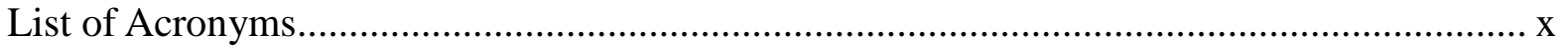

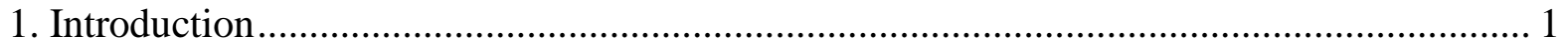

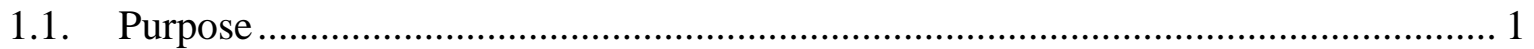

$1.2 \quad$ Estimates of Inter-Basin Flow ....................................................................... 2

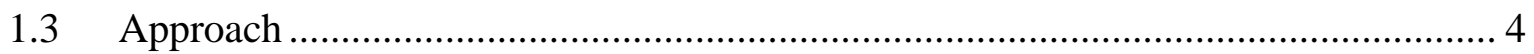

2. Objectives and Methods.............................................................................................. 9

2.1 Six Alternative Groundwater Models...................................................................... 9

2.1.1 Recharge Estimation Methods ................................................................. 9

2.1.2 Geological Interpretations in Northern Yucca Flat ............................................ 10

2.2 Estimation of Inter-Basin Flow and Model Calibration..............................................11

2.3 Morris Method for Identifying Critical Parameters for $\mathrm{Q}_{\mathrm{y}}$ ……………………….... 12

2.4 Uncertainty Analysis of $\mathrm{Q}_{\mathrm{y}}$ Estimates ................................................................... 13

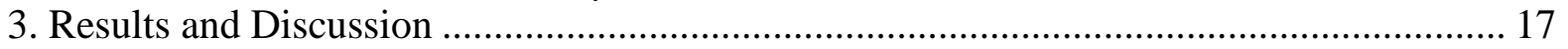

3.1 Results of Model Calibration ....................................................................... 17

3.2 Results of Morris Analysis ........................................................................................ 18

3.3 Results of MC Simulations and Selection of Optimum Realizations ....................... 24

3.4 Examination of Selected Realizations................................................................. 26

3.4.1 Water budget ..................................................................................................... 26

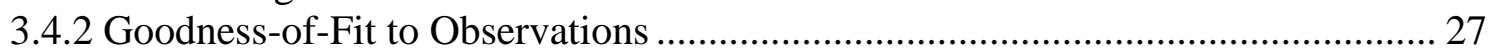

3.5 Aspects of the Model that Influence $\mathrm{Q}_{\mathrm{y}}$....................................................................... 33

3.6 Assessment of Relative Model Performance ........................................................... 41

3.7 Limitations of the DVRFS-based Models for Simulation of $\mathrm{Q}_{\mathrm{y}}$.............................. 42

3.8 Preliminary Investigation of Effects of Boundary Flow on Estimation of $\mathrm{Q}_{\mathrm{y}}$......... 43

4. Summary and Conclusions ......................................................................................... 51

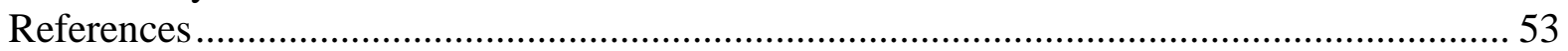

Appendix A. Tables and Figures for MODELS G1R5, G2R2, G2R5, G3R2 and G3R5 ....... 57

Appendix B. Conversion of the Climax sub-CAU Flow Model to Steady State

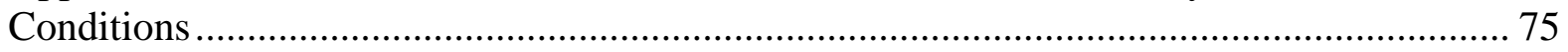

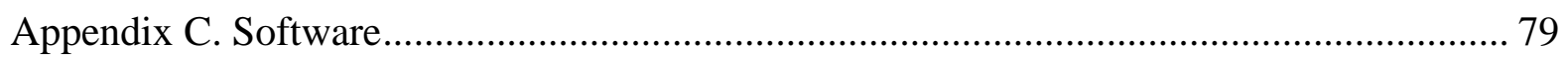




\section{LIST OF FIGURES}

1. Total inter-basin flow into northern Yucca Flat simulated by the 2007 Climax Mine sub-CAU calibrated model. ............................................................................................. 2

2. Example of a centered parameter study; $\mathrm{d} 1$ and $\mathrm{d} 2$ represent two parameters.................... 6

3. The relationship between $\mathrm{Q}_{\mathrm{y}}$ (red squares) and SSWR (green squares) with model parameters (a) DEEP_DRN, (b)K11_ICU, (c) K221_LCA, (d) K241LCA_T1,(e) K242G_LCA, (f) K242A_LCA, (g) K243_LCA, (h) K4222S_VSU, and (i) K422LNEVSU. DEEP_DRN is a drain conductance used to simulate deep, warmwater springs and springs in playa deposits.

4. Locations of the northern Yucca Flat area (shaded), the cross section (red) through which the inter-basin groundwater flow into northern Yucca Flat is estimated, and the two cross sections (blue) representing the northern and southern boundary of the northern Yucca Flat Area

5. MOGA Pareto front obtained from 2,500 simulations of 20 generations......

6. Mean and standard deviation of the elementary effects identified in the Morris analysis for (a) all 44 parameters and (b) 42 parameters after excluding the two parameters marked in red in (a).

7. Spatial distributions of hydraulic conductivity parameters K242G_LCA, K243_LCA, K242A_LCA, and K221_LCA. 22

8. Spatial distributions of hydraulic conductivity parameters K422S_VSU, and K422LNEVSU, and drain parameter DEEP_DRN. 22

9. Spatial distribution of hydraulic conductivity parameter K11_ICU.................................. 23

10. Spatial distribution of hydraulic conductivity parameter K241LCA_T1 .......................... 23

11. Histograms of the $\mathrm{Q}_{\mathrm{y}}$ estimates for the six models......................................................... 24

12. Probability density functions of the $\mathrm{Q}_{\mathrm{y}}$ estimates for the six models............................... 25

13. Plot of $\mathrm{Q}_{\mathrm{y}}$ and SSWR for model G3R2 showing (a) all 2,000 realizations, and (b) the realizations with the lowest values of $\mathrm{Q}_{\mathrm{y}}$ and SSWR.

14. Weighted residuals and weighted simulated equivalents for (a) hydraulic head and (b) discharge (blue) and constant-head boundary flow (yellow).

15. Weighted observed value and weighted simulated values for (a) hydraulic head and (b) discharge (blue) and constant-head boundary flow (yellow). 29

16. Spatial distribution of unweighted head residuals and the contours of hydraulic head in layer 1 of model G3R2.

17. Distribution of weighted head residuals and the contours of hydraulic head in layer 1 of model G3R2.

18. Contours of $\mathrm{Q}_{\mathrm{y}}$ in northern Yucca Flat for the calibrated G3R2 model at (a) cross section $\mathrm{J}=63$ and (b) cross section $\mathrm{J}=101$, and for realization 1768 at (c) cross section $\mathrm{J}=63$ and (d) cross section $\mathrm{J}=101$

19. Contours of $\mathrm{Q}_{\mathrm{y}}$ across the entire model domain for the calibrated G3R2 model at (a) cross section $\mathrm{J}=63$ and (b) cross section $\mathrm{J}=101$, and for realization 1768 at (c) cross

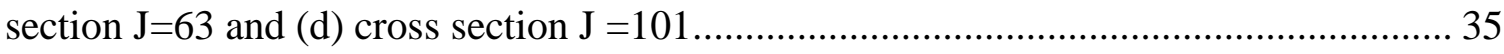

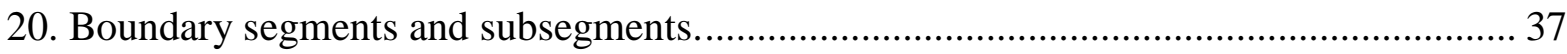

21. Plots of $\mathrm{Q}_{\mathrm{y}}$ estimate with simulated flow rate at the six boundary segments. .................. 38 
22. Model cell groups representing drains used to simulate natural ground-water discharge.

23. The relationship between the $\mathrm{Q}_{\mathrm{y}}$ estimate and summed spring discharges in Ash

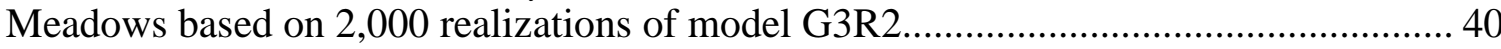

24. The relationships between three kinds of SSWRs and $Q_{y}$.

25. Distribution of weighted head residuals and the contours of hydraulic head in layer 1 of model G3R2.

26. Weighted observed value and weighted simulated values in model G3R2 for (a) hydraulic head (filled red square for original calibration and open blue square for revised calibration) and (b) discharge (filled blue triangle for original calibration and open red triangle for revised calibration) and constant-head boundary flow (filled yellow gradient for original calibration and open green gradient for revised calibration).

27. Contours of $\mathrm{Q}_{\mathrm{y}}$ in northern Yucca Flat for model G3R2 at (a) cross section $\mathrm{J}=63$ and (b) cross section $\mathrm{J}=101$, and across the entire model domain at (c) cross section $\mathrm{J}=63$ and (d) cross section $\mathrm{J}=101$ in the new calibration.

\section{LIST OF TABLES}

1. Optimum $\mathrm{Q}_{\mathrm{y}}$ and SSWR values and ensemble statistics for the MC simulations. There are 2,000 realizations simulated for each model.

2. Number of calibrated parameters, $Q_{y}$ value and SSWR value associated with the final calibration results for each model.

3. Mean $(\mu)$ and standard deviation $(\sigma)$ of the elementary effects from the Morris analysis of model G3R2. The nine critical parameters are identified in red.................... 20

4. Ranges of the nine critical parameters from the Morris analysis for model G3R2. ........ 21

5. Simulated water budgets for the entire model domain for the optimal realization of each of the six models.

6. Simulated water budgets for the northern Yucca Flat area for the optimal realization of each of the six models.

7. Summary statistics for measures of goodness-of-fit for model G3R2........................... 28

8. Observed discharge values, simulated discharge values, and weighted residuals for model G3R2.

9. Observed, simulated constant-head boundary flow values, and residuals for model G3R2

10. The range of unweighted and weighted hydraulic head residuals for model G3R2 ........ 32

11. Water budgets for the northern Yucca Flat area for the calibrated G3R2 model and realization 1768 .

12. Water budgets for the entire domain for the calibrated model and realization 1768 ....... 36

13. Unweighted observations (estimated for the model) and simulated values of constant-head boundary flow. 
14. Drains whose unweighted simulated values differ by more than $1,000 \mathrm{~m}^{3} / \mathrm{d}$ between the calibrated model and realization 1768 .

15. Observations and simulated values of constant-head boundary flows for all six

models.

16. Summary statistics for measures of goodness-of-fit for model G3R2.

17. Observed discharge values $\left(\mathrm{m}^{3} / \mathrm{d}\right)$ and corresponding simulated values using the original and revised weight for the Stone Cabin-Railroad boundary segment in model G3R2.

18. Estimated (used as observations in calibration) and simulated values of constanthead boundary flow using the original and revised weight for the Stone CabinRailroad boundary segment in model G3R2.

\section{LIST OF ACRONYMS}

$\begin{array}{ll}\text { CAU } & \text { Corrective Action Unit } \\ \text { CP } & \text { Control Point } \\ \text { CSS } & \text { Composite Scaled Sensitivity } \\ \text { DAKOTA } & \text { Design Analysis Kit for Optimization and Terascale Applications } \\ \text { DVRFS } & \text { Death Valley Regional Flow System } \\ \text { SD } & \text { Delta Deuterium } \\ \text { HFM } & \text { Hydrostratigraphic Framework Models } \\ \text { LCA } & \text { Lower Carbonate Aquifer } \\ \text { MC } & \text { Monte Carlo } \\ \text { MOGA } & \text { Multi-Objective Genetic Algorithm } \\ \text { NNSS } & \text { Nevada National Security Site } \\ \text { NOBs } & \text { Number of Observations } \\ \text { PES } & \text { Parameter Estimation } \\ \text { SSWR } & \text { Sum of Squared Weighted Residuals } \\ \text { UCA } & \text { Upper Carbonate-Rock Aquifer } \\ \text { UCCU } & \text { Upper Clastic Confining Unit } \\ \text { UGTA } & \text { Underground Test Area } \\ \text { USGS } & \text { U.S. Geological Survey } \\ \text { UTM } & \text { Universal Transverse Mercator }\end{array}$




\section{INTRODUCTION}

\subsection{Purpose}

Estimates of inter-basin groundwater flow into northern Yucca Flat on the Nevada National Security Site (NNSS) are a critical component of Yucca Flat-Climax Mine CAU flow models under development for the Underground Test Area (UGTA) program. These flows, in combination with their uncertainty, must be properly accounted for in the CAU flow model in order to provide a defensible regional framework for calculations of radionuclide transport that will support determinations of the Yucca Flat-Climax Mine contaminant boundary.

The 2007 Climax Mine sub-CAU flow model (Pohlmann et al., 2007) (generally referred to herein as the 2007 sub-CAU model) provides estimates of the ranges of groundwater flow rates for the northern boundaries of the Yucca Flat-Climax Mine CAU model. The regional groundwater flow context is provided through the use of the Death Valley Regional Flow System (DVRFS) model framework (Belcher et al., 2004), which is the most complete and up-to-date regional model encompassing Yucca Flat. Flow uncertainty originated directly from parametric uncertainty and model uncertainty (Pohlmann et al., 2007; Ye et al., 2010), where the latter is represented by alternative conceptualizations of recharge and hydrostratigraphic framework.

The range in northern Yucca Flat flows estimated by the 2007 sub-CAU model did not, however, fully encompass low flows estimated by other methods (e.g., water balance and other numerical models). The higher flows simulated by the 2007 sub-CAU model resulted from a complex interplay between the configuration of hydrostratigraphic models in northern Yucca Flat and parameterization of the DVRFS model. As discussed later in this report, there are aspects of the regional DVRFS model that have important consequences for the magnitude of regional flow estimates, which therefore influence rates of flow into northern Yucca Flat.

The purpose of this study is to determine whether the Climax sub-CAU flow model can simulate rates of flow into northern Yucca Flat that are similar to other estimates, given available hydrogeologic models and new model parameterization considered in this study. This evaluation is accomplished through revisions to the 2007 sub-CAU model with particular emphasis placed on enhancements to the calibration process to focus on parameters critical to inter-basin flow to northern Yucca Flat. The results will provide the CAU model with boundary flow rates and information about their uncertainty, as well as provide information for consideration in revisions to the DVRFS model that are currently being undertaken by the USGS.

There are other aspects of the 2007 sub-CAU model, and by extension the DVRFS model, that contribute to the magnitude of simulated regional flow and thus may influence estimates of inter-basin flow to northern Yucca Flat. For example, uncertainty in the configuration of perimeter boundary conditions and the estimates of flow rates through segments of these boundaries are addressed in the DVRFS model through assignment of low observation weights to boundary flows. In some cases this approach results in large deviations between estimated and simulated flow rates and large flows simulated at several perimeter boundary segments that are inconsistent with general conceptualizations of the 
regional flow system. This and other issues are being addressed by the USGS in revisions to the DVRFS model (Claudia Faunt, personal communication, 2010), but the results were not available for inclusion in the present study. Because reduction in simulated flows through selected perimeter boundaries, with corresponding reduction in internal flows, would likely result in lower rates of inter-basin flow into northern Yucca Flat, only this aspect of the model is addressed in the current study.

To facilitate discussion, this report describes only the aspects of the 2007 sub-CAU model that are directly relevant to this study. For a full description of the Climax Mine subCAU model, readers are referred to Pohlmann et al. (2007).

\subsection{Estimates of Inter-Basin Flow}

Based on 25 combinations of five hydrostratigraphic framework models (HFMs) and five regional recharge models, the 2007 sub-CAU calibrated flow model simulates interbasin flow rates into northern Yucca Flat that range from 44,407 to 106,622 $\mathrm{m}^{3} / \mathrm{d}$. These results, clustered by recharge model and plotted in Figure 1, show that variation in flow rate among the five HFMs within a single recharge model is greater than that for a single HFM across all recharge models, indicating that inter-basin flow is largely controlled by the configuration of the HFM in northern Yucca Flat. Thus, estimates of flow are heavily dependent on the conceptualization of subsurface hydrostratigraphy in the region north of Yucca Flat, which is limited by an almost complete lack of borehole hydrostratigraphic data (Bechtel Nevada, 2006).

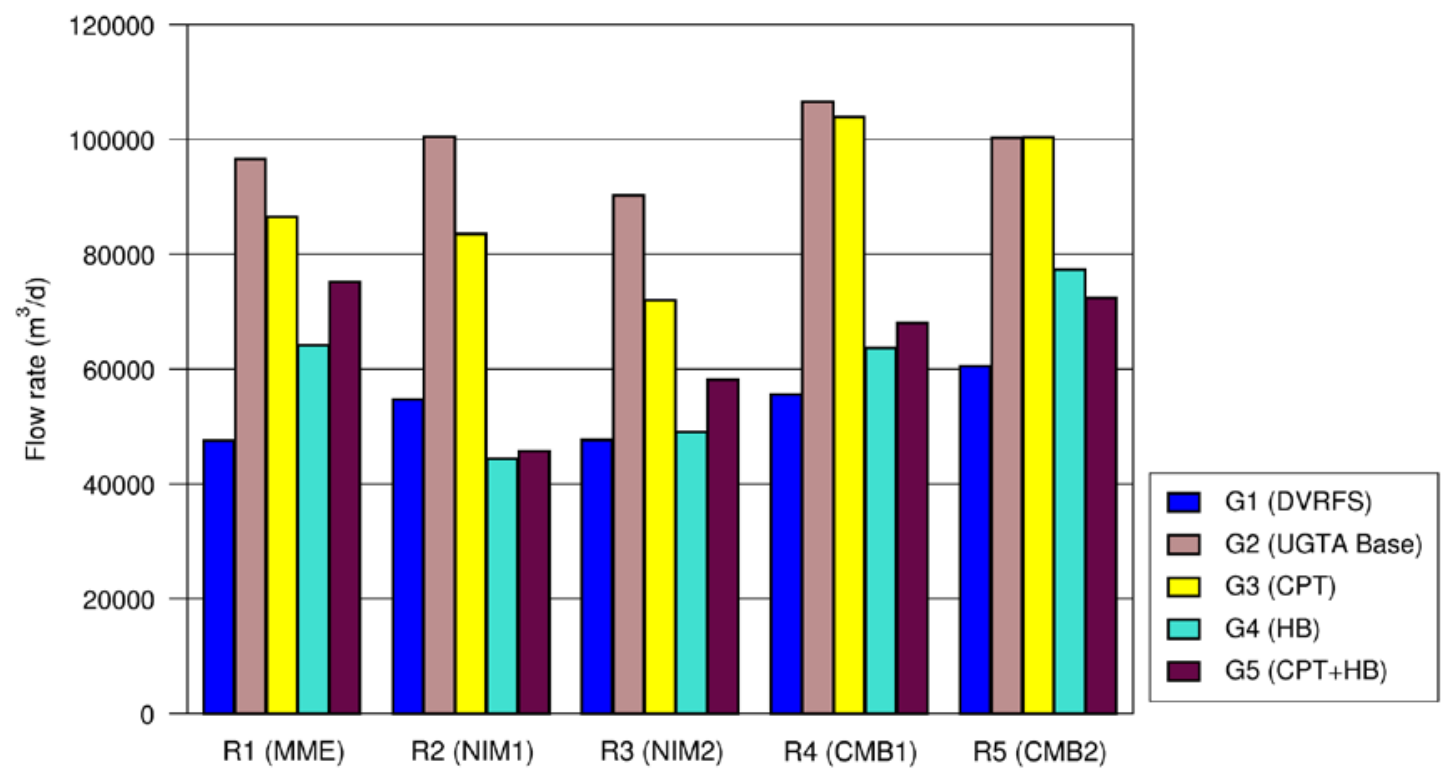

Figure 1. Total inter-basin flow into northern Yucca Flat simulated by the 2007 Climax Mine subCAU calibrated model. Each cluster represents the flow rates simulated for the five HFMs for a single recharge model. Flows are calculated at the cross section through the Climax Mine nuclear tests, as shown in Figure 4.

It should also be noted that mesh refinement in the 2007 sub-CAU model results in an approximate five percent increase in volumetric flow through the model as compared to the DVRFS model (Pohlmann et al., 2007). As a result, the flow rate shown for the combination 
of DVRFS HFM and Recharge Model 2 (G1R2) in the sub-CAU model in Figure 1 is higher than the corresponding value for the original DVRFS model that is discussed below.

Other studies that address inter-basin groundwater flow from the north into northern Yucca Flat include the following:

1) Utilizing a regional water balance and a subsurface geologic configuration (predicated on the upper clastic confining unit (UCCU) that dominates the saturated stratigraphic section north of Yucca Flat), Winograd and Thordarson (1975) estimated $1,180 \mathrm{~m}^{3} / \mathrm{d}$ of flow through the lower carbonate aquifer (LCA) in Yucca Flat, with a portion of that originating as recharge in the basin. In their view, LCA is present in the area only as isolated blocks and therefore does not form a continuous path for groundwater flow into Yucca Flat from basins to the north. The flow estimate of Winograd and Thordarson (1975) thus reflects the low hydraulic conductivity associated with the predominant UCCU.

2) Using hydraulic heads, water budgets, and interbasin flow estimates available through 1984, Harrill et al. (1988) delineated the major regional flow systems in the Great Basin. Their budget for Yucca Flat estimates recharge of 2,370 $\mathrm{m}^{3} / \mathrm{d}$ and subsurface discharge to Frenchman Flat of 3,380 $\mathrm{m}^{3} / \mathrm{d}$. The balance of $1,010 \mathrm{~m}^{3} / \mathrm{d}$ is presumed to represent inter-basin flow from the north and is consistent with the estimate of Winograd and Thordarson (1975). Halford (2009) cites these earlier estimates and presents additional evidence supporting the conceptualization of minimal flow from the north, including high hydraulic gradients between Emigrant Valley and Yucca Flat that often suggest flow across an impermeable barrier, the nearest significant recharge occurs 40 miles distant in Railroad Valley, and the presence of low-permeability granite associated with the Climax Mine stock instead of thick carbonate rocks encountered by well ER-8-1 in extreme northern Yucca Flat.

3) UGTA and USGS geologists both now conceive of an important flow path into northern Yucca Flat formed by continuous sections of LCA in the area of the Climax Stock. The UGTA regional flow model (IT Corporation, 1996a), which is based on a three-dimensional geologic model of the NNSS region (IT Corporation, 1996b), simulated approximately 25,300 $\mathrm{m}^{3} / \mathrm{d}$ water entering Yucca Flat from the north. This higher value as compared to Winograd and Thordarson's (1975) estimate results from the inclusion of pathways of higher hydraulic conductivity LCA.

4) The DVRFS model developed by the USGS (Belcher et al., 2004) utilizes a similar, though more detailed, conceptualization of the pre-Tertiary hydrostratigraphy north of Yucca Flat and simulates a flow rate of $40,829 \mathrm{~m}^{3} / \mathrm{d}$ into northern Yucca Flat. Incorporation of the UGTA base HFM for Yucca Flat (Bechtel Nevada, 2006) in the 2007 sub-CAU model results in over a two-fold increase in flow into northern Yucca Flat as compared to utilizing the DVRFS HFM, though the UGTA HFM provides a better fit of the flow model to the observed data.

5) Modeling of limited geochemical and isotopic data collected from wells near the water table in the Yucca Flat basin suggests that groundwater in northern Yucca Flat originates from a mixture of recharge, flow from the north through the LCA, and groundwater leakage from alluvial or volcanic aquifers in Emigrant Valley (Farnham et al., 2006). Though flow rates could not be determined using these methods alone, 
this modeling suggests that some portion of groundwater originating in basins to the north is required to simulate the compositions of conservative tracers observed in northern Yucca Flat (i.e., at well UE-15d).

6) Utilizing the DVRFS model as a framework, SNJV (2006) simulated the uncertainty in flows in the vicinity of Yucca Flat by incorporating six alternative HFMs developed for the Yucca Flat CAU in addition to the DVRFS HFM, and six alternative regional recharge models in addition to the DVRFS recharge model. Volumetric flows were simulated at the outer perimeter of the Yucca Flat CAU HFM with the northern boundary corresponding to the northern cross-section shown as a blue line on Figure 4. Values of flow simulated through this northern boundary ranged from $6,800 \mathrm{~m}^{3} / \mathrm{d}$ to $33,700 \mathrm{~m}^{3} / \mathrm{d}$ (SNJV, 2006) illustrating the magnitude of uncertainty associated with the conceptualizations of the system. It should be noted that with the exception of an initial calibration run, individual model combinations were not calibrated and model fits to observations were not reported.

7) Carroll et al. (2008) used a steady-state stable isotope mixing model to independently verify that most of the inter-basin flows simulated by the DVRFS model are reasonable when compared to observed delta deuterium $(\delta \mathrm{D})$ values in groundwater in the Death Valley region. However, in the Yucca Flat area, the fit to observed $\delta \mathrm{D}$ values is improved either by routing some groundwater from Emigrant Valley east and south around the NNSS or by locally increasing isotopically heavier mountain block recharge. In the re-routing solution, the optimized $\delta \mathrm{D}$ mixing model, though routing water around Yucca Flat from Emigrant Valley directly to Frenchman Flat, still simulated flow of $18,200 \mathrm{~m}^{3} / \mathrm{d}$ into Yucca Flat to provide the best fit to observed groundwater $\delta \mathrm{D}$ values.

8) The ER-6-1 \#2 aquifer test at Yucca Flat suggests that flow within Yucca Flat is about 3,300 $\mathrm{m}^{3} / \mathrm{d}$ (Halford, 2011). This implies a correspondingly low flow rate into northern Yucca Flat and challenges the various modeled flow rates, although the actual flow into northern Yucca Flat is still poorly known. In addition, slow recovery of water levels during the aquifer test suggests values of hydraulic conductivity that are several orders of magnitude lower than that used in the DVRFS model. This aquifer test provides by far the most direct estimation of inter-basin flow into northern Yucca Flat.

Differences between the estimates described above and those of the 2007 sub-CAU model reflect uncertainty inherent to quantifying these inter-basin groundwater flows. From the modeling point of view, this uncertainty may be caused by (1) uncertainty in the methods used to estimate inter-basin flow, (2) uncertainty in model parameters (especially when the number of calibrated parameters is large), and (3) uncertainty between different conceptual models. The latter two forms of uncertainty are addressed in this study, which is based on the 2007 sub-CAU model.

\subsection{Approach}

The range in simulated inter-basin flow rates results from propagation of model uncertainty and parameter uncertainty. The 2007 sub-CAU model includes 25 model combinations to reflect five possible conceptualizations of the recharge process and five plausible ways of constructing the hydrostratigraphic framework in northern Yucca Flat. As 
shown in Figure 1, every model combination provides a different estimate of inter-basin flow to northern Yucca Flat. In addition to this model uncertainty, for each individual model, uncertainty in model parameters (e.g., hydraulic conductivity and drain conductance) also contributes to uncertainty in the estimated inter-basin flow. In the 2007 sub-CAU model, 32 parameters in the vicinity of the northern Yucca Flat area were calibrated and some of the calibrated parameters were subject to large uncertainty. The model calibration was performed using all observations (head, head change, discharge, and constant-head boundary flow) included in the DVRFS model, rather than only those observations in northern Yucca Flat, to most effectively constrain the calibration using the entire flow system.

Generally speaking, the uncertainty in the estimation of inter-basin flow is difficult to reduce because observations of inter-basin flow are always sparse. In the 2007 sub-CAU model, although a large number of observations of hydraulic head, head change, discharge, and constant-head boundary flow were used for calibration; observations of inter-basin flow were unavailable.

To determine whether the magnitude of simulated inter-basin flow can be reduced, the approach taken in this study is to identify the hydraulic parameters that are most critical to the flow and then find values for each of these parameters that simultaneously simulate low flows and produce acceptable model fit to observations. Model parameterization is the focus, particularly hydraulic conductivity and drain conductance, since uncertainty in these aspects of the model is considered high. In contrast, existing hydrostratigraphic framework and recharge models (as described in Section 2.1) are utilized unmodified as these are assumed to fully represent conceptual model uncertainty (Pohlmann et al., 2007). However, because the steady-state Climax Mine sub-CAU model is comprised of 93 calibration parameters, of which 56 define horizontal hydraulic conductivity (the others represent potential flow barriers, groundwater discharge, depth decay of hydraulic conductivity, vertical anisotropy, and recharge multipliers), an efficient, quantitative method is required to objectively identify the parameters critical to inter-basin flow.

In this study, the relationship between values of model parameters, estimates of interbasin flow to northern Yucca Flat, denoted as $\mathrm{Q}_{\mathrm{y}}$, and model goodness-of-fit (as defined by SSWR) is investigated using the method of centered parameter study as implemented in the DAKOTA (Design Analysis Kit for Optimization and Terascale Applications) software toolkit (Adams et al., 2009). In the centered parameter study, a model is executed with multiple coordinate-based parameters for investigating function contours in the vicinity of a specific parameter point. As illustrated in Figure 2 for two parameters, the specific parameter point is at the center, and a number of parameter points are generated around the center with the same increment for the parameter. In this study, the specific point is represented by the calibrated parameter values of the flow model. Instead of varying all parameters simultaneously, the values of only a single parameter vary in each study. The results therefore indicate local sensitivity. Figure 3 plots for one case of the revised sub-CAU model the relationship between $\mathrm{Q}_{\mathrm{y}}$ and SSWR for the nine parameters to which $\mathrm{Q}_{\mathrm{y}}$ estimates are most sensitive according to the Morris method (details of the Morris method are described in Section 2). The figure shows that $\mathrm{Q}_{\mathrm{y}}$ increases as values of each of these parameters increase though $\mathrm{Q}_{\mathrm{y}}$ is more sensitive to certain parameters. For example, Figure 3c shows that when the value of parameter K221_LCA (the parameter most influential to $\mathrm{Q}_{\mathrm{y}}$ estimation) increases 


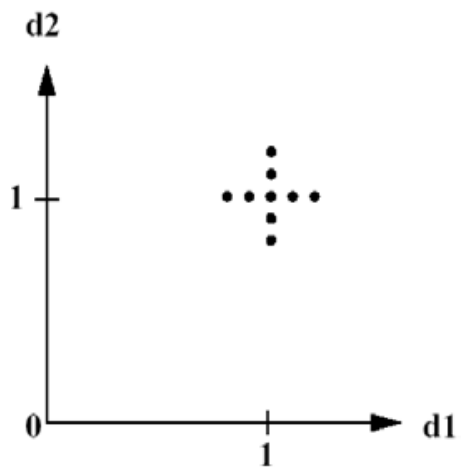

Figure 2. Example of a centered parameter study; d1 and d2 represent two parameters. From Adams et al. (2009).
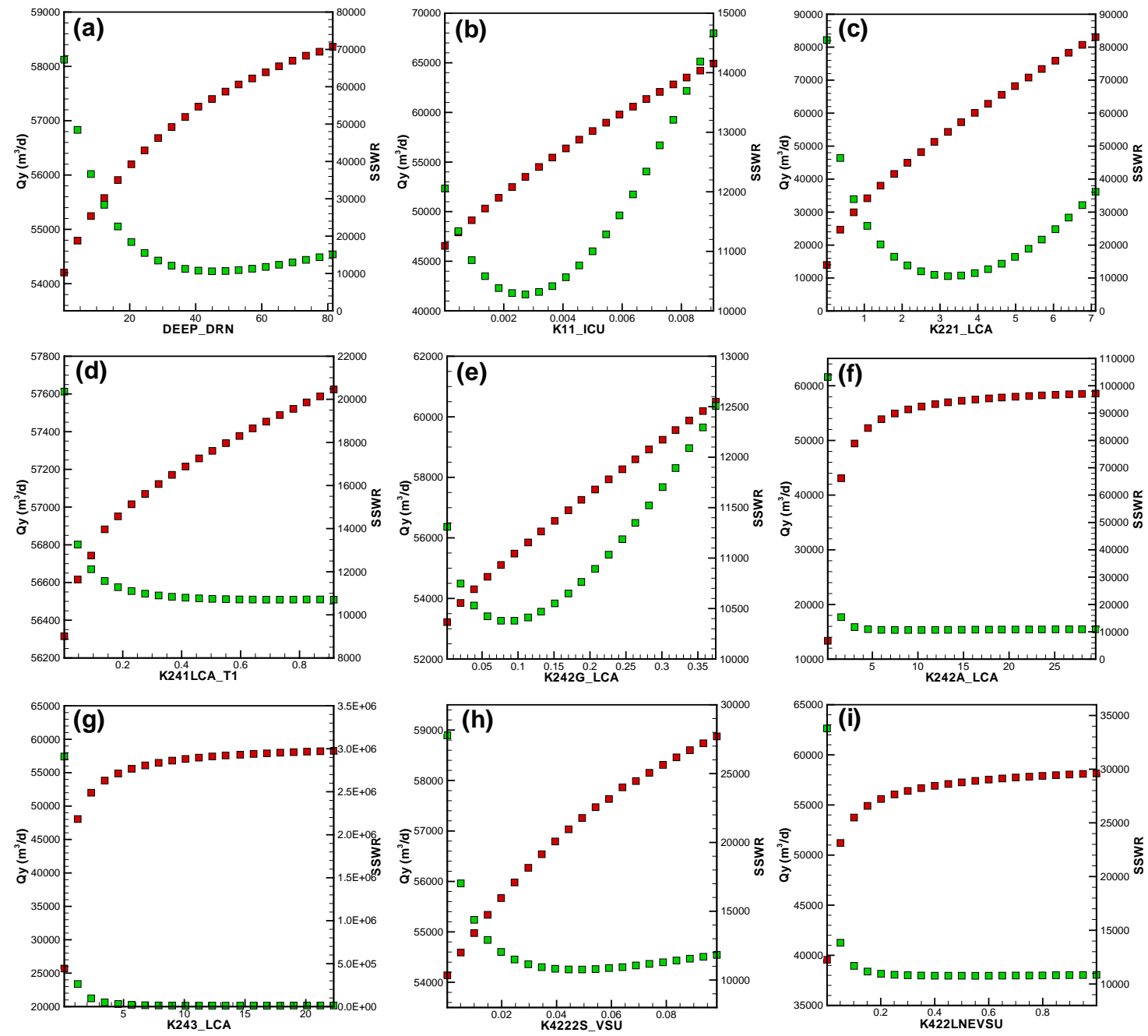

Figure 3. The relationship between $\mathrm{Q}_{\mathrm{y}}$ (red squares) and SSWR (green squares) with model parameters (a) DEEP_DRN, (b)K11_ICU, (c) K221_LCA, (d) K241LCA_T1,(e) K242G_LCA, (f) K242A_LCA, (g) K243_LCA, (h) K4222S_VSU, and (i) K422LNEVSU. DEEP_DRN is a drain conductance used to simulate deep, warm-water springs and springs in playa deposits. 
from 0.01 to $7.11 \mathrm{~m} / \mathrm{d}$, $\mathrm{Q}_{\mathrm{y}}$ increases from 13,984 to 83,068 $\mathrm{m}^{3} / \mathrm{d}$, demonstrating how uncertainty in model parameters can give rise to a range in estimates of $\mathrm{Q}_{\mathrm{y}}$. Figure 3 also illustrates the sensitivity of SSWR to these nine model parameters. It is not surprising that a small reduction of SSWR during model calibration may cause large changes in $\mathrm{Q}_{\mathrm{y}}$. Therefore, evaluation of $\mathrm{Q}_{\mathrm{y}}$ depends on consideration of model calibration, parameter uncertainty, and model uncertainty. This is the theoretical basis of this study. The centered parameter study (Figure 3 ) is also the basis for determining parameter ranges for the uncertainty analysis presented in Section 2.3. 
THIS PAGE INTENTIONALLY LEFT BLANK 


\section{OBJECTIVES AND METHODS}

To achieve this study's goal of evaluating the feasibility of reducing inter-basin groundwater flow to northern Yucca Flat simulated by the Climax Mine sub-CAU model, the specific objectives of the modeling are as follows:

1) Use MODFLOW-2000 to calibrate the alternative models against observations of hydraulic heads, discharges, and boundary flows.

2) Use the Morris method to determine for each individual model the parameters that are most critical to the estimation of $\mathrm{Q}_{\mathrm{y}}$.

3) Use Monte Carlo (MC) methods to investigate for each individual model the uncertainty in the estimation of $\mathrm{Q}_{\mathrm{y}}$ due to parametric uncertainty.

4) Investigate for each model whether the $Q_{y}$ estimates are consistent with estimates from other studies.

5) Identify an optimum MC realization for each model that yields a consistent $Q_{y}$ estimate and simulations of state variables (e.g., hydraulic head and flow) that honor field observations and the conceptualization of the flow system.

The methods used in this study are discussed in the remainder of this section. Modeling results are presented and discussed in Section 3. Given that there are six models considered in this study, the discussion focuses on the model that provides the best combination of $\mathrm{Q}_{\mathrm{y}}$ and SSWR. Detailed modeling results for the other five models are included in the appendices.

\subsection{Six Alternative Groundwater Models}

The 2007 sub-CAU model considered a total of 25 models resulting from combining five plausible conceptualizations of the recharge process with five possible formulations of hydrostratigraphic framework. Among the five recharge conceptualizations, Pohlmann et al. (2007) showed that three are significantly less plausible than the other two. Similarly, two hydrostratigraphic framework models are considered implausible relative to the other three. Therefore, this study considers two alternative conceptualizations of recharge and three alternatives of the hydrostratigraphic framework that are briefly described below. Further details are presented in Pohlmann et al. (2007). Note that the area described in this report as northern Yucca Flat refers to a specific area defined by the boundaries of hydrostratigraphic models developed for the Yucca Flat-Climax Mine CAU and delineated on Figure 4.

\subsubsection{Recharge Estimation Methods}

R2 (NIM1): Net infiltration method with runon-runoff. This method employs a distributed-parameter watershed model for estimating temporal and spatial distribution of net infiltration and potential recharge (Hevesi et al., 2003).

R5 (CMB2): Chloride mass-balance method with alluvial and elevation masks (Russell and Minor, 2002). This method estimates groundwater recharge based on the elevationdependent chloride mass-balances within hydrologic input and output components of individual hydrologic basins. 


\subsubsection{Geological Interpretations in Northern Yucca Flat}

G1 (USGS): USGS interpretation as used in the DVRFS (Belcher et al., 2004)

G2 (BAS): UGTA Base interpretation (Bechtel Nevada, 2006)

G3 (CPT): UGTA CP Thrust alternative interpretation (Bechtel Nevada, 2006)

The notations (i.e., R2 or NIM1, R5 or CMB2, and G1 through G3) are adopted from Pohlmann et al. (2007) for convenience in comparing model results. Incorporating the alternatives of the recharge and hydrostratigraphic components into the sub-CAU modeling framework results in a total of six groundwater models denoted as G1R2, G1R5, G2R2, G2R5, G3R2, and G3R5. Details of the development of the 2007 sub-CAU numerical models using the MODFLOW-2000 groundwater flow simulation code are presented in Pohlmann et al. (2007). The MODFLOW-2000 code will subsequently be referred to in this report as MODFLOW.

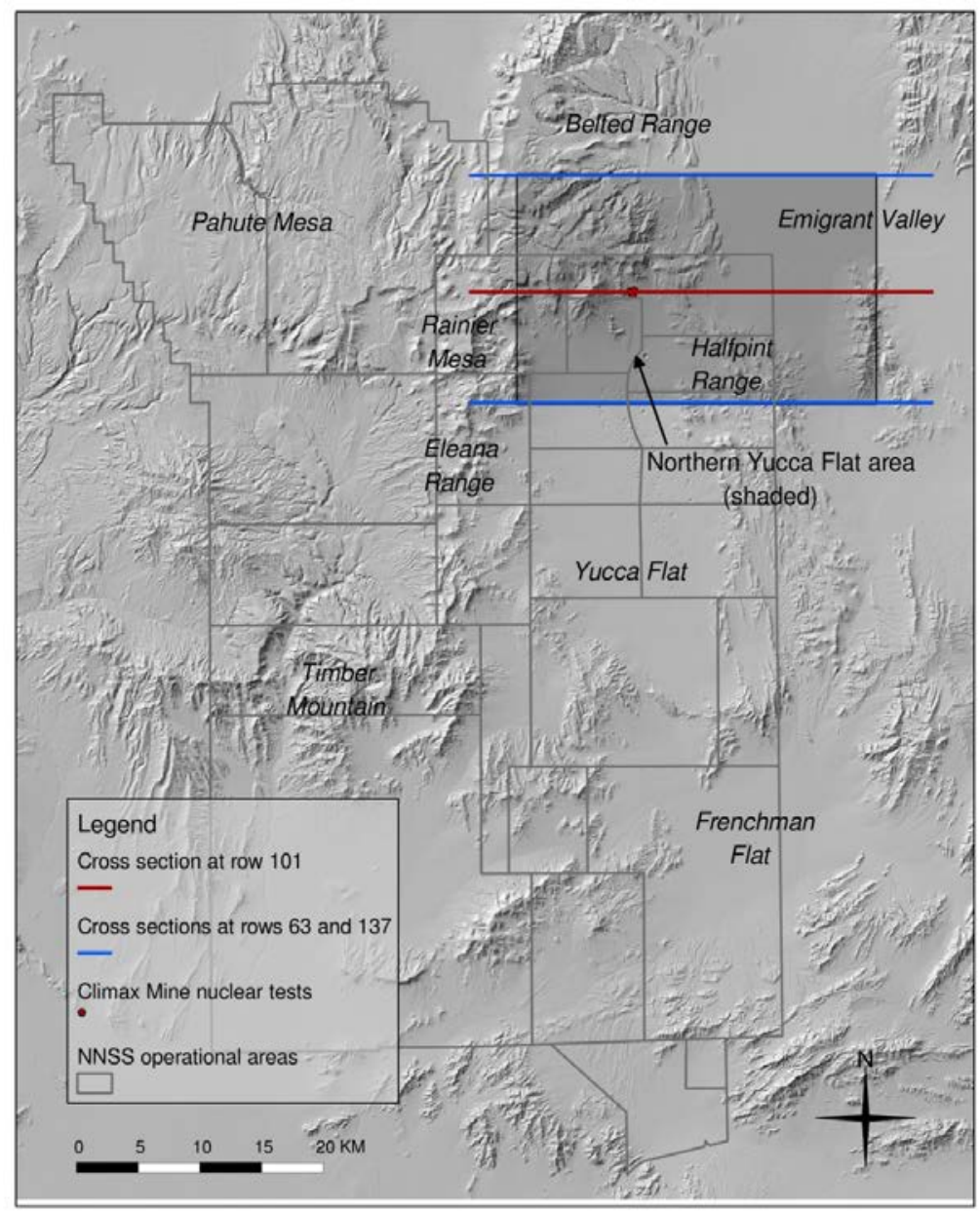

Figure 4. Locations of the northern Yucca Flat area (shaded), the cross section (red) through which the inter-basin groundwater flow into northern Yucca Flat is estimated, and the two cross sections (blue) representing the northern and southern boundary of the northern Yucca Flat Area. The row numbers in the legend refer to the Climax sub-CAU model grid. 


\subsection{Estimation of Inter-Basin Flow and Model Calibration}

In this study, the inter-basin flow is estimated at a cross section located at 4,120,125 m North between 570,500 and 608,000 m East (UTM Zone 11, NAD27) that corresponds to row 101 between columns 90 and 216 of the sub-CAU model MODFLOW grid (marked in red on Figure 4). Note that this cross section is in a slightly different location from the cross section used in Pohlmann et al. (2007), which was located along row 137 between columns 95 and 211). Net $\mathrm{Q}_{\mathrm{y}}$ at this cross section is calculated by summing together the simulated cell-by-cell flow terms in the y-direction (north to south) in all sixteen model layers. The analysis is not restricted to the regional lower carbonate aquifer; all hydrostratigraphic units contributing to inter-basin flow are considered. Although the cross section extends beyond the borders of Yucca Flat to include a portion of Emigrant Valley, most flow occurs in a narrow band of LCA extending north from Yucca Flat.

Model calibration plays an important role in this study, because it is used to reduce the deviation between model simulations and corresponding field observations of hydraulic heads, discharges, and constant-head boundary flow. In addition, as discussed below, it provides the basis for determining the ranges of model parameters used in the Morris analysis of parameter sensitivity and MC simulation of uncertainty. The model calibration is conducted using the parameter estimation (PES) feature of MODFLOW.

Different from the transient conditions used in the 2007 sub-CAU model, the revised models developed in this study are all steady state, representing conditions prior to groundwater development. Simulation times for running the steady state models are dramatically reduced, which makes possible more comprehensive inverse modeling and MC simulations. The steady-state model is developed from the transient 2007 sub-CAU model by removing and revising components related to transient-state simulations. For example, the parameters related to specific storage and observations of head-changes are removed in the steady-state models. The observations used to calibrate the steady-state models include hydraulic heads, discharges, and constant-head boundary flows. In comparison with the 2007 sub-CAU model, the numbers of head and discharge observations are reduced from 2,227 to 700 and from 49 to 45, respectively. The number of constant-head boundary flow observations remains the same at fifteen. Details about converting the model from transient to steady-state conditions are given in Appendix B.

Following conversion of the models to steady-state conditions, sensitivity analyses and calibration are undertaken following the methods of Belcher et al. (2004) and Pohlmann et al. (2007). The sensitivity analysis is first conducted using the sensitivity feature of MODFLOW

and values of the Composite Scaled Sensitivity (CSS) are used to identify parameters that can be reasonably estimated based on the observations. Due to complexity of these models, runs attempting to calibrate all of the selected parameters diverge owing to unreasonably large changes in values of several parameters. When this occurs, some parameters are fixed to achieve convergence. Although the automated calibration yields the minimum SSWR, the simulated heads at several locations of the domain were found to be unreasonably high. Several parameter values are thus adjusted manually to obtain reasonable hydraulic head distribution. The final parameter values for all six models are listed in Appendix A. 


\subsection{Morris Method for Identifying Critical Parameters for $\mathbf{Q}_{\mathbf{y}}$}

Given that the number of calibrated parameters for the six models ranges from 49 to 58, it is computationally difficult to evaluate uncertainty for all parameters. In addition, there is no need to include parameters to which $\mathrm{Q}_{\mathrm{y}}$ estimates are insensitive. Therefore, only critical parameters are considered and they are selected using the Morris method. The Morris method is briefly described here; for more details the reader is referred to Morris (1991) and Saltelli et al. (2004). The method is a screening tool to identify the critical factors (e.g., model parameters) that have significant effects on model outputs (e.g., $\mathrm{Q}_{\mathrm{y}}$ in this study). It is particularly useful for models with a large number of parameters like the sub-CAU model in this study. The method is based on the elementary effect, which is calculated for the $i$-th model input as

$$
d_{i}(\mathbf{x})=\frac{y\left(x_{1}, \ldots, x_{i-1}, x_{i}+\Delta, x_{i+1}, \ldots, x_{k}\right)-y(\mathbf{x})}{\Delta}
$$

where $\mathbf{x}$ are model inputs, $\mathrm{y}$ is model output, and $\Delta$ is a predetermined multiplier for the $i$-th model input. Although it is a "one factor at a time" method, in which only one input factor is modified between two successive runs of the model, the method covers the entire range of parameters in successive runs by varying the input factors over their possible ranges. In this sense, the method can be regarded as global (Saltelli et al., 2004). After $r$ Morris runs, the absolute mean effect and standard deviation of the $i$-th parameter are calculated via

$$
\mu_{i}=\frac{1}{r} \sum_{j=1}^{r}\left|d_{i j}\right|
$$

and

$$
\sigma_{i}=\sqrt{\frac{1}{r} \sum_{j=1}^{r}\left(d_{i j}-\mu_{i}\right)^{2}}
$$

where $d_{i j}$ is the elementary effect of the $i$-th parameter for the $j$-th Morris run. The mean effect, $\mu_{i}$, reveals the influence of parameter $x_{i}$ on the model output. The larger the mean effect, the more influence parameter $x_{i}$ has on the output. The standard deviation also discloses important information about the parameter sensitivity. A large value of $\sigma_{i}$ indicates that the parameter has a nonlinear effect on the output or interactions with other parameters.

The ranges of all model parameters required by the Morris method were determined from two sources of information. The first is Belcher et al. (2004), who list the ranges of selected parameters for the DVRFS model as compiled from literature sources; the other source is the parameter covariance matrix obtained from the inverse modeling. The covariance matrix, based on the linear assumption, is a measure of parameter estimation uncertainty. Note that the sets of parameter ranges from these two sources are always inconsistent because they have different physical and statistical meanings. In addition, ranges based on field data are always of several orders of magnitude, and in general, more random samples are needed in the Morris analysis as well as for MC simulations if larger parameter ranges are used. With all the factors considered and after several rounds of trial and error, the range for each parameter for the Morris runs and subsequent MC simulations is determined as $(0.01 \hat{\theta}, 2 \hat{\theta})$ (where $\hat{\theta}$ is the calibrated parameter value). This range is determined based on 
the centered parameter study shown in Figure 3, which shows that for this parameter range $\mathrm{Q}_{\mathrm{y}}$ can be significantly reduced while maintaining a reasonable SSWR. This range, essentially $(0,2 \hat{\theta})$, is also chosen to ensure that the calibrated parameter value is at the center of the range; $0.01 \hat{\theta}$ instead of zero, is used as the lower bound because the Morris method requires model execution at the ends of the range. A larger range may yield better results (in terms of $\mathrm{Q}_{\mathrm{y}}$ reduction and goodness-of-fit), but may increase the computational cost, since more parameter samples are needed for large ranges. A uniform distribution within this range is assumed for each parameter. The rationale for using this range is that the random samples used in the Morris runs and MC simulations are centered on the calibrated values. The lower bound of $0.01 \hat{\theta}$ is selected so that the upper and lower bounds are approximately symmetric about $\hat{\theta}$. Most of the estimated ranges are within the physical ranges listed in Belcher et al. (2004), although a few exceed the physical ranges because the calibrated values are not within the physical range. The parameter ranges are not given in this report but can be estimated based on the calibrated parameter values listed in Table A-1 of Appendix A. Correlation between model parameters reflected in the parameter covariance matrix is not incorporated in the MC simulation because there is no physical evidence of the reliability of the correlation, considering that it is calculated based on linearization of a nonlinear model. Disregarding the correlation should not affect the conclusions of this study, since only one realization is selected after the MC simulation and the Latin Hypercube Sampling (LHS) method used for the MC simulation is able to generate random samples over the parameter space. However, if a full uncertainty assessment is conducted with the distribution of $\mathrm{Q}_{\mathrm{y}}$ as the final product, consideration of the parameter correlation will be necessary and the correlation needs to be estimated from other sources in addition to the parameter covariance matrix.

\subsection{Uncertainty Analysis of $Q_{\mathbf{y}}$ Estimates}

Evaluation of $\mathrm{Q}_{\mathrm{y}}$ estimates involves not only quantifying uncertainty of the parameter estimates but also striking a balance between the two objectives of minimizing $Q_{y}$ and maximizing the goodness-of-fit (i.e., minimization of SSWR). This problem is first tackled using the Multi-Objective Genetic Algorithm (MOGA) implemented in the DAKOTA toolkit (Adams et al., 2009). The Pareto front given by MOGA is expected to give the best combination of $\mathrm{Q}_{\mathrm{y}}$ and SSWR as well as uncertainty in the two quantities. However, the highly complex DVRFS model system causes convergence of MOGA to be unacceptably slow. Figure 5 plots the results of a MOGA run with a total of 2,500 forward model simulations. This takes about 10 days and includes 20 generations of parameters. The variations in $\mathrm{Q}_{\mathrm{y}}$ and SSWR between generations 10 and 20 are small, indicating a low rate of convergence. In addition, the best combination of $\mathrm{Q}_{\mathrm{y}}$ and SSWR of the 2,500 simulation is still worse than that of 2,000 Monte Carlo simulations, as is discussed below. Although MOGA may theoretically outperform MC method if the number of simulations is large enough, the computational time required for running a large number of MOGA realizations is not possible in this study. In addition, since the MOGA realizations are not independent (a realization is formed by the operations of mutation and crossover of the previous realization), it is difficult to conduct parallel computing for MOGA. 


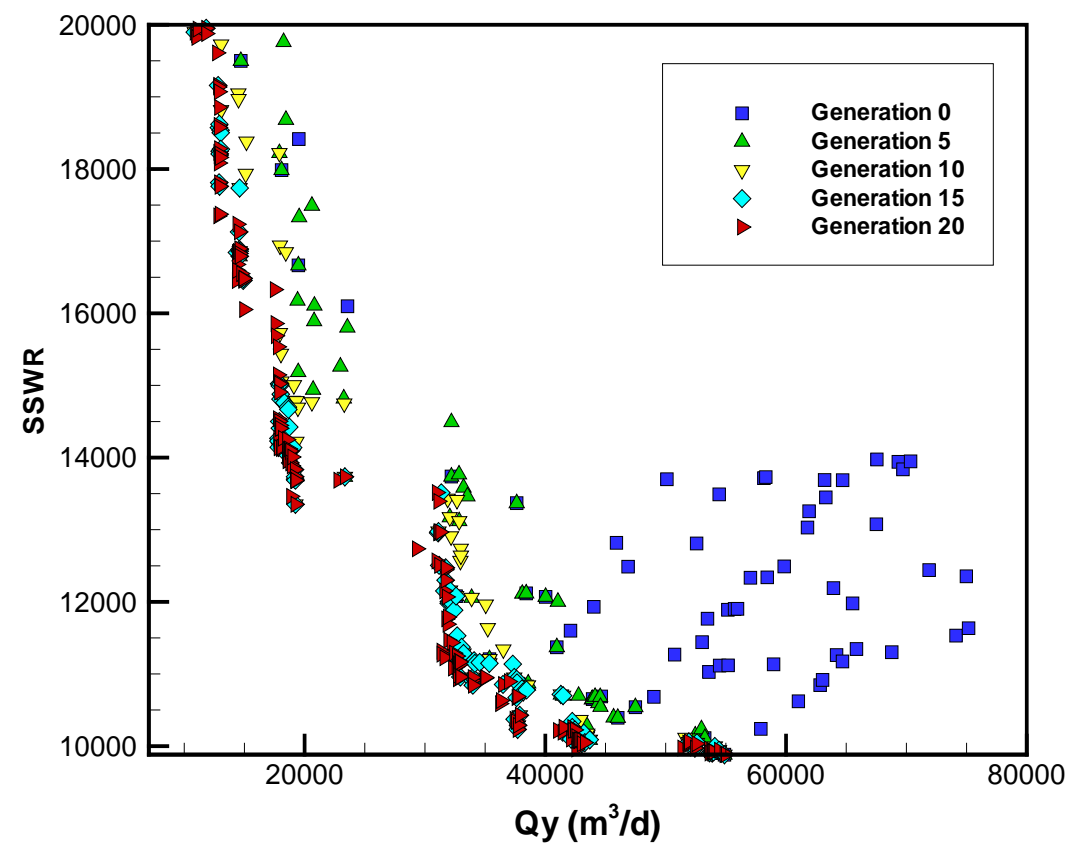

Figure 5. MOGA Pareto front obtained from 2,500 simulations of 20 generations.

An alternative to MOGA for uncertainty analysis is to conduct MC simulations. Using MC for multi-objective optimization has become popular in the last decade (Vrugt et al. 2003). Instead of using advanced MC methods (e.g., Markov chain Monte Carlo or nullspace Monte Carlo), the simple Monte Carlo method is used in this study though it also can suffer from a low rate of convergence. In order to alleviate this problem, Latin Hypercube sampling (LHS) as implemented in DAKOTA is used. LHS generates random samples in the entire parameter space and it has been demonstrated (Helton and David, 2003) that LHS is more robust than random sampling especially when there are multiple random parameters. Since six to nine parameters are selected from the Morris analyses, the simple MC is considered appropriate. Another way of quantifying uncertainty in $\mathrm{Q}_{\mathrm{y}}$ estimates is to use regression-based methods (e.g., Keating et al., 2003). Although regression-based methods are more computationally efficient than MC methods, the former method is subject to linearization of the flow model and thus not used in this study.

After the MC simulations are complete, the optimum $\mathrm{Q}_{\mathrm{y}}$ for each model is selected from the MC realizations according to the following two criteria:

1) $Q_{y}$ must be approximately equal to or lower than the value of $25,000 \mathrm{~m}^{3} / \mathrm{d}$ obtained in the UGTA regional flow model (IT Corporation, 1996b), which is considered reasonable among the estimates described in Section 1.

2) For the realizations that have the $Q_{y}$ estimates satisfying the condition above, the realization having the optimum $\mathrm{Q}_{\mathrm{y}}$ estimate must have the lowest SSWR.

As shown in Figure 3, the SSWR corresponding to the optimum $\mathrm{Q}_{\mathrm{y}}$ may be larger than that of the calibrated model, indicating a worse goodness-of-fit. In this case, the fit between model simulations and field observations is evaluated to ensure that the deteriorated fit is still 
reasonable (e.g., no trend of bias) and that simulated heads and flows are consistent with the conceptualization of the flow system. This selection of optimum $\mathrm{Q}_{\mathrm{y}}$ is qualitative and problem specific, and will be discussed in more detail in Section 3 together with the modeling results. It is worth pointing out that the selected optimum $\mathrm{Q}_{\mathrm{y}}$ is subject to the six conceptual models considered in this study.

The steps in the modeling procedure are summarized as follows:

1) Calibrate each model.

2) Determine the ranges of parameters for the Morris runs and MC simulations.

3) Conduct Morris runs for each model to determine the parameters to which the $Q_{y}$ estimate is most sensitive (critical parameters).

4) Conduct MC simulations for the critical parameters to evaluate uncertainty in $Q_{y}$ and SSWR.

5) For each model, select the optimum $Q_{y}$ with a reasonable SSWR value. 
THIS PAGE INTENTIONALLY LEFT BLANK 


\section{RESULTS AND DISCUSSION}

A summary of the modeling results is given here, followed by detailed discussions beginning in Section 3.1. Table 1 lists the optimum values of $\mathrm{Q}_{\mathrm{y}}\left(\mathrm{m}^{3} / \mathrm{d}\right)$ (selected from the two criteria given in the last section) and corresponding SSWR for each of the six models. Although these results cannot be directly compared with those of the 2007 sub-CAU model because different models (steady-state rather than transient conditions) are used to calculate $\mathrm{Q}_{\mathrm{y}}$, the table shows that the estimated $\mathrm{Q}_{\mathrm{y}}$ values are substantially reduced from those simulated by the 2007 model. Note that Qy and SSWR values for G1R2 and G1R5 are higher than for all other models. The results for G2R2 and G3R2 are very similar to each other but are worse than the results for G2R5 and G3R5. However, as discussed in Section 3.6, the $\mathrm{Q}_{\mathrm{y}}$ and SSWR results for G2R2 and G3R2 are considered better because these models give better simulations of constant-head boundary flow with lower SSWR for constant-head boundary flows. Subsequent sections discuss all six models, but detailed results are focused on model G3R2, with results for the other models presented in Appendix A.

Table 1. Optimum $\mathrm{Q}_{\mathrm{y}}$ and SSWR values and ensemble statistics for the MC simulations. There are 2,000 realizations simulated for each model.

\begin{tabular}{ccccccc}
\hline Model & G1R2 & G1R5 & G2R2 & G2R5 & G3R2 & G3R5 \\
\hline Optimum MC Realization & & & & & & \\
$\quad \mathrm{Q}_{\mathrm{y}}\left(\mathrm{m}^{3} / \mathrm{d}\right)$ & 24,444 & 25,743 & 22,672 & 19,173 & 22,988 & 21,747 \\
$\quad$ SSWR & 12,491 & 12,380 & 11,560 & 10,678 & 11,455 & 11,170 \\
MC Ensemble Statistics & & & & & & \\
$\quad$ Mean & 44,428 & 43,697 & 53,270 & 24,908 & 50,344 & 33,908 \\
$\quad$ Lower Quartile & 31,449 & 32,745 & 37,243 & 20,022 & 36,691 & 26,028 \\
$\quad$ Upper Quartile & 58,447 & 55,818 & 69,345 & 29,907 & 64,471 & 41,849 \\
\hline
\end{tabular}

\subsection{Results of Model Calibration}

Calibration starts from a local sensitivity analysis using the sensitivity feature of MODFLOW. Based on their CSS values, a set of 58 parameters is selected for calibration of the six models. These parameters include the 55 parameters calibrated in the DVRFS model (Belcher et al., 2004) and three other parameters (K2CARBVANI, K221_LCA, and K4UP_VSUC) that are found to have high CSS values. Some parameter values are fixed owing to divergence during model calibration. The final number of calibrated parameters, and values of $\mathrm{Q}_{\mathrm{y}}$ and SSWR are listed in Table 2 for each of the six models and the values of the calibrated parameters are listed in Table A-1 of Appendix A. After calibration, it was

observed that unrealistically high heads were simulated in several locations of the domain. To resolve this, five parameter values (four hydraulic conductivities and one depth-decay of hydraulic conductivity) are manually adjusted to achieve reasonable head distributions. The same five manually-adjusted parameters are used for all six models because these parameters are related to the DVRFS model framework that is common to all six models. However, to achieve the best fit for each model the final values of these parameters differ across models, as shown in Table A-1. It should be noted that manual adjustment of these parameters increases SSWR values. Other calibration results (e.g., head distributions) for G3R2 are presented in Section 3.3 together with those of the MC results. The results for the other models are given in the appendices. 
Table 2. Number of calibrated parameters, $Q_{y}$ value and SSWR value associated with the final calibration results for each model.

\begin{tabular}{ccccccc}
\hline Model & G1R2 & G1R5 & G2R2 & G2R5 & G3R2 & G3R5 \\
\hline Number of calibrated parameters & 51 & 49 & 58 & 49 & 58 & 49 \\
$\mathrm{Q}_{\mathrm{y}}\left(\mathrm{m}^{3} / \mathrm{d}\right)$ & 50289 & 50445 & 60152 & 27579 & 57252 & 39509 \\
SSWR & 9883 & 10384 & 10886 & 10140 & 10767 & 11375 \\
\hline
\end{tabular}

Table 2 lists the $\mathrm{Q}_{\mathrm{y}}$ and SSWR values for the final calibrated models (including the manual adjustment of model parameters). Models G1R2 and G3R5 give the lowest and highest SSWR values, respectively; SSWR values for the other four models are very similar to each other. The $Q_{y}$ values for G1R2, G1R5, G2R2, and G3R2 are significantly higher than those for G2R5 and G3R5. The latter two $Q_{y}$ values are also significantly lower than their corresponding values in the 2007 sub-CAU model. These reduced flow rates are attributed to the re-calibration of the model associated with the conversion to steady-state conditions and the uncertainty inherent to the parameters.

Reducing the numbers of head and discharge observations causes changes in the values of calibrated parameters, with some changes being dramatic. In particular, the values of the parameters found critical to the $\mathrm{Q}_{\mathrm{y}}$ estimate become smaller. Taking model G2R2 as an example, after re-calibration, the value of the most critical parameter, K221_LCA, becomes about half of that in the 2007 sub-CAU model.

It should be noted that the $\mathrm{Q}_{\mathrm{y}}$ and SSWR values for G3R5 listed in Table 1 are lower than for the same model in Table 2. This is because the automated calibration of G3R5 using MODFLOW did not converge. The $\mathrm{Q}_{\mathrm{y}}$ and SSWR values in Table 2 are the result of manual calibration, in which an iteration (before divergence occurred) with reasonable $\mathrm{Q}_{\mathrm{y}}$ and SSWR values was selected and its parameters were manually adjusted to reduce the SSWR. The smaller SSWR value in Table 1 indicates that the MC simulation yielded a realization with better goodness-of-fit.

\subsection{Results of Morris Analysis}

The Morris method is used to identify the parameters critical to simulation of $\mathrm{Q}_{\mathrm{y}}$. To avoid numerical instability, the Morris analysis is applied only to hydraulic conductivity and drain conductance parameters. The parameters excluded from the Morris analysis include the three hydrogeological barrier parameters (B_PAHRUMP, B_DV_N, and B_SOLTARIO), six depth decay parameters (KDP_VOL, KDEP_LCA, KDP_LCANO, KDP_LCAT1, KDEP_UCCU, and KDEP_XL), and three anisotropy ratios (K2CARBVANI, K3_VOLVANI, and K4_VFVANVL). In addition, the two infiltration multipliers (RCH_2 and RCH_35) are also excluded because uncertainty in recharge is handled as model uncertainty, not parametric uncertainty. The parameter ranges are determined in the manner described above, and 450 Morris run are conducted. The number of Morris runs is chosen so that the number of samples is a positive integer multiple of the number of parameters plus one, which increases the economy of the design as compared to running the same integer multiple as number of parameters (Adams et al., 2009). Taking model G3R2 as an example, since 44 parameters were included in the Morris run and the number of elementary effects, $r$, was set to a value of ten, a total of 450 runs were conducted. 
The means and standard deviations of all the elementary effects for model G3R2 are listed in Table 3. Plots of these statistics in Figure 6 reveal the following three patterns:

1) Extremely high mean and high standard deviation for parameters K221_LCA and K242A_LCA (red squares in Figure 6a) indicates that uncertainty in these two parameters results in large uncertainty in $\mathrm{Q}_{\mathrm{y}}$. The high mean indicates that the parameters have an important overall influence on the $\mathrm{Q}_{\mathrm{y}}$ estimate. The high standard deviation indicate that the parameters are either interacting with other parameters or have a non-linear effect on the $\mathrm{Q}_{\mathrm{y}}$ estimate.

2) Relatively high mean but low standard deviation for K243_LCA, K11_ICU, K422LNEVSU, K242G_LCA, DEEP_DRN, K4222S_VSU and K241LCA_T1 (green squares in Figures 6a and 6b) indicates the significant impact of these parameters on calculation of $\mathrm{Q}_{\mathrm{y}}$ resulting from the first-order effect. In other words, the low standard deviation indicates that the elementary effects are roughly constant within the parameter ranges, meaning that these parameters have an approximately linear effect on the $\mathrm{Q}_{\mathrm{y}}$ estimate and little interaction with other parameters.

3) Low mean and low standard deviation for other parameters (blue squares in Figure 6a and 6b) indicates the insignificant impact of the parameters on calculation of $\mathrm{Q}_{\mathrm{y}}$.

Therefore, for model G3R2, the Morris analysis identifies nine critical parameters for contributing to the estimate of $\mathrm{Q}_{\mathrm{y}}$ (also highlighted in red in Table 3).

The hydrogeological significance of these parameters is examined from a physical point of view in terms of their ranges (Table 4) and the relationship of their spatial distribution to the cross section through which $\mathrm{Q}_{\mathrm{y}}$ is calculated (Figures 7 through 10). Figure 7 shows that the three most critical parameters (K221_LCA, K242A_LCA, and K243_LCA) are all components of the LCA flow path that enters Yucca Flat from the north and continues southward through the basin. In addition, since the magnitudes and ranges of these three parameters are also larger than all other parameters (Table 4), it is not surprising that the $\mathrm{Q}_{\mathrm{y}}$ estimate is most sensitive to them. For parameters K242G_LCA, K422S_VSU and K422LNEVSU, although their values and ranges are comparatively smaller, the locations of the hydraulic conductivity zones predominately upgradient of Yucca Flat (Figures 7 and 8) render them important. Parameters K11ICU and K241LCA_T1 occupy only small areas in the vicinity of Yucca Flat though they are both present in other areas of the domain (Figures 9 and 10). Thus, they may impact not only the $\mathrm{Q}_{\mathrm{y}}$ estimate but also model calibration and simulation of heads and flows. Parameter DEEP_DRN (deep drain conductance is used to simulate deep, warm-water springs) has a significant effect on the $\mathrm{Q}_{\mathrm{y}}$ estimate because it is associated with the three discharge observations OBS-AM-NORTH, OBS-AM-SOUTH, and OBS-AM-CENTER located downgradient of Yucca Flat (Figure 8). Qualitatively speaking, large values of DEEP_DRN lead to high values of simulated discharge, which in turn requires large $\mathrm{Q}_{\mathrm{y}}$ estimates to maintain mass balance, as the flow direction is from north to south. A quantitative analysis of the discharge simulations and their relationship with the $\mathrm{Q}_{\mathrm{y}}$ estimate is given in Section 3.5. 
Table 3. Mean $(\mu)$ and standard deviation $(\sigma)$ of the elementary effects from the Morris analysis of model G3R2. The nine critical parameters are identified in red.

\begin{tabular}{|c|c|c|}
\hline Parameter & Mean $(\mu)$ & Standard deviation $(\sigma)$ \\
\hline K221_LCA & $3.62 \mathrm{E}+004$ & $2.67 \mathrm{E}+004$ \\
\hline K242A__LCA & $2.65 E+004$ & $4.53 E+004$ \\
\hline K243_LCA & $9.04 \mathrm{E}+003$ & $1.78 \mathrm{E}+004$ \\
\hline K11_ICU & $7.21 \mathrm{E}+003$ & $6.14 \mathrm{E}+003$ \\
\hline K422LNEVSU & $4.48 \mathrm{E}+003$ & $8.74 \mathrm{E}+003$ \\
\hline K242G_LCA & $4.32 \mathrm{E}+003$ & $3.66 \mathrm{E}+003$ \\
\hline DEEP_DRN & $4.32 \mathrm{E}+003$ & $6.03 E+003$ \\
\hline K4222S_VSU & $3.15 E+003$ & $1.96 \mathrm{E}+003$ \\
\hline K241LCA_T1 & $2.79 E+003$ & $4.22 \mathrm{E}+003$ \\
\hline K4_VF_AQ & $1.56 \mathrm{E}+003$ & $2.78 \mathrm{E}+003$ \\
\hline K2421_LCA & $1.53 \mathrm{E}+003$ & $2.26 \mathrm{E}+003$ \\
\hline UP_PLY_DRN & $1.51 \mathrm{E}+003$ & $2.50 \mathrm{E}+003$ \\
\hline K422GW_VSU & $1.46 \mathrm{E}+003$ & $2.00 \mathrm{E}+003$ \\
\hline UPPER_DRN & $1.32 \mathrm{E}+003$ & $2.14 \mathrm{E}+003$ \\
\hline K4_VF_CU & $1.17 \mathrm{E}+003$ & $2.23 E+003$ \\
\hline K243PP_LCA & $1.14 \mathrm{E}+003$ & $2.78 \mathrm{E}+003$ \\
\hline K2422b_LCA & $8.91 E+002$ & $1.72 \mathrm{E}+003$ \\
\hline K11DV_XCU & $7.68 \mathrm{E}+002$ & $1.39 \mathrm{E}+003$ \\
\hline K2412fL̄CA & $7.62 \mathrm{E}+002$ & $9.41 \mathrm{E}+002$ \\
\hline K42UP_VSU & $7.40 \mathrm{E}+002$ & $1.04 \mathrm{E}+003$ \\
\hline K4UP_VSUP & $5.52 \mathrm{E}+002$ & $8.35 \mathrm{E}+002$ \\
\hline K4UP_VSUC & $5.51 \mathrm{E}+002$ & $5.52 \mathrm{E}+002$ \\
\hline K2YMLCA & $4.39 E+002$ & $7.20 \mathrm{E}+002$ \\
\hline K12223LCCU & $4.34 \mathrm{E}+002$ & $6.47 \mathrm{E}+002$ \\
\hline K422LNWVSU & $4.30 \mathrm{E}+002$ & $7.03 \mathrm{E}+002$ \\
\hline K422DV_VSU & $4.20 \mathrm{E}+002$ & $5.72 \mathrm{E}+002$ \\
\hline K1221UCCU & $4.00 \mathrm{E}+002$ & $4.42 \mathrm{E}+002$ \\
\hline K422GV_VSU & $3.39 \mathrm{E}+002$ & $5.50 \mathrm{E}+002$ \\
\hline $\mathrm{K} \mathrm{PVA}^{-}$ & $3.09 E+002$ & $3.75 E+002$ \\
\hline K3211TMVA & $2.70 \mathrm{E}+002$ & $4.25 E+002$ \\
\hline K3215BCU34 & $2.63 \mathrm{E}+002$ & $3.37 \mathrm{E}+002$ \\
\hline K32CH24LF & $2.51 \mathrm{E}+002$ & $3.73 E+002$ \\
\hline K321521_PP & $2.43 \mathrm{E}+002$ & $3.20 \mathrm{E}+002$ \\
\hline UP_PAH_DRN & $1.91 \mathrm{E}+002$ & $4.39 \mathrm{E}+002$ \\
\hline K1̄'CCU_XCU & $1.88 \mathrm{E}+002$ & $1.25 \mathrm{E}+002$ \\
\hline K3BRU123 & $1.18 \mathrm{E}+002$ & $1.80 \mathrm{E}+002$ \\
\hline K3C_TM & $1.17 \mathrm{E}+002$ & $1.88 \mathrm{E}+002$ \\
\hline K241SMWLCA & $9.67 \mathrm{E}+001$ & $1.79 \mathrm{E}+002$ \\
\hline K32BR4CH13 & $8.13 E+001$ & $1.06 \mathrm{E}+002$ \\
\hline K2412_LCA & $6.71 \mathrm{E}+001$ & $3.25 E+001$ \\
\hline K241SM_LCA & $4.28 \mathrm{E}+001$ & $1.05 \mathrm{E}+002$ \\
\hline K11C_XIL̄CU & $4.22 \mathrm{E}+001$ & $3.71 \mathrm{E}+001$ \\
\hline K122esLCCU & $3.87 E+001$ & $6.05 E+001$ \\
\hline UP_DVN_DRN & $2.31 \mathrm{E}+001$ & $4.23 \mathrm{E}+001$ \\
\hline
\end{tabular}



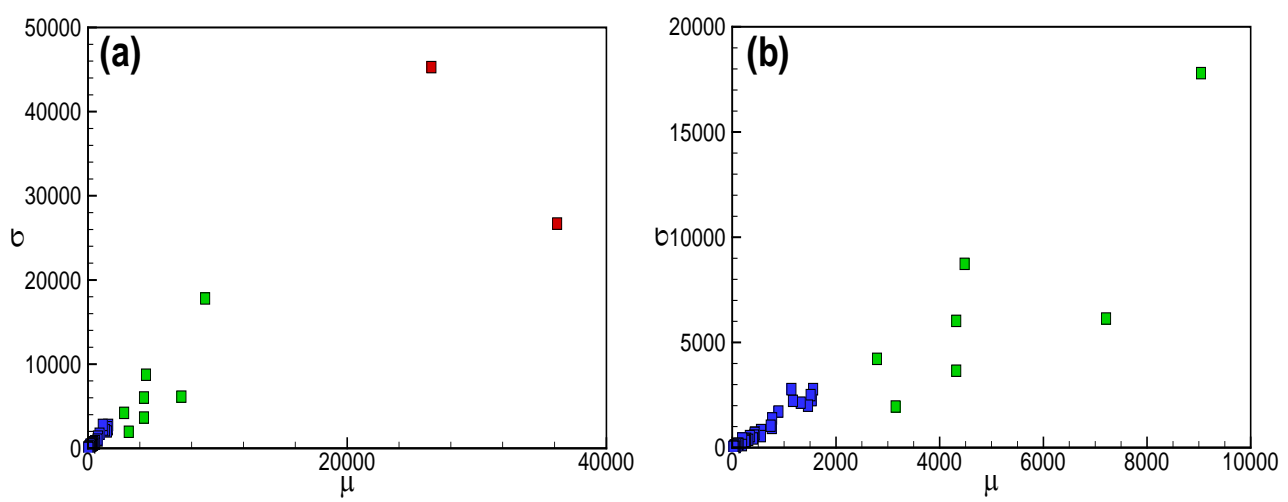

Figure 6. Mean and standard deviation of the elementary effects identified in the Morris analysis for (a) all 44 parameters and (b) 42 parameters after excluding the two parameters marked in red in (a).

Table 4. $\quad$ Ranges of the nine critical parameters from the Morris analysis for model G3R2.

\begin{tabular}{lcc}
\hline Parameter & Lower bound & Upper bound \\
\hline K221_LCA (m/d) & $3.56 \mathrm{E}-02$ & $7.12 \mathrm{E}+00$ \\
K242A_LCA (m/d) & $1.48 \mathrm{E}-01$ & $2.96 \mathrm{E}+01$ \\
K243_LCA (m/d) & $1.12 \mathrm{E}-01$ & $2.24 \mathrm{E}+01$ \\
K11_ICU (m/d) & $4.55 \mathrm{E}-05$ & $9.11 \mathrm{E}-03$ \\
K422LNEVSU (m/d) & $5.00 \mathrm{E}-03$ & $9.93 \mathrm{E}-01$ \\
K242G_LCA (m/d) & $1.88 \mathrm{E}-03$ & $3.77 \mathrm{E}-01$ \\
DEEP_DRN (m/d/m) & $4.08 \mathrm{E}-01$ & $8.16 \mathrm{E}+01$ \\
K4222S_VSU (m/d) & $4.93 \mathrm{E}-04$ & $9.86 \mathrm{E}-02$ \\
K241LCA_T1 (m/d) & $4.59 \mathrm{E}-03$ & $9.17 \mathrm{E}-01$ \\
\hline
\end{tabular}

For models G1R2 and G1R5, the Morris analysis identifies six critical parameters: DEEP_DRN, UP_PLY_DRN, K242G_LCA, K242A_LCA, K243_LCA and K4222S_VSU. The spatial distributions of these parameters are shown in Figure A-7. For models G2R2, G2R5, and G3R5, the Morris analysis identifies the same nine critical parameters as it does for model G3R2. The spatial distributions of these nine parameters for models G2R2 and G2R5 are shown in Figure A-8.

Due to the large spatial distribution of the parameters (Figures 7 through 10), adjusting values of the parameters may potentially deteriorate goodness-of-fit between model simulations and field observations. This issue is carefully examined for the selected realization, and as discussed in the next section, the goodness-of-fit remains satisfactory for the selected realization in which $\mathrm{Q}_{\mathrm{y}}$ is significantly reduced. 


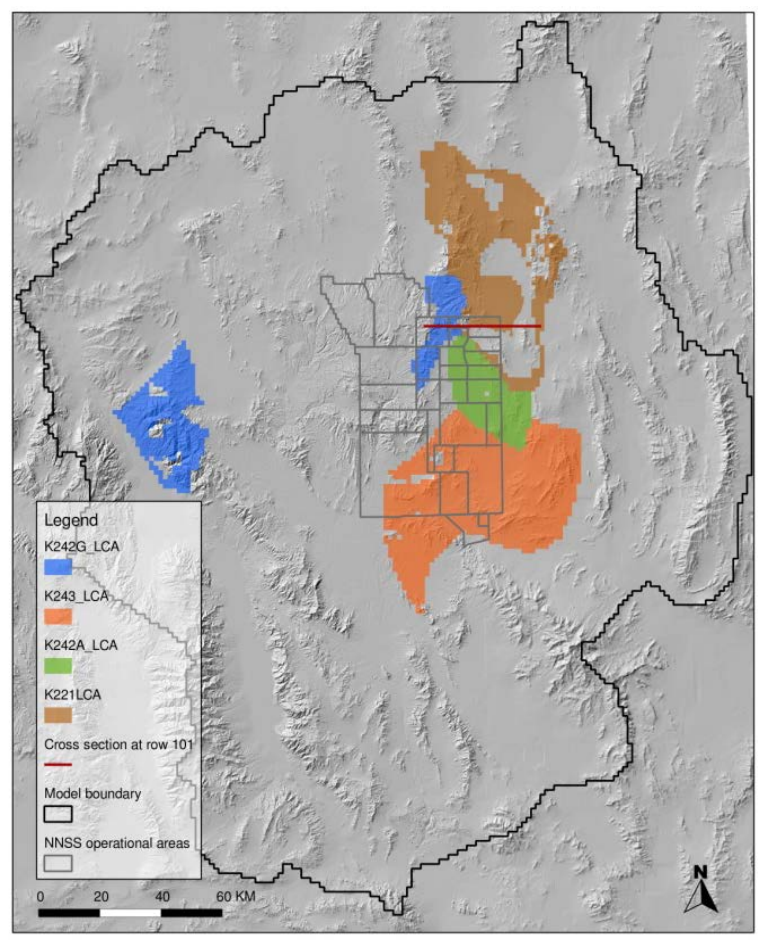

Figure 7. Spatial distributions of hydraulic conductivity parameters K242G_LCA, K243_LCA, K242A_LCA, and K221_LCA. The cross section through which $\mathrm{Q}_{\mathrm{y}}$ is calculated is highlighted in red.

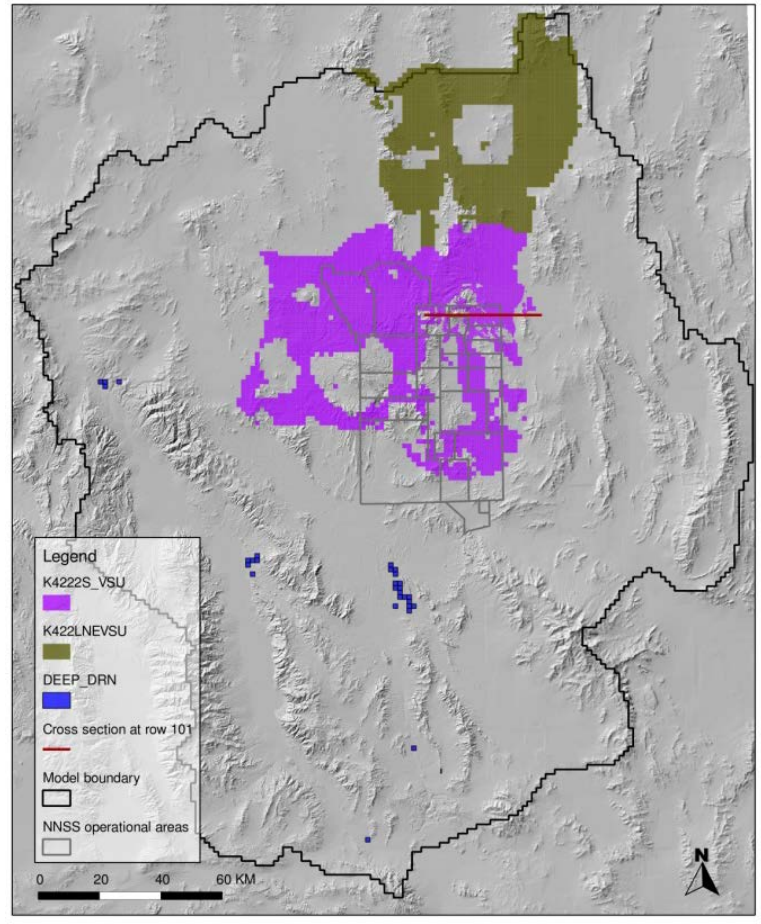

Figure 8. Spatial distributions of hydraulic conductivity parameters K422S_VSU, and K422LNEVSU, and drain parameter DEEP_DRN. The cross section through which $\mathrm{Q}_{\mathrm{y}}$ is calculated is highlighted in red. 


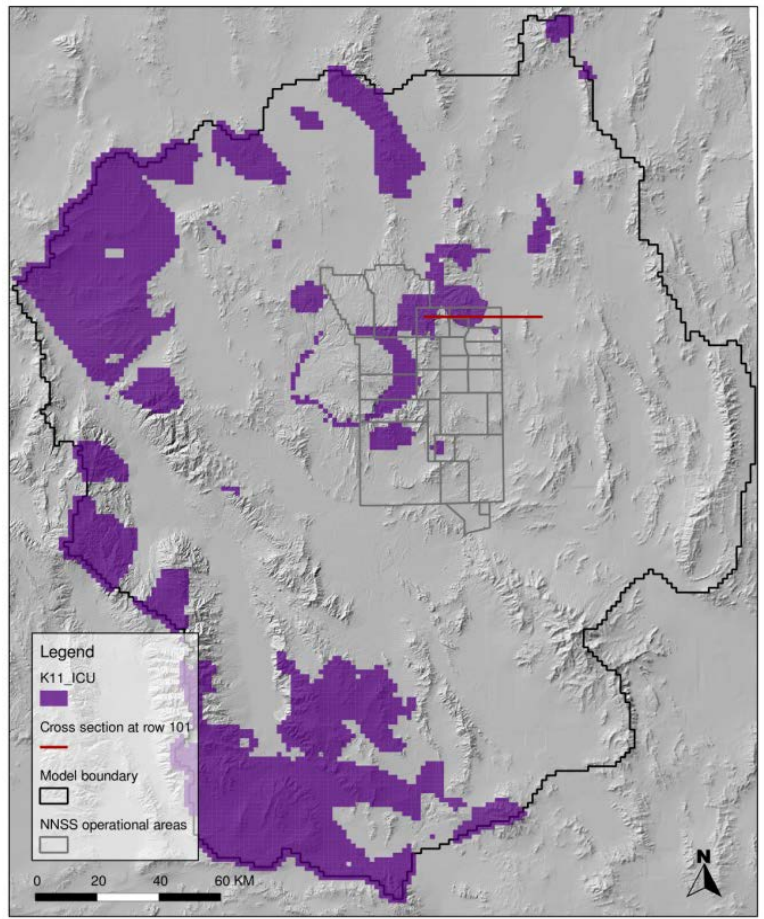

Figure 9. Spatial distribution of hydraulic conductivity parameter K11_ICU. The cross section through which $\mathrm{Q}_{\mathrm{y}}$ is calculated is highlighted in red.

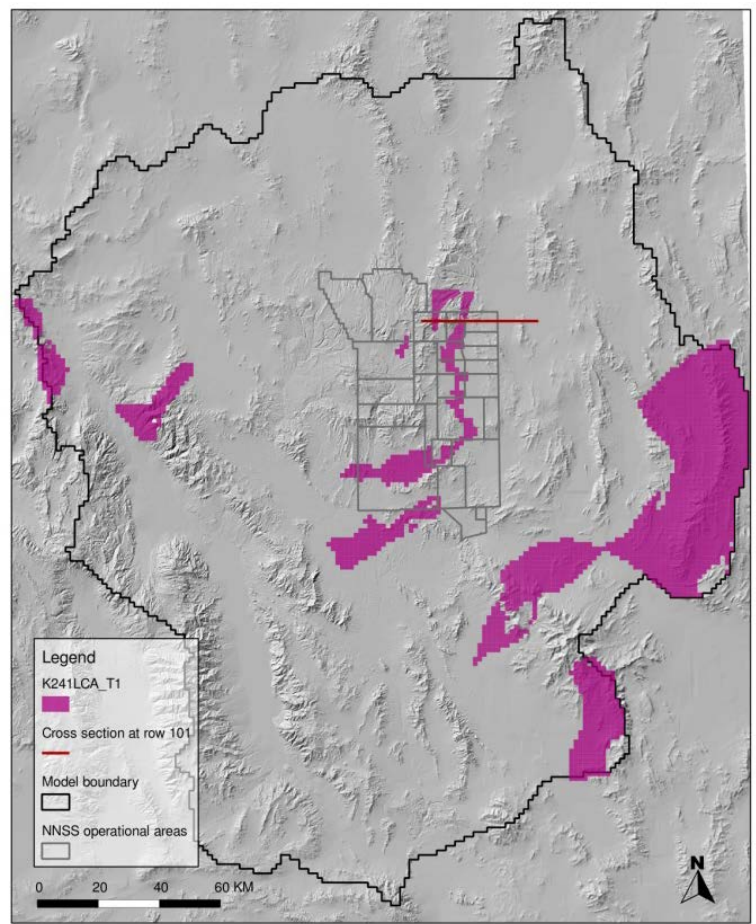

Figure 10. Spatial distribution of hydraulic conductivity parameter K241LCA_T1. The cross section through which $\mathrm{Q}_{\mathrm{y}}$ is calculated is highlighted in red. 


\subsection{Results of MC Simulations and Selection of Optimum Realizations}

The MC simulations were conducted for the critical parameters identified using the Morris method. For model G3R2, the MC simulations were conducted for the nine critical parameters (K221_LCA, K242A_LCA, K243_LCA, K11_ICU, K422LNEVSU, K242G_LCA, DEEP_DRN, K4222S_VSU and K241LCA_T1), since as discussed above the Morris analysis indicates that the estimate of $\mathrm{Q}_{\mathrm{y}}$ is mainly related to uncertainty in these parameters. Uniform distributions are assigned to these parameters over the parameter ranges described in Section 2.3, and it assumed that these parameters distributions are independent. Using the LHS method for sampling, 2,000 MC simulations are conducted for each model. Similarly, MC simulations for models G1R2 and G1R5 are conducted for the six critical parameters (DEEP_DRN, UP_PLY_DRN, K242G_LCA, K242A_LCA, K243_LCA and K4222S_VSU) selected by the Morris analysis for these models. Figure 11 plots the histograms of $\mathrm{Q}_{\mathrm{y}}$ for all six models based on the 2,000 MC realizations and the associated probability density functions of the normal distribution fitted to each histogram. This figure illustrates the large uncertainty in the $\mathrm{Q}_{\mathrm{y}}$ estimate for the individual models.
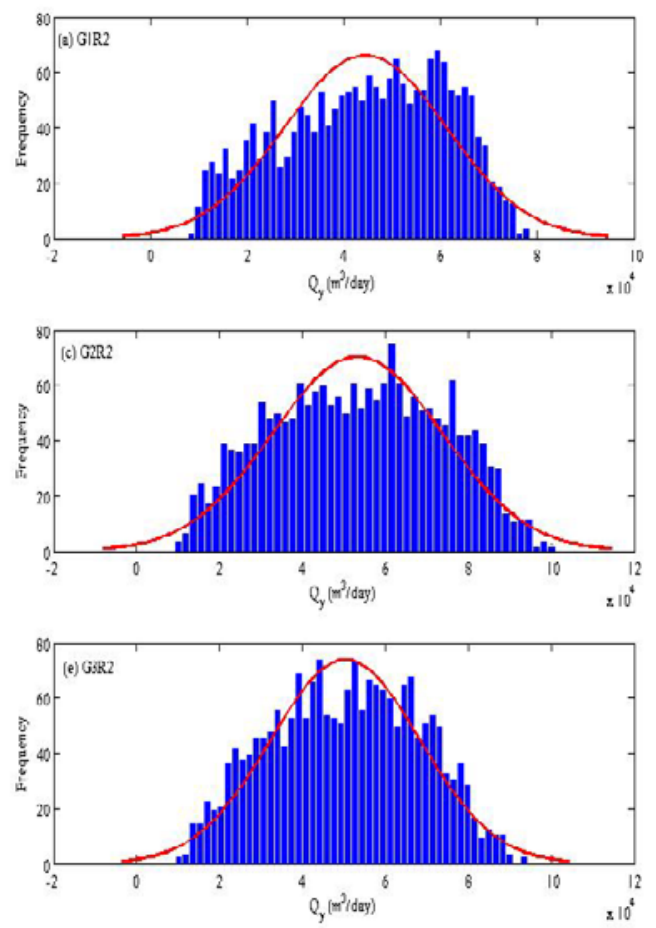
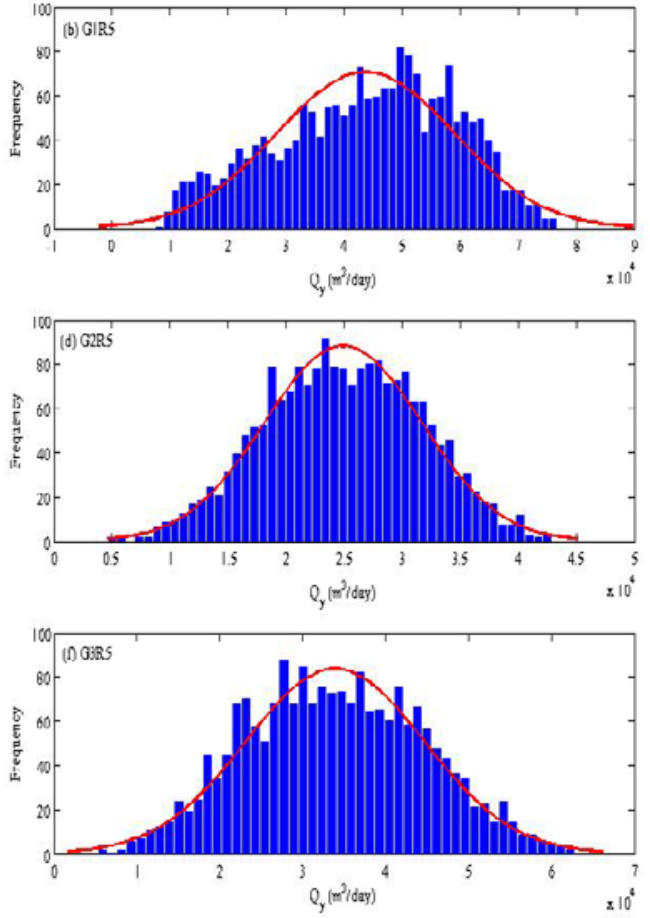

Figure 11. Histograms of the $\mathrm{Q}_{\mathrm{y}}$ estimates for the six models. The red lines represent the normal distribution fitted to the histograms. Note that different scales are used to best illustrate the distribution for each model.

Figure 12 plots the probability density functions of $\mathrm{Q}_{\mathrm{y}}$ for the six models. Since the $\mathrm{Q}_{\mathrm{y}}$ distributions are not normal for models G1R2 and G1R5, the density functions are fitted using the MATLAB kernel smoothing density estimator (ksdensity). The distributions are different for different models, and the difference illustrates the model uncertainty. While the distributions are similar for models G1R2 and G1R5 that have the same geological model, the distributions for models G2R2 and G2R5 are different. This is also the case for models 
G3R2 and G2R5. In particular, model G2R5 has the lowest uncertainty and model G2R2 has the highest uncertainty. Since the objective of this study is not to quantify uncertainty in the $\mathrm{Q}_{\mathrm{y}}$ estimates, but to investigate the feasibility of simulating low $\mathrm{Q}_{\mathrm{y}}$ as defined according to the two criteria given in Section 2.4, the following sections are focused on selecting and examining the realization having the optimum $\mathrm{Q}_{\mathrm{y}}$.

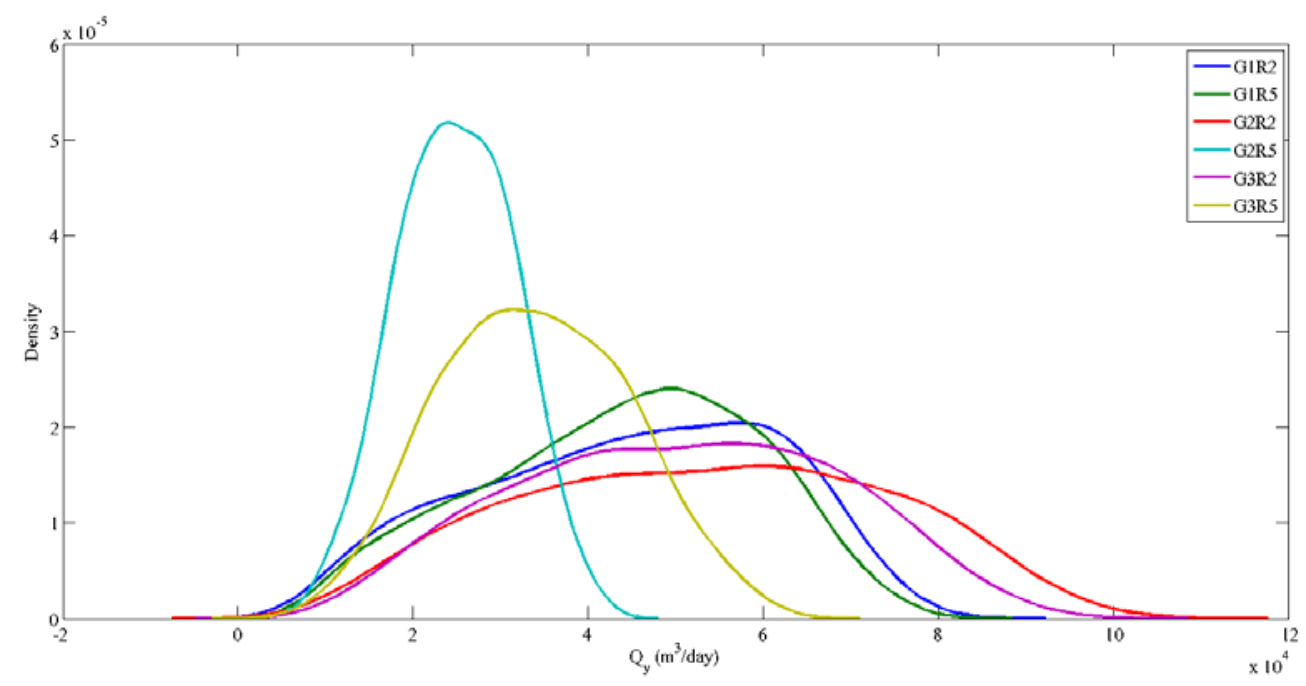

Figure 12. Probability density functions of the $\mathrm{Q}_{\mathrm{y}}$ estimates for the six models. The density functions are fitted using the MATLAB kernel smoothing density estimator (ksdensity).

In order to select the realization from each model that optimizes the combination of low $\mathrm{Q}_{\mathrm{y}}$ and SSWR, the values of $\mathrm{Q}_{\mathrm{y}}$ and SSWR for all 2,000 MC realizations are plotted for each model. As an example, Figure 13(a) plots this relationship for model G3R2. For a better view of the optimal values, Figure 13(b) plots the realizations with the lowest values. Figure 13(b) shows that a Pareto front can be roughly delineated for this multi-objective optimization problem with the two competing objectives of minimizing both $\mathrm{Q}_{\mathrm{y}}$ and SSWR. Using all 2,000 combinations of $\mathrm{Q}_{\mathrm{y}}$ and SSWR, the two individual objectives of each realization can be combined into a single composite function and the smallest composite chosen. While this can be done using utility theory, the weighted sum method, or other methods, the problem lies in the proper selection of the weights or utility functions to characterize the decision-maker's preferences about different objectives. In practice, it can be very difficult to precisely and accurately select these weights. Another approach for selecting the optimum realization is to calculate the fitness value of an individual, which is proportional to the number of other individuals it dominates (Ngatchou et al., 2005; Fonseca and Fleming, 1993). However, this approach does not allow control based on expectations about one or both of the objectives. In this analysis for example, this approach cannot account for the expectation of $\mathrm{Q}_{\mathrm{y}}$ less than 25,000 $\mathrm{m}^{3} / \mathrm{d}$ and SSWR less than 15,000. 

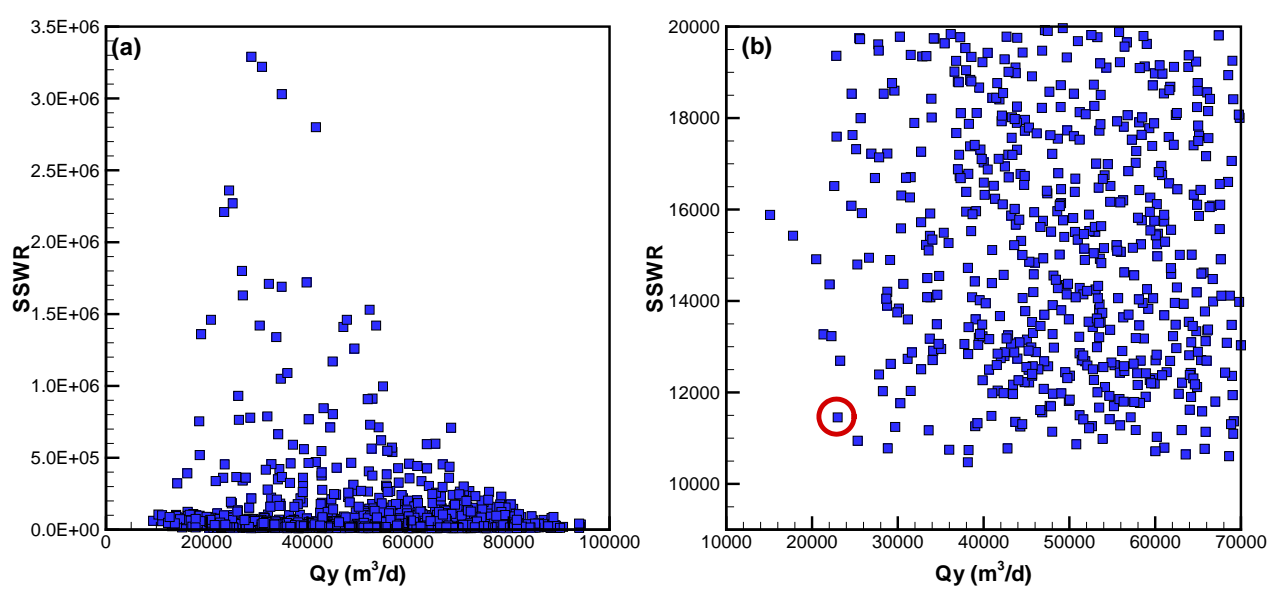

Figure 13. Plot of $\mathrm{Q}_{\mathrm{y}}$ and SSWR for model G3R2 showing (a) all 2,000 realizations, and (b) the realizations with the lowest values of $\mathrm{Q}_{\mathrm{y}}$ and SSWR. The realization indicated by the red circle is selected as the optimum.

Since there are only two competing objectives and there is prior information for the $\mathrm{Q}_{\mathrm{y}}$ estimate (from the other approaches discussed in Section 1.2), a method suggested by Fonseca and Fleming (1993) is used. First, the constraint of $Q_{y}$ is determined as $25,000 \mathrm{~m}^{3} / \mathrm{d}$ based on the independent estimates of inter-basin flow into northern Yucca Flat. This constraint excludes realizations whose $Q_{y}$ values are larger than 25,000 $\mathrm{m}^{3} / \mathrm{d}$, resulting in only a small percentage of realizations that satisfy this objective, as shown in Figure 13(b). From these realizations, the realization with the lowest SSWR is considered the optimum realization. Following this methodology, realization 1768 (highlighted in Figure 13b) is selected for G3R2 with SSWR of 11,455 and $\mathrm{Q}_{\mathrm{y}}$ of $22,988 \mathrm{~m}^{3} / \mathrm{d}$. In the same manner, the optimum realization is selected for each individual model, and the corresponding $\mathrm{Q}_{\mathrm{y}}$ and SSWR values are listed in Table 1. The parameter values for the selected realization for each of the six models are listed in Table A-2.

\subsection{Examination of Selected Realizations}

The simulation results for the selected realizations are examined in terms of water budgets and goodness-of-fit to observations of hydraulic head, discharge, and constant-head flow. While the water budgets for all six models are discussed below, examination of the goodness-of-fit is presented only for model G3R2 (figures showing goodness-of-fit for the other models are included in the appendices). The next section explains how $\mathrm{Q}_{\mathrm{y}}$ is reduced in the selected realizations in comparison to the calibrated model.

\subsubsection{Water budget}

Table 5 lists the water budgets for the entire domain for the optimal realization selected from each of the six models. The overall water budget discrepancies are considered satisfactory. Similar to the results of the 2007 sub-CAU model, the recharge of model R5 is significantly larger than that of model R2. The recharge values of G1R2, G2R2, and G3R2 are different, because the infiltration multipliers are calibrated for these models associated with R2. Note also that the inflow and outflow values through the constant-head boundary and drains are significantly different for different models. 
Similar to Table 5, Table 6 lists the water budgets for the northern Yucca Flat area located between the east-west cross sections at columns $\mathrm{I}=90$ and $\mathrm{I}=216$ between rows $\mathrm{J}=63$ and $J=137$. The $\mathrm{Q}_{\mathrm{y}}$ values calculated at the reference cross section at row $\mathrm{J}=101$ are also listed in Table 6. The percent discrepancy in northern Yucca Flat area is relatively larger than that of the entire DVRFS. As for the entire model domain, the recharge of model R5 in northern Yucca Flat is significantly larger than that of model R2. While the total inflows and outflows for the six models are also different, their relative ranges are not as large as those for the entire model domain listed in Table 5. This is due to the imposed constraint for choosing realizations where $\mathrm{Q}_{\mathrm{y}}$ must be less than $25,000 \mathrm{~m}^{3} / \mathrm{d}$. Since $\mathrm{Q}_{\mathrm{y}}$ has a direct relationship to the budget in northern Yucca Flat, if the budget is too different, a similar $\mathrm{Q}_{\mathrm{y}}$ cannot be obtained.

Table 5. Simulated water budgets for the entire model domain for the optimal realization of each of the six models.

\begin{tabular}{c|cccccc}
\hline & G1R2 & G1R5 & G2R2 & G2R5 & G3R2 & G3R5 \\
\hline Total inflow $\left(\mathrm{m}^{3} / \mathrm{d}\right)$ & 394172 & 582146 & 367139 & 491383 & 350395 & 555545 \\
\hline Constant head boundary flow & 175780 & 221071 & 180405 & 130308 & 165582 & 194470 \\
Recharge & 218392 & 361075 & 186734 & 361075 & 184812 & 361075 \\
\hline Total outflow (m $/ \mathrm{d})$ & 394067 & 581897 & 366890 & 491289 & 350217 & 555312 \\
\hline Constant head boundary flow & 130900 & 213936 & 110253 & 196794 & 100704 & 223657 \\
Drains & 263167 & 367960 & 256637 & 294494 & 249513 & 331655 \\
\hline Percent Discrepancy (\%) & 0.03 & 0.04 & 0.07 & 0.02 & 0.05 & 0.04 \\
\hline
\end{tabular}

Table 6. Simulated water budgets for the northern Yucca Flat area for the optimal realization of each of the six models.

\begin{tabular}{c|cccccc}
\hline & G1R2 & G1R5 & G2R2 & G2R5 & G3R2 & G3R5 \\
\hline Total inflow $\left(\mathrm{m}^{3} / \mathrm{d}\right)$ & 30762 & 34291 & 26801 & 27522 & 27233 & 30299 \\
\hline $\begin{array}{l}\text { Qx at the cross section of I=90 } \\
\text { Qy at the cross section of J=63 }\end{array}$ & 4000 & 9227 & 3245 & 9227 & 3492 & 9227 \\
\hline Total outflow (m $\left.{ }^{3} / \mathrm{d}\right)$ & 21839 & 19035 & 19607 & 13848 & 19750 & 15960 \\
\hline $\begin{array}{l}\text { Qx at the cross section of I=216 } \\
\text { Qy at the cross section of J=137 }\end{array}$ & 29644 & 32337 & 26100 & 25678 & 26469 & 28403 \\
\hline Percent Discrepancy (\%) & -3.63 & -5.70 & -2.62 & -6.70 & -2.81 & -6.26 \\
\hline $\begin{array}{l}\mathbf{Q}_{\mathbf{y}} \text { at the cross section of J=101 } \\
\left(\mathrm{m}^{3} / \mathrm{d}\right)\end{array}$ & 24444 & 25743 & 22672 & 19173 & 22988 & 21747 \\
\hline
\end{tabular}

\subsubsection{Goodness-of-Fit to Observations}

Goodness-of-fit is discussed here only for the selected realization of model G3R2; discussion of other models is given in the appendices. Goodness-of-fit is first evaluated using the summary statistics (Table 7), followed by detailed evaluations of individual observations, assessment of spatial distribution of weighted and unweighted residuals, and other graphical analysis for each kind of observation (i.e., hydraulic head, discharge, and constant-head boundary flow). 
Table 7 lists the values of SSWR and average positive and negative weighted residuals. Similar to the regression results of Belcher et al. (2004), the SSWR of hydraulic heads dominates the overall SSWR. The averaged positive and negative weighted residuals for the observations of boundary flow are better than those of the other two kinds of observations. Table 7 also lists the overall fitted error, which is the square root of SSWR divided by the number of observations (NOBs). The overall fitted error is a measure of model fit relative to the weighting that can be compared for different types of observations. Following Hill and Tiedeman (2007), a value of 1.0 for the overall fitted error suggests that a consistent match between regression error and observation error. The boundary flow has the smallest overall fitted error in this study, which is opposite to the findings of Belcher et al. (2004) for the DVRFS model where the boundary flow has the largest overall fitted error. When all observations are considered, the overall fitted error is 3.88, larger than the value of 2.7 reported by Belcher et al. (2004). When the overall fitted error is larger than 1.0, it suggests that model error exists. If the weights are considered to be reasonable, then the weighted residuals should be random and follow a normal distribution. In this model, the weighted residuals are large in some areas and small in others, indicating that the error distribution is not random.

Table 7. Summary statistics for measures of goodness-of-fit for model G3R2.

\begin{tabular}{cccccc}
\hline $\begin{array}{c}\text { Type of } \\
\text { observations }\end{array}$ & $\begin{array}{c}\text { Number of } \\
\text { observations }\end{array}$ & SSWR & $\begin{array}{c}\text { Average positive } \\
\text { weighted residual }\end{array}$ & $\begin{array}{c}\text { Average negative } \\
\text { weighted residual }\end{array}$ & $\begin{array}{c}\text { [SSWR/ } \\
\text { NOBs] }^{1 / 2}\end{array}$ \\
\hline $\begin{array}{c}\text { Hydraulic head } \\
\text { Discharge }\end{array}$ & 700 & 10,864 & 2.36 & -2.11 & 3.94 \\
$\begin{array}{c}\text { Constant-head } \\
\text { boundary flow }\end{array}$ & 45 & 554 & 3.49 & -2.65 & 3.51 \\
$\quad$ Total & $\mathbf{7 6 0}$ & $\mathbf{1 1 , 4 5 5}$ & $\mathbf{2 . 3 6}$ & -1.29 & 1.57 \\
\hline
\end{tabular}

Figure 14 plots the weighted residuals with the weighted simulated values of hydraulic heads, discharges, and constant-head boundary flows. The weighted residuals of head (Figure 14a) are scattered evenly about 0.0 for the entire range of weighted simulated equivalents, indicating that overall the residuals are unbiased. For the weighted residuals of discharge and constant-head flow, a slightly negative bias is observed (Figure 14b). This bias indicates that the simulated discharges and constant-head flows are higher than their corresponding observations. Considering that the discharges (outflows) are negative, the magnitudes of simulated discharges are lower than those of observed discharges as a result of reductions in the $\mathrm{Q}_{\mathrm{y}}$ estimates, as discussed below.

The same conclusions about the residuals can also be drawn based on Figure 15 that plots the weighted simulations with the weighted observations. In Figure 15a, the hydraulic head values fall on the 1:1 line (mainly due to the large scale). In Figure 15b, while the values of discharge and constant-head boundary flow are randomly scattered about the 1:1 line, a slight bias is noticeable, which is consistent with the finding from Figure 14b.

Plots of weighted residuals and weighted simulated equivalents, as shown in Figure 14, are shown in Figures A-9 through A-13 for models G1R2, G1R5, G2R2, G2R5, and G3R5, respectively. The plots of weighted observed value and weighted simulated values, as shown in Figure 15, are shown in Figure A-14 through A-18 for model G1R2, G1R5, G2R2, G2R5, and G3R5, respectively. 
(a)

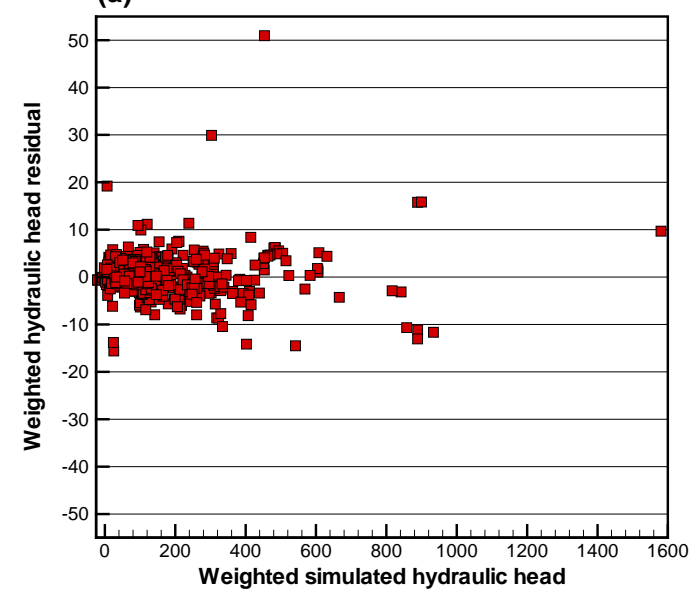

(b)

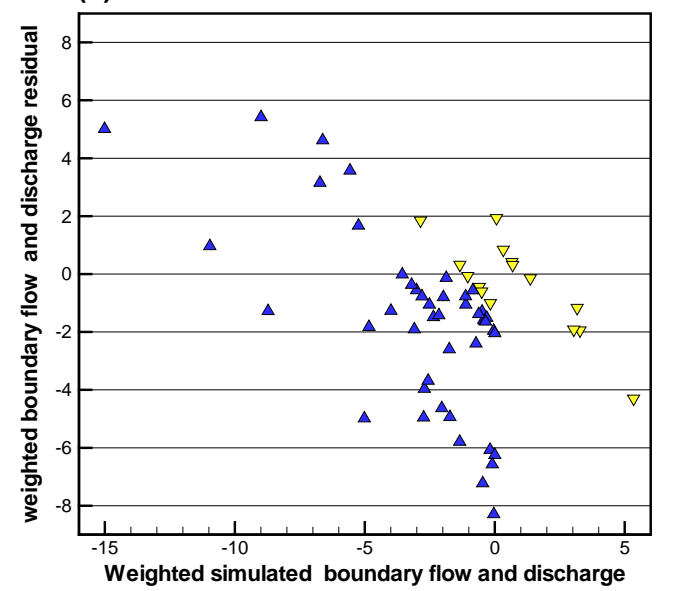

Figure 14. Weighted residuals and weighted simulated equivalents for (a) hydraulic head and (b) discharge (blue) and constant-head boundary flow (yellow).

(a)

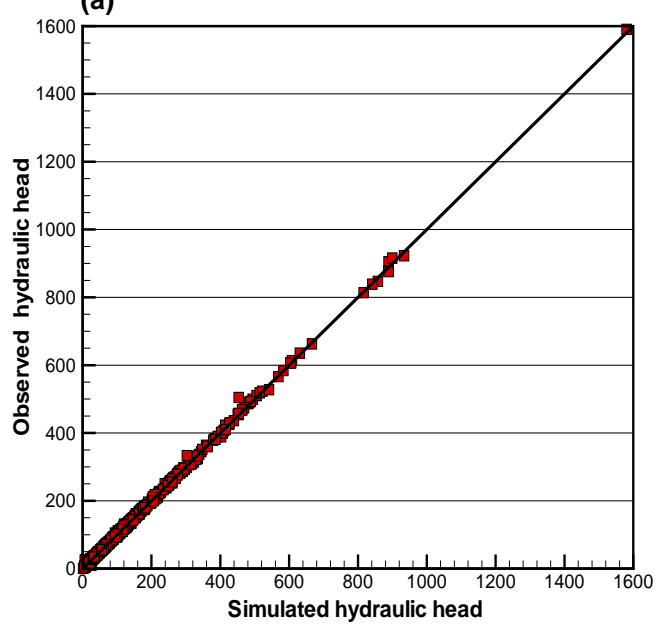

(b)

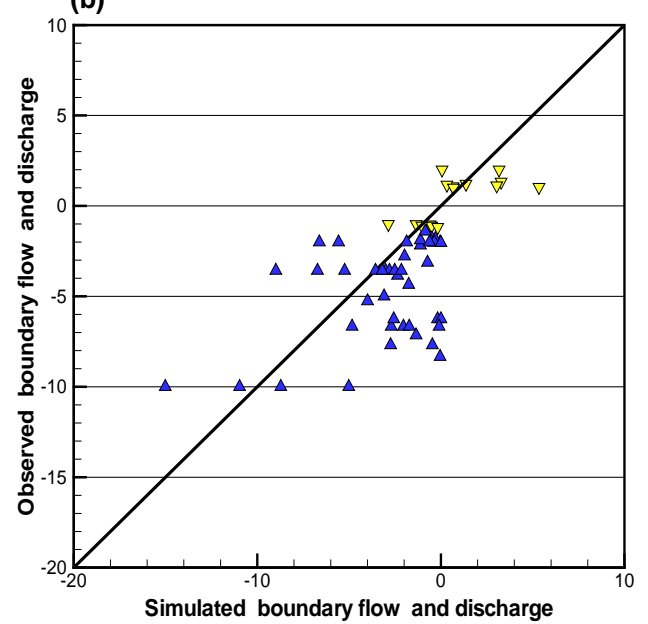

Figure 15. Weighted observed value and weighted simulated values for (a) hydraulic head and (b) discharge (blue) and constant-head boundary flow (yellow).

The simulated discharges and constant-head flows are further investigated by examining the observed and simulated values as well as the unweighted and weighted residuals. Tables 8 and 9 list these quantities for the discharge and constant-head boundary flows, respectively. Assuming that the weighted residuals are Gaussian with mean of zero, the weighted residuals are considered to be large if they are three times larger than the overall fitted error. In this analysis, the overall fitted error of 3.88 for all three types of observations is used. For discharge, Table 8 shows that all the weighted residuals are within \pm 11.64 , suggesting that there are no extremely large residuals. On the other hand, if the weighted residuals are larger than 3 , the unweighted residuals are larger than three times of the standard deviation of measurement error, indicating that the deviation between simulations and observation is too large. In this study, 37.8\% (17 out of 45) of weighted residuals are larger than three, larger than the value of $28.6 \%$ reported by Belcher et al. (2007). 
Table 8. $\quad$ Observed discharge values, simulated discharge values, and weighted residuals for model G3R2.

\begin{tabular}{|c|c|c|c|c|}
\hline Observation name & $\begin{array}{c}\text { Observations } \\
\left(\mathrm{m}^{3} / \mathrm{d}\right)\end{array}$ & $\begin{array}{c}\text { Simulations } \\
\left(\mathrm{m}^{3} / \mathrm{d}\right)\end{array}$ & $\begin{array}{l}\text { Unweighted residual } \\
\left(\mathrm{m}^{3} / \mathrm{d}\right)\end{array}$ & $\begin{array}{c}\text { Weighted Residual } \\
\left(\mathrm{m}^{3} / \mathrm{d}\right)\end{array}$ \\
\hline OBS-AM-NORTH & -18337 & -3467 & -14870 & -5.79 \\
\hline OBS-AM-CENTR & -23193 & -7089 & -16104 & -4.63 \\
\hline OBS-AM-SOUTH & -9484 & -3824 & -5660 & -2.59 \\
\hline OBS-AM-AMFLT & -5660 & -1313 & -4347 & -2.40 \\
\hline OBS-AM-CARSL & -468 & -92 & -376 & -1.61 \\
\hline OBS-AM-UPDRN & -3230 & -1311 & -1919 & -3.96 \\
\hline OBS-OV-COFFR & -4390 & -3333 & -1057 & -1.27 \\
\hline OBS-OV-SPRDL & -8898 & -13359 & 4461 & 5.01 \\
\hline OBS-OV-OASIS & -3629 & -3165 & -464 & -1.28 \\
\hline OBS-OV-BEATY & -3394 & -1208 & -2186 & -4.95 \\
\hline OBS-TC-TECOP & -12097 & -59 & -12038 & -8.29 \\
\hline OBS-TC-AMCAN & -3360 & -203 & -3157 & -7.23 \\
\hline OBS-TC-SPERY & -1328 & -280 & -1048 & -1.58 \\
\hline OBS-TC-CHRNC & -1766 & -39 & -1727 & -1.96 \\
\hline OBS-TC-RESTS & -2512 & -73 & -2439 & -6.07 \\
\hline OBS-SHOSH-N & -2235 & 0 & -2235 & -6.25 \\
\hline OBS-SHOSH-S & -4780 & -69 & -4711 & -6.57 \\
\hline OBS-STEWRT-V & -996 & -409 & -587 & -3.68 \\
\hline OBS-STEWRT-P & -2383 & -653 & -1730 & -1.30 \\
\hline OBS-SARCO-NE & -30958 & -15911 & -15047 & -1.06 \\
\hline OBS-SARCO-SW & -12174 & -7226 & -4948 & -0.77 \\
\hline OBS-SARCO-CH & -1530 & -259 & -1271 & -1.51 \\
\hline OBS-FRANKWEL & -1150 & -207 & -943 & -1.64 \\
\hline OBS-FRNKLK-N & -2350 & -1442 & -908 & -1.49 \\
\hline OBS-FRNKLK-S & -741 & 0 & -741 & -2.04 \\
\hline OBS-FRNKLK-E & -428 & -257 & -171 & -0.56 \\
\hline OBS-CHICAGOV & -1462 & -1042 & -420 & -0.80 \\
\hline OBS-INDIANSP & -2240 & -1124 & -1116 & -4.98 \\
\hline OBS-GRAPE-SP & -2450 & -1516 & -934 & -1.91 \\
\hline OBS-GRAPE-SC & -1035 & -319 & -716 & -1.38 \\
\hline OBS-DV-SARAT & -8311 & -7013 & -1298 & -0.56 \\
\hline OBS-DV-CONFI & -3236 & -8146 & 4910 & 5.42 \\
\hline OBS-DV-MORMN & -13356 & -19617 & 6261 & 1.67 \\
\hline OBS-DV-BADWT & -20098 & -15758 & -4340 & -0.77 \\
\hline OBS-DV-MIDDL & -6625 & -12475 & 5850 & 3.15 \\
\hline OBS-DV-FRNFN & -11522 & -8120 & -3402 & -1.05 \\
\hline OBS-DV-COTTN & -10224 & -10194 & -30 & -0.01 \\
\hline OBS-DV-MESQU & -29002 & -25995 & -3007 & -0.37 \\
\hline OBS-DV-WESTF & -18223 & -10978 & -7245 & -1.42 \\
\hline OBS-DV-TRVRT & -4633 & -5079 & 446 & 0.96 \\
\hline OBS-DV-TEXAS & -1220 & -316 & -904 & -4.94 \\
\hline OBS-DV-NEVAR & -1884 & -1368 & -516 & -1.83 \\
\hline OBS-PENOYERV & -12833 & -35760 & 22927 & 3.57 \\
\hline OBS-PAH-BENT & -17900 & -16727 & -1173 & -0.13 \\
\hline O-PAH-MANS & -821 & -2718 & 1897 & 4.62 \\
\hline
\end{tabular}


Table 9. Observed, simulated constant-head boundary flow values, and residuals for model G3R2

\begin{tabular}{lcccc}
\hline Observation name & $\begin{array}{c}\text { Observations } \\
\left(\mathrm{m}^{3} / \mathrm{d}\right)\end{array}$ & $\begin{array}{c}\text { Simulations } \\
\left(\mathrm{m}^{3} / \mathrm{d}\right)\end{array}$ & $\begin{array}{c}\text { Unweighted residual } \\
\left(\mathrm{m}^{3} / \mathrm{d}\right)\end{array}$ & $\begin{array}{c}\text { Weighted Residual } \\
\left(\mathrm{m}^{3} / \mathrm{d}\right)\end{array}$ \\
\hline C_LASV0303 & -3633 & -2081 & -1552 & -0.44 \\
C_SHPR0401 & -4410 & -2001 & -2409 & -0.60 \\
C_SHPR0402 & -15305 & -20134 & 4829 & 0.32 \\
C_SHPR0403 & -4959 & -4665 & -294 & -0.07 \\
C_SHPR0404 & 5927 & 3632 & 2295 & 0.42 \\
C_PAHR0501 & 1827 & 2047 & -220 & -0.15 \\
C_PAHR0502 & -2346 & -341 & -2005 & -1.00 \\
C_PAHR0505 & -2521 & -7149 & 4628 & 1.85 \\
C_GRDN0603 & 2334 & 653 & 1681 & 0.84 \\
C_STNC0700 & 12476 & 64116 & -51640 & -4.30 \\
C_CLAY0800 & 667 & 1639 & -972 & -1.94 \\
C_EURS0900 & 15100 & 491 & 14609 & 1.93 \\
C_PANA1100 & 15000 & 23771 & -8771 & -1.17 \\
C_OWLS1203 & 1682 & 4559 & -2877 & -1.92 \\
C_SILU0100 & 500 & 343 & 157 & 0.31 \\
\hline
\end{tabular}

For the constant-head boundary flows, Table 9 shows that $100 \%$ of the weighted residuals are within three times of the overall fitted error $( \pm 11.64)$. Since the corresponding value in the DVRFS model is 87\% (Belcher et al., 2004), the simulation of boundary flow is improved in model G3R2 in this study. For nine out of the fifteen constant-head boundary flow observations, weighted residuals are equal to or less than 1.0 and only one (C_STNC0700) exceeds 3.0 at the Stone Cabin-Railroad boundary segment. This indicates that the simulated constant-head boundary flows are consistent with the standard deviation of the observation error, considering that weighted residuals that exceed 3.0 are considered to indicate poor simulation. At the Stone Cabin-Railroad boundary segment, the simulated flow into the model is much higher than the estimated constant-head boundary flow, which also occurred in the DVRFS model. In the DVRFS model, the simulated inflow on the Stone Cabin-Railroad boundary segment is $81,500 \mathrm{~m}^{3} / \mathrm{d}$, which is almost 7 times larger than the observed value.

To examine the head residuals, Table 10 lists the ranges of unweighted and weighted head residuals and the number of residuals falling within the ranges. Among the 700 unweighted head residuals, 315 of them are within the range of $+10 \mathrm{~m}$ and $-10 \mathrm{~m}$, and 474 are within the range of $+20 \mathrm{~m}$ and $-20 \mathrm{~m}$. For the weighted residuals, 590 residuals are within the one overall fitted error of \pm 3.88 , and only 11 residuals are greater (in absolute values) than three times the overall fitted error. This suggests that the goodness-of-fit to head observations is satisfactory. 
Table 10. The range of unweighted and weighted hydraulic head residuals for model G3R2.

\begin{tabular}{|c|c|c|c|c|c|c|c|c|c|c|}
\hline \multirow{2}{*}{$\begin{array}{l}\text { Unweighted } \\
\text { residuals }\end{array}$} & $\begin{array}{l}\text { Ranges } \\
\text { (m) }\end{array}$ & $<-100$ & $\begin{array}{c}-100 \text { to } \\
-50\end{array}$ & $\begin{array}{l}-50 \text { to } \\
-20\end{array}$ & $\begin{array}{c}-20 \text { to } \\
-10\end{array}$ & $\begin{array}{c}-10 \text { to } \\
10\end{array}$ & $\begin{array}{l}10 \text { to } \\
20\end{array}$ & $\begin{array}{c}20 \text { to } \\
50\end{array}$ & $\begin{array}{c}50 \text { to } \\
100\end{array}$ & $>100$ \\
\hline & $\begin{array}{l}\text { Number of } \\
\text { residuals }\end{array}$ & 3 & 21 & 91 & 65 & 315 & 94 & 52 & 34 & 25 \\
\hline \multirow{2}{*}{$\begin{array}{l}\text { Weighted } \\
\text { residuals }\end{array}$} & $\begin{array}{l}\text { Ranges } \\
\text { (m) }\end{array}$ & & $<-11.64$ & $\begin{array}{c}-7.76 \\
\text { to } \\
-11.64\end{array}$ & $\begin{array}{c}-3.88 \\
\text { to } \\
-7.76\end{array}$ & $\begin{array}{c}-3.88 \\
\text { to } \\
3.88\end{array}$ & $\begin{array}{c}3.88 \\
\text { to } \\
7.76\end{array}$ & $\begin{array}{c}7.76 \\
\text { to } \\
11.64\end{array}$ & $>11.64$ & \\
\hline & $\begin{array}{l}\text { Number of } \\
\text { residuals }\end{array}$ & & 6 & 8 & 34 & 590 & 51 & 6 & 5 & \\
\hline
\end{tabular}

Figure 16 plots the spatial distributions of the unweighted head residuals. Qualitatively speaking, the goodness-of-fit between simulated and observed heads is generally good in areas having low hydraulic gradients, but worse in areas having large hydraulic gradients. Similar to Figure 16, Figure 17 plots the spatial distributions of the weighted residuals. This figure indicates a nonrandom distribution, because the positive and negative residuals are clustered instead of randomly distributed in the domain. This is partially a result of clustering of the head observations. If the observation weights are assigned properly to address this clustering, the average standard deviation of the regression should be close to one and the spatial distribution of the weighted residuals should be random. In this model, the average standard deviation of the regression is 3.88 and clusters of hydraulic head weighted residuals are observed, which may indicate model error. Figures corresponding to Figures 16 and 17 for the other five models are shown in Figure A-19 through A-28.

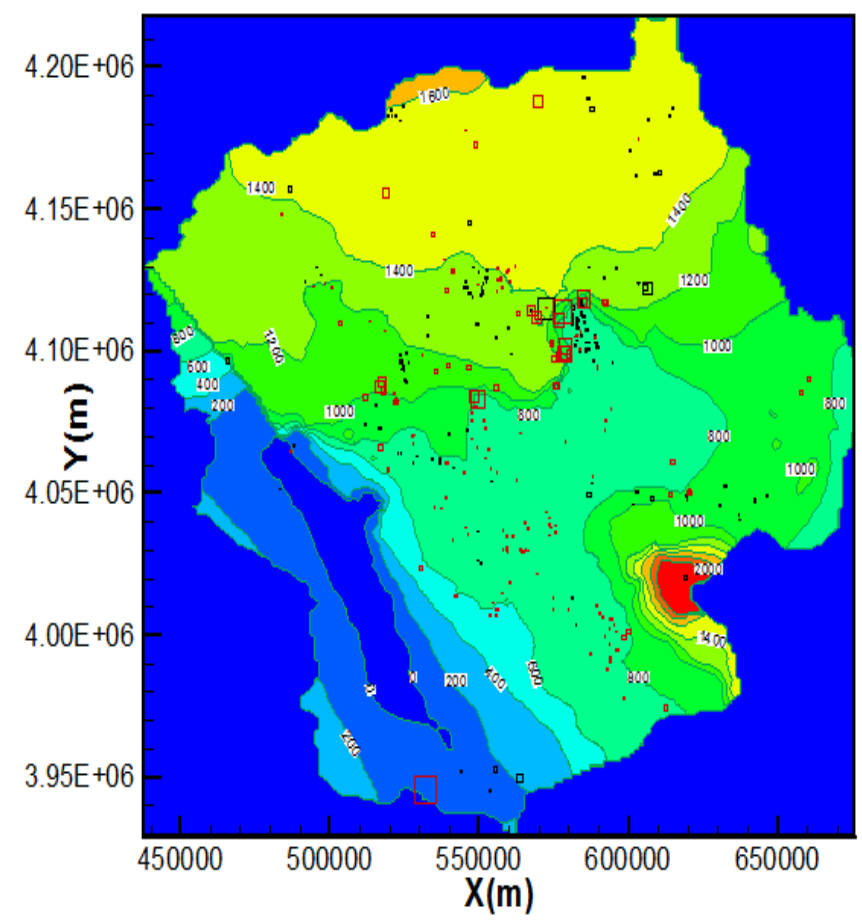

Figure 16. Spatial distribution of unweighted head residuals and the contours of hydraulic head in layer 1 of model G3R2. The red and black squares represent positive and negative residuals, respectively. Symbol size is scaled to the magnitude of the weighted residuals. 


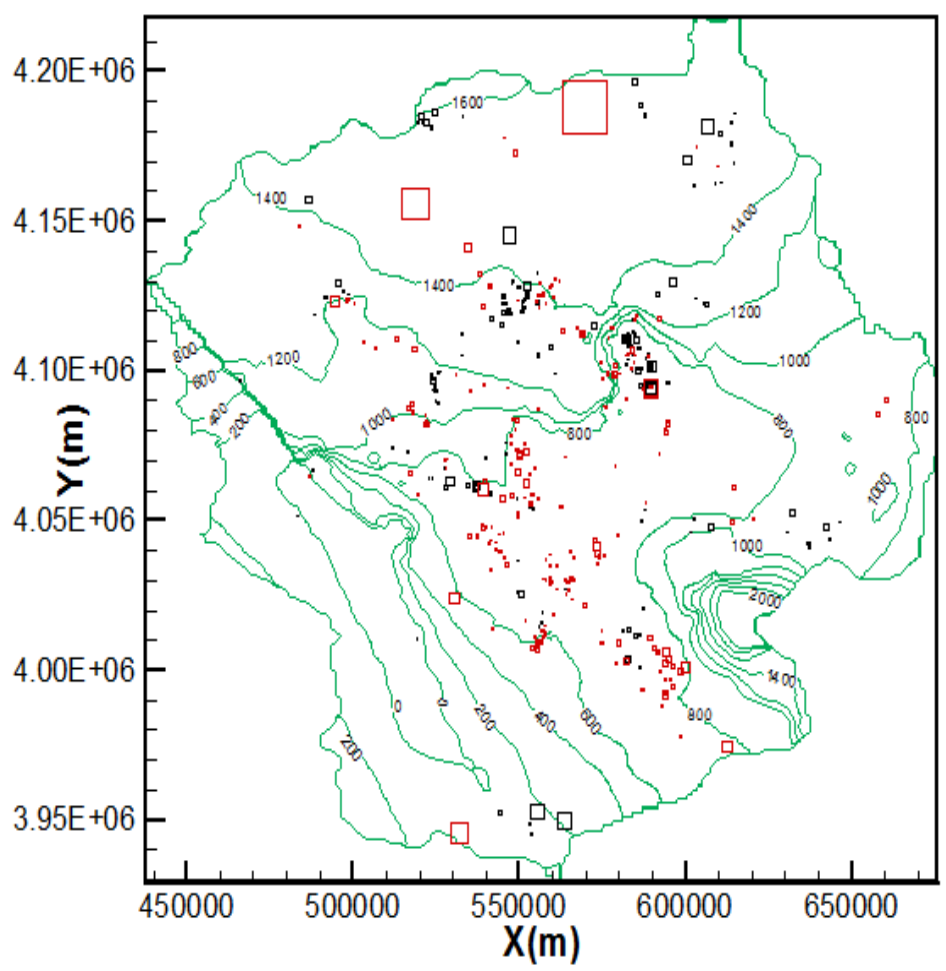

Figure 17. Distribution of weighted head residuals and the contours of hydraulic head in layer 1 of model G3R2. The red and black squares represent positive and negative residuals, respectively. Symbol size is scaled to the magnitude of the weighted residuals.

To summarize, the simulation results of realization 1768 from model G3R2 are reasonable and the goodness-of-fit is acceptable and consistent with the DVRFS model (Belcher et al., 2004). Therefore, the simulated $\mathrm{Q}_{\mathrm{y}}$ of this realization can be considered as a reasonable representation of inter-basin flow to northern Yucca Flat. An open question that has not been addressed in the evaluation of goodness-of-fit is that the number of head observations is overwhelmingly larger than the number of observations of discharge and constant-head boundary flow (Table 7). Since the head observations are clustered in space (Figures 16 and 17), the large number of head observations may cause bias in model calibration and modeling analysis. For example, satisfactory fitting to hydraulic head may be less desirable to satisfactory fitting to discharge and constant-head boundary flow. To address this issue requires a declustering analysis, and this is warranted for future study.

\subsection{Aspects of the Model that Influence $\mathbf{Q}_{\mathbf{y}}$}

The mechanisms that result in the reduction of simulated $\mathrm{Q}_{\mathrm{y}}$ of model G3R2 from $57,252 \mathrm{~m}^{3} / \mathrm{d}$ in the calibrated model to $22,988 \mathrm{~m}^{3} / \mathrm{d}$ in realization 1768 include reduction in model inflow, re-routing of flow around Yucca Flat, and increase in model outflow. Table 11 lists the water budgets of the calibrated model and realization 1768 in the northern Yucca Flat area. While the recharge inflows are the same for the calibrated model and realization 1768 (because the infiltration multipliers do not vary in the $\mathrm{MC}$ simulations), the inflow $\mathrm{Q}_{\mathrm{y}}$ at cross section $\mathrm{J}=63$ in realization 1768 is about one-third that of the calibrated model. With 
the small difference in $\mathrm{Q}_{\mathrm{y}}$ (both inflow and outflow) between the calibrated model and realization 1798, it can be concluded that the change of $\mathrm{Q}_{\mathrm{y}}$ at the cross section at row $\mathrm{J}=101$ is mainly due to the reduction of inflow $\mathrm{Q}_{\mathrm{y}}$ to the northern Yucca Flat area.

Table 11. Water budgets for the northern Yucca Flat area for the calibrated G3R2 model and realization 1768 .

\begin{tabular}{cccc}
\hline & Calibrated model & Realization 1768 & Difference \\
\hline Total inflow $\left(\mathrm{m}^{3} / \mathrm{d}\right)$ & 61019 & 27233 & -33786 \\
\hline $\mathrm{Q}_{\mathrm{x}}$ at cross section $\mathrm{I}=90$ & 3492 & 3492 & 0 \\
$\mathrm{Q}_{\mathrm{y}}$ at cross section $\mathrm{J}=63$ & 4280 & 3991 & -289 \\
\hline $\mathrm{Q}_{\mathrm{x}}$ at cross section $\mathrm{I}=216$ & 53247 & 19750 & -33497 \\
$\mathrm{Q}_{\mathrm{y}}$ at cross section $\mathrm{J}=137$ & 60331 & 26469 & -33862 \\
\hline Total outflow & 769 & 834 & 65 \\
\hline $\mathbf{Q}_{\mathbf{y}}$ at cross section $\mathbf{J}=\mathbf{1 0 1}\left(\mathrm{m}^{3} / \mathrm{d}\right)$ & 59562 & 25635 & -33927 \\
\hline
\end{tabular}

The reduction in $\mathrm{Q}_{\mathrm{y}}$ between the cross sections at $\mathrm{J}=63$ and $\mathrm{J}=101$ is depicted in Figure 18. To investigate whether the reduction is due to re-routing of flow through other parts of the cross sections, Figure 19 plots the contours of $\mathrm{Q}_{\mathrm{y}}$ at the same model rows, but across the entire model domain. Comparing Figures 18 and 19 shows visually that the reduction in $\mathrm{Q}_{\mathrm{y}}$ in northern Yucca Flat causes an observable increase in flow through other portions of these cross sections. In other words, internal re-routing of a portion of flow through other portions of the model causes a reduction in $\mathrm{Q}_{\mathrm{y}}$. This is further confirmed by evaluating $Q_{\mathrm{y}}$ values along the two cross sections. The $\mathrm{Q}_{\mathrm{y}}$ value at the cross section of $\mathrm{J}=63$ is $104,990 \mathrm{~m}^{3} / \mathrm{d}$ for the calibrated model and $74,117 \mathrm{~m}^{3} / \mathrm{d}$ for realization 1768 . The $\mathrm{Q}_{\mathrm{y}}$ value at the cross section of $\mathrm{J}=101$ is $102,740 \mathrm{~m}^{3} / \mathrm{d}$ for the calibrated model and $71,671 \mathrm{~m}^{3} / \mathrm{d}$ for realization 1768. The difference between the calibrated model and realization 1768 is $30,873 \mathrm{~m}^{3} / \mathrm{d}$ at the cross section of $\mathrm{J}=63$ and $31,069 \mathrm{~m}^{3} / \mathrm{d}$ at the cross section of $\mathrm{J}=101$. These values are lower than their corresponding values at the northern Yucca Flat area listed in Table 11, which indicates that there is some redistribution of $\mathrm{Q}_{\mathrm{y}}$ over the entire cross sections of $J=63$ and $J=101$. In other words, $Q_{y}$ is significantly reduced at the northern Yucca Flat area and increased slightly in other parts of the cross sections.

To understand how changes in the values of critical parameters influence $\mathrm{Q}_{\mathrm{y}}$, water budgets for the entire domain are compared for the calibrated model and realization 1768 (Table 12). Inflow through the constant-head boundary decreases from $179,462 \mathrm{~m}^{3} / \mathrm{d}$ for the calibrated model to $165,582 \mathrm{~m}^{3} / \mathrm{d}$ for realization 1768 , a reduction of $13,880 \mathrm{~m}^{3} / \mathrm{d}$. As shown in Table 13, this reduction is mainly attributed to reduced inflow at boundary segment C_STNC0700 (Stone Cabin-Railroad) shown in Figure 20. There are several reasons that this segment is important to the $\mathrm{Q}_{\mathrm{y}}$ estimate. First, the head contours show that the overall flow direction is from north to south, and the C_STNC0700 segment is located right upgradient of the cross section on which $\mathrm{Q}_{\mathrm{y}}$ is estimated. The C_STNC0700 segment is also more important than other segments in a statistical sense. Based on the 2,000 realizations of model G3R2, Figure 21 plots the relationship between the simulated boundary inflow and $\mathrm{Q}_{\mathrm{y}}$ estimates at four boundaries (Pahranagat, including segments C_PAHR0501, C_PAHR0502, and C_PAHR0505; C-GRDN0603 segment of Garden-Coal; C-STNC0700 of Stone CabinRailroad; and C_CLAY0800 of Clayton) located north of Yucca Flat. This figure shows that 
(a) $\mathrm{J}=63$

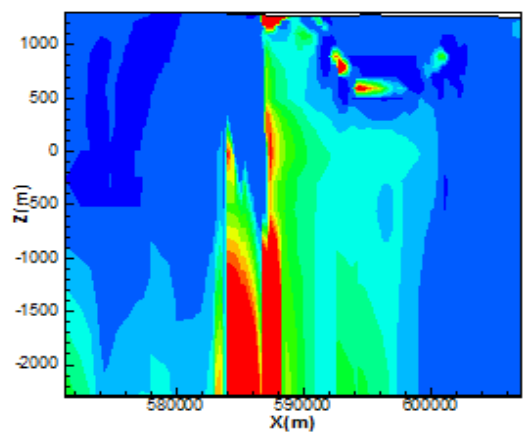

(b) $\mathbf{J}=101$

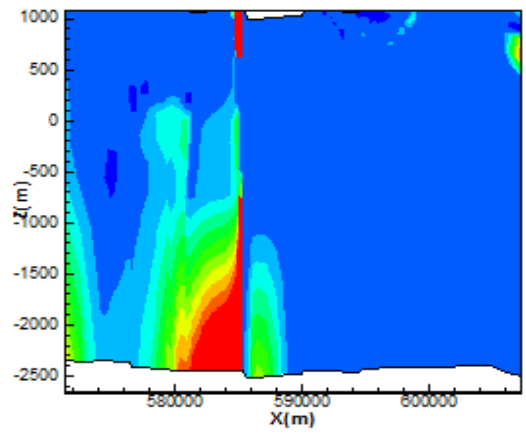

(c) $\mathrm{J}=63$

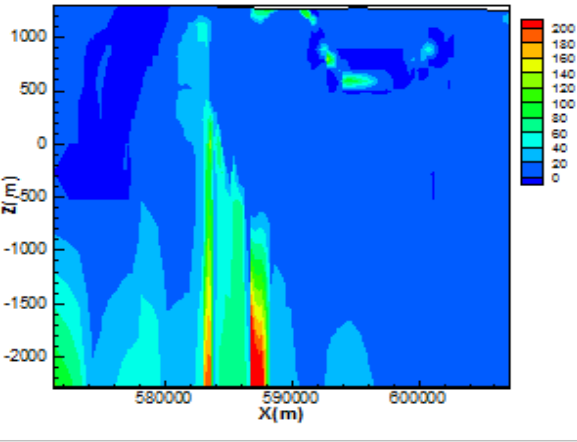

(d) $\mathrm{J}=101$

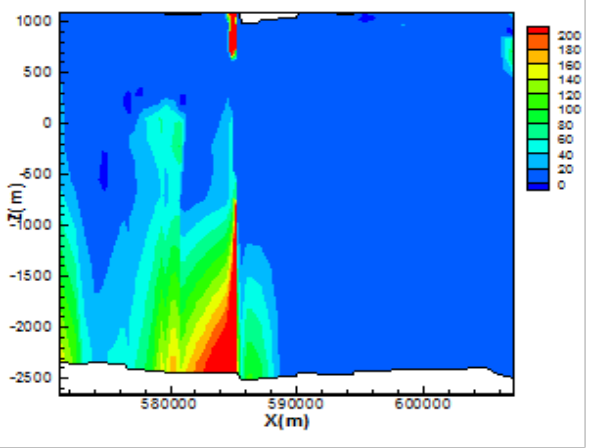

Figure 18. Contours of $\mathrm{Q}_{\mathrm{y}}$ in northern Yucca Flat for the calibrated G3R2 model at (a) cross section $\mathrm{J}=63$ and (b) cross section $\mathrm{J}=101$, and for realization 1768 at (c) cross section $\mathrm{J}=63$ and (d) cross section $\mathrm{J}=101$.
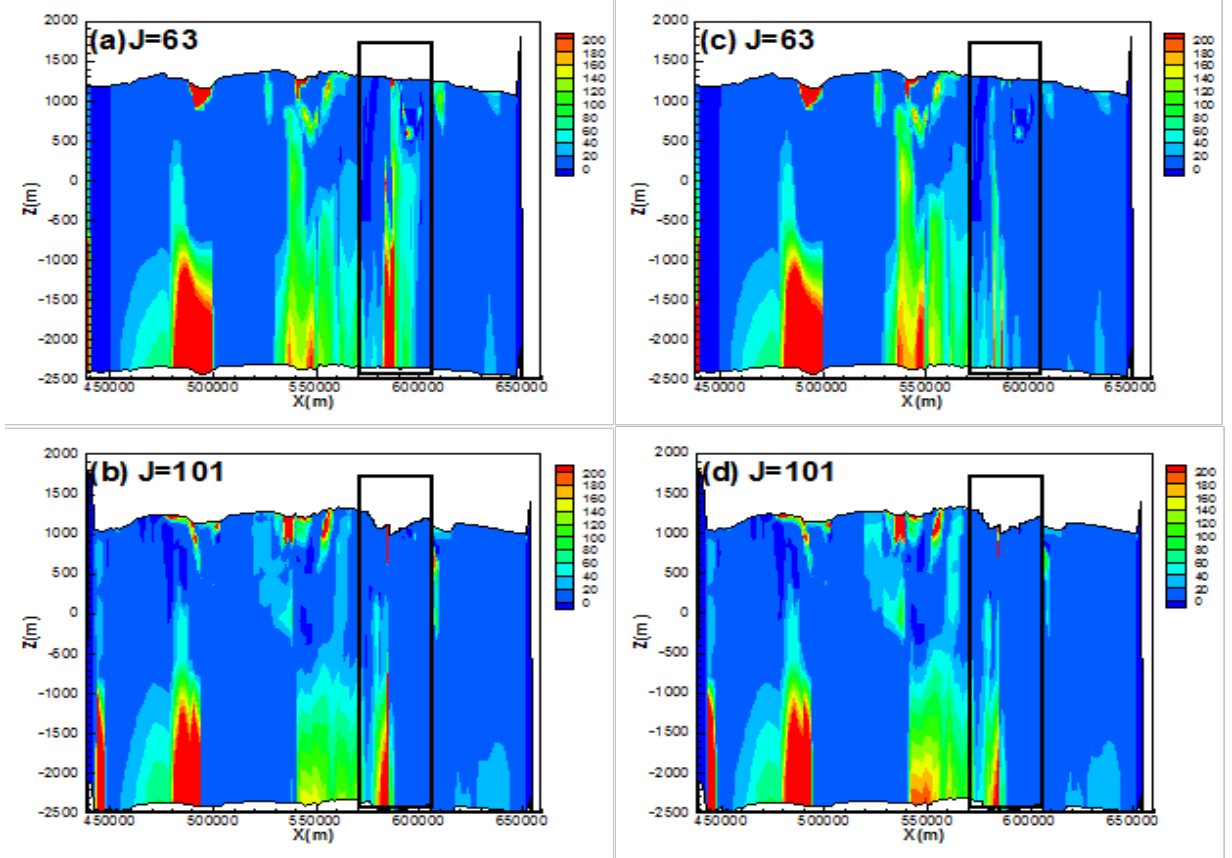

Figure 19. Contours of $\mathrm{Q}_{\mathrm{y}}$ across the entire model domain for the calibrated G3R2 model at (a) cross section $J=63$ and (b) cross section $J=101$, and for realization 1768 at (c) cross section $\mathrm{J}=63$ and (d) cross section $\mathrm{J}=101$. The northern Yucca Flat area is marked with the black square. 
Table 12. Water budgets for the entire domain for the calibrated model and realization 1768.

\begin{tabular}{|c|c|c|c|}
\hline & Calibrated model & Realization 1768 & Difference \\
\hline Total inflow $\left(\mathrm{m}^{3} / \mathrm{d}\right)$ & 364275 & 350395 & -13880 \\
\hline Constant head boundary flow & 179462 & 165582 & -13880 \\
\hline Recharge & 184812 & 184812 & 0 \\
\hline Total outflow $\left(\mathrm{m}^{3} / \mathrm{d}\right)$ & 364225 & 350217 & -14008 \\
\hline Constant head boundary flow & 98167 & 100704 & 2537 \\
\hline Drains & 266058 & 249513 & -16545 \\
\hline
\end{tabular}

Table 13. Unweighted observations (estimated for the model) and simulated values of constanthead boundary flow.

\begin{tabular}{ccccc}
\hline Observation name & Observation & Calibrated model & Realization 1768 & Difference \\
\hline C_LASV0303 & -3633 & -2190 & -2081 & 109 \\
C_SHPR0401 & -4410 & -2041 & -2001 & 40 \\
C_SHPR0402 & -15305 & -20871 & -20134 & 737 \\
C_SHPR0403 & -4959 & -4951 & -4665 & 286 \\
C_SHPR0404 & 5927 & 4163 & 3632 & -531 \\
C_PAHR0501 & 1827 & 2482 & 2047 & -435 \\
C_PAHR0502 & -2346 & 87 & -341 & -428 \\
C_PAHR0505 & -2521 & -6629 & -7149 & -520 \\
C_GRDN0603 & 2334 & 928 & 653 & -275 \\
C_STNC0700 & 12476 & 79680 & 64116 & -15564 \\
C_CLAY0800 & 667 & 1492 & 1639 & 147 \\
C_EURS0900 & 15100 & 503 & 491 & -12 \\
C_PANA1100 & 15000 & 23774 & 23771 & -3 \\
C_OWLS1203 & 1682 & 4555 & 4559 & 4 \\
C_SILU0100 & 500 & 312 & 343 & 31 \\
\hline
\end{tabular}

there is essentially no correlation between the $\mathrm{Q}_{\mathrm{y}}$ estimate and the boundary flow at segments C_PAHR0501, C_PAHR0502, and C_CLAY0800. The figure depicts a positive correlation between $\mathrm{Q}_{\mathrm{y}}$ and the boundary flow rate at C-STNC0700 with a relatively large correlation coefficient of 0.69. At segments C_PAHR0505 and C-GRDN0603, although the correlation between $\mathrm{Q}_{\mathrm{y}}$ and boundary flow rate is significant, the magnitudes of the simulated boundary flow rate are small, and their effect on $\mathrm{Q}_{\mathrm{y}}$ is thus smaller relative to the effect of the inflow at segment C-STNC0700. Compared to the inflow from the Stone Cabin-Railroad boundary, the inflow from the Garden-Coal and Pahranagat boundaries are much smaller, thus flow to the cross-section of $\mathrm{Q}_{\mathrm{y}}$ mainly comes from the Stone Cabin-Railroad boundary, which renders the flow on the Stone Cabin-Railroad boundary a key factor for the $\mathrm{Q}_{\mathrm{y}}$ estimate.

The rates used as observations of groundwater flow through the perimeter boundaries of the DVRFS model are estimated by Harrill and Bedinger (2004) using two methods. One utilizes regional hydraulic gradients, hydrogeologic cross-sectional areas, and hydraulic conductivities and applies Darcy's law to each boundary segment and the other is based on estimated water budgets for basins contributing to each boundary segment. For the Stone Cabin-Railroad segment, Harrill and Bedinger (2004) applied only the Darcy method since this boundary crosses through hydrologic basins whose water budgets were estimated only for entire basins. Their Darcy calculations resulted in an estimated net inflow of 12,500 $\mathrm{m}^{3} / \mathrm{d}$ 
through this boundary segment. A standard deviation of 12,000 $\mathrm{m}^{3} / \mathrm{d}$ (estimated value rounded down to nearest 500) was assigned for the purpose of calculating a weight for this observation in the model (Faunt et al., 2004). Earlier water-budget estimates of flow through this area are considerably lower. Van Denburgh and Rush (1974) and Harrill et al. (1988) estimated that about 3,400 $\mathrm{m}^{3} / \mathrm{d}$ (1,000 acre-feet per year) flows from southern Railroad Valley to Kawich Valley, an area that encompasses the eastern portion of the STNC boundary segment. Farther west along the STNC boundary, interbasin flow is thought to be minimal or directed southwest (Rush and Everett, 1966; Rush, 1968; Harrill et al., 1988).
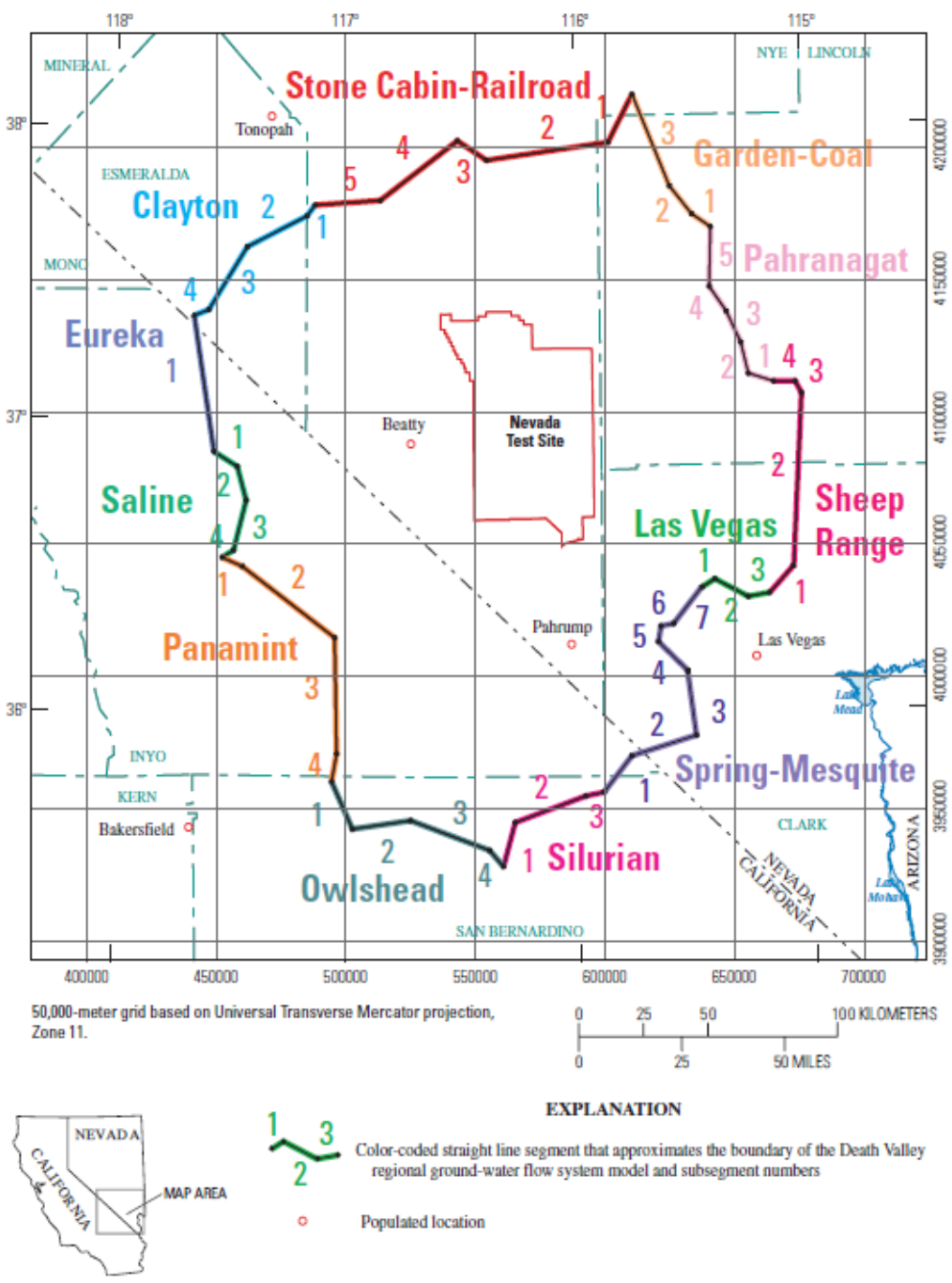

Figure 20. Boundary segments and subsegments. From Belcher et al. (2004). 

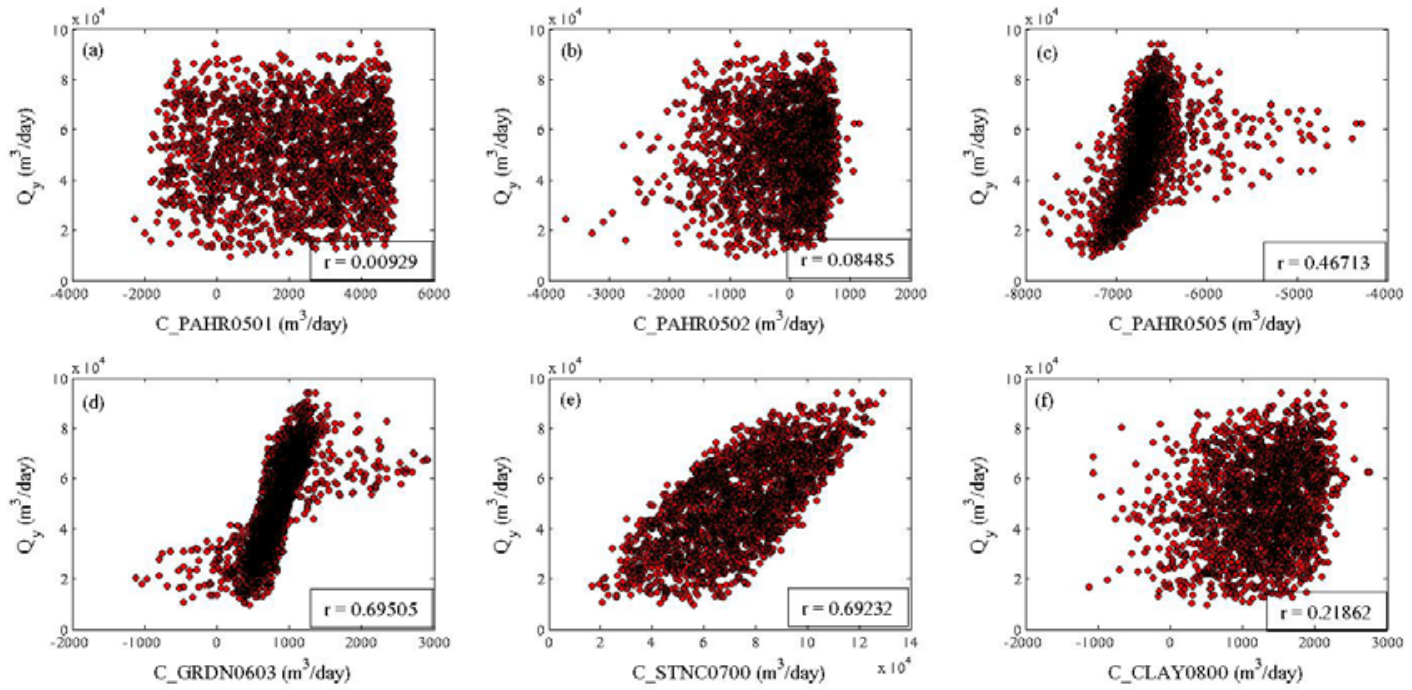

Figure 21. Plots of $\mathrm{Q}_{\mathrm{y}}$ estimate with simulated flow rate at the six boundary segments. Pearson correlation coefficients are calculated for each figure.

Reduction in constant-head boundary flow results from reductions in the values of K221_LCA and K422LNEVSU, parameters that extend from northern Yucca Flat to the northern part of the domain (Figures 7 and 8). Decreasing the values of these two parameters increases the hydraulic head in the northern part of the domain and thus reduces the hydraulic head gradient and subsequently the boundary inflow. It is noted that the simulated constanthead boundary flow at the Stone Cabin-Railroad segment in realization 1768 is still about five times as large as the estimated value of Belcher et al. (2004). It is likely that the simulated constant-head boundary flow at the Stone Cabin-Railroad segment can be further reduced, which will further reduce $\mathrm{Q}_{\mathrm{y}}$ to the northern Yucca Flat area.

$\mathrm{Q}_{\mathrm{y}}$ in northern Yucca Flat is also influenced by the increase of simulated discharge in realization 1768 at drain OBS-PENOYERV (location indicated on Figure 22). For the drains listed in Table 14, the differences in unweighted discharges between the calibrated model and realization 1768 are larger than $1,000 \mathrm{~m}^{3} / \mathrm{d}$. The largest increase occurs for drain OBSPENOYERV. For this drain, the simulated discharge for realization 1768 is $35,760 \mathrm{~m}^{3} / \mathrm{d}$, $14,520 \mathrm{~m}^{3} / \mathrm{d}$ larger than that of the calibrated model. This significant increase in discharge is believed to contribute to the decrease in $\mathrm{Q}_{\mathrm{y}}$ simulated in northern Yucca Flat. The increase in simulated discharge at OBS-PENOYERV may be caused by changes in hydraulic heads in its vicinity, since the drain conductance (UPPER_DRN) corresponding to this observation is fixed during the MC simulations. Reduction in discharge in realization 1768 for drains OBS-AM-CENTR, OBS-AM-NORTH, OBS-AM-SOUTH, OBS-AM-AMFLT and OBS-DV-TEXAS is believed to be caused by the decrease in $\mathrm{Q}_{\mathrm{y}}$ to Yucca Flat, because they are all located south of Yucca Flat where simulated southward flow decreases. Based on the 2,000 realizations of model G3R2, Figure 23 plots the $\mathrm{Q}_{\mathrm{y}}$ estimates and the sum of simulated discharges at OBS-AM-CENTR, OBS-AM-NORTH and OBS-AM-SOUTH. This figure shows a strong positive correlation between the summed discharge and $\mathrm{Q}_{\mathrm{y}}$ with a correlation coefficient of 0.86 indicating that reduction of $\mathrm{Q}_{\mathrm{y}}$ in realization 1768 causes decreased discharge simulated at the three observation locations. Since the three observations are 
associated with parameter DEEP_DRN, Figure 23 also explains why the Morris analysis selects it as a critical parameter.

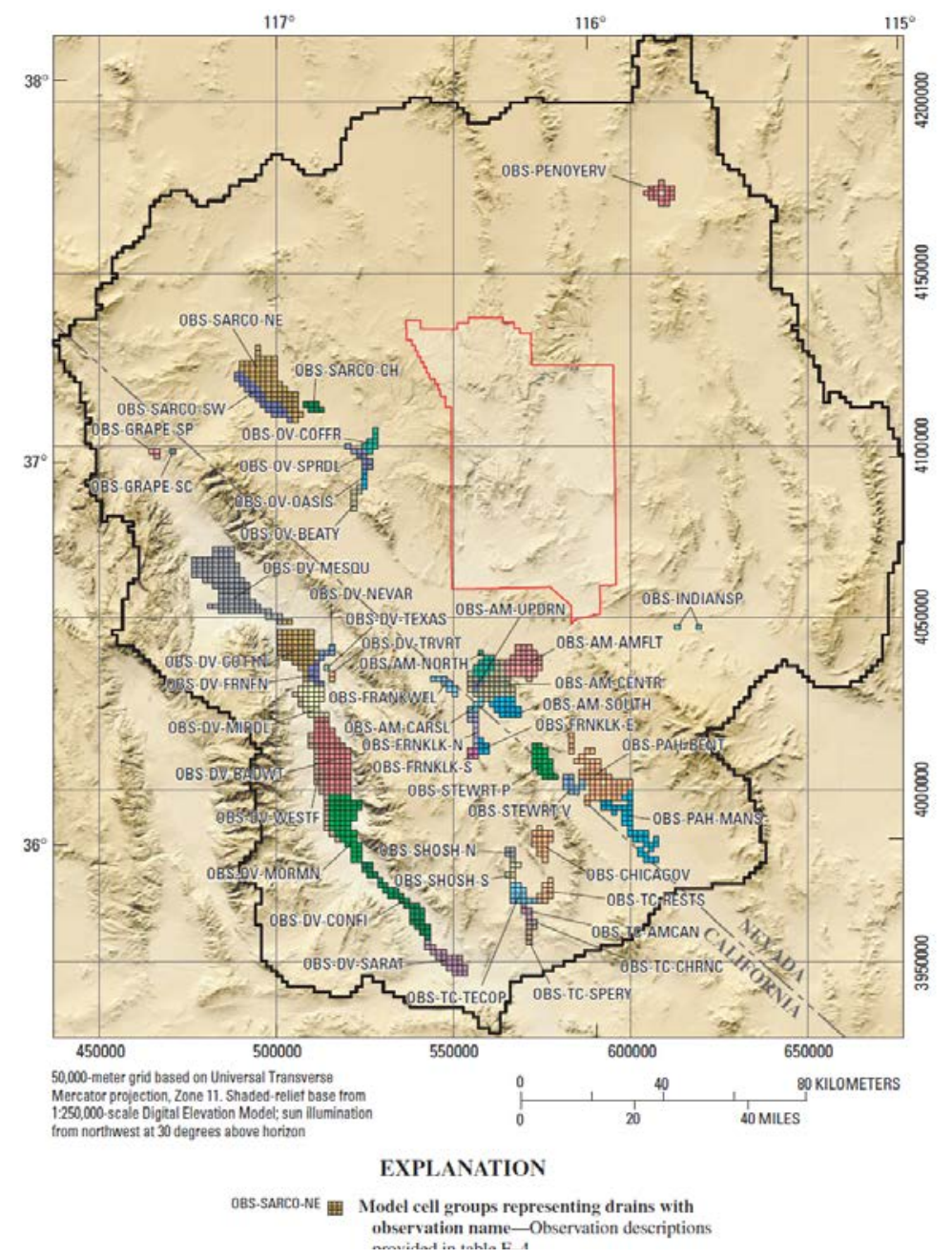

Figure 22. Model cell groups representing drains used to simulate natural ground-water discharge. From Belcher et al. (2004).

Table 14. Drains whose unweighted simulated values differ by more than $1,000 \mathrm{~m}^{3} / \mathrm{d}$ between the calibrated model and realization 1768.

\begin{tabular}{ccccc}
\hline Observation name & Observation & Calibrated model & Realization 1768 & Difference \\
\hline OBS-AM-NORTH & -18337 & -9512 & -3467.41 & 6044 \\
OBS-AM-CENTR & -23193 & -20613 & -7088.96 & 13524 \\
OBS-AM-SOUTH & -9484 & -14052 & -3823.67 & 10228 \\
OBS-AM-AMFLT & -3212 & -5560 & -1313 & 1899 \\
OBS-DV-TEXAS & -1409 & -1220 & -316 & 1093 \\
OBS-PENOYERV & -12833 & -21239 & -35760 & -14520 \\
\hline
\end{tabular}




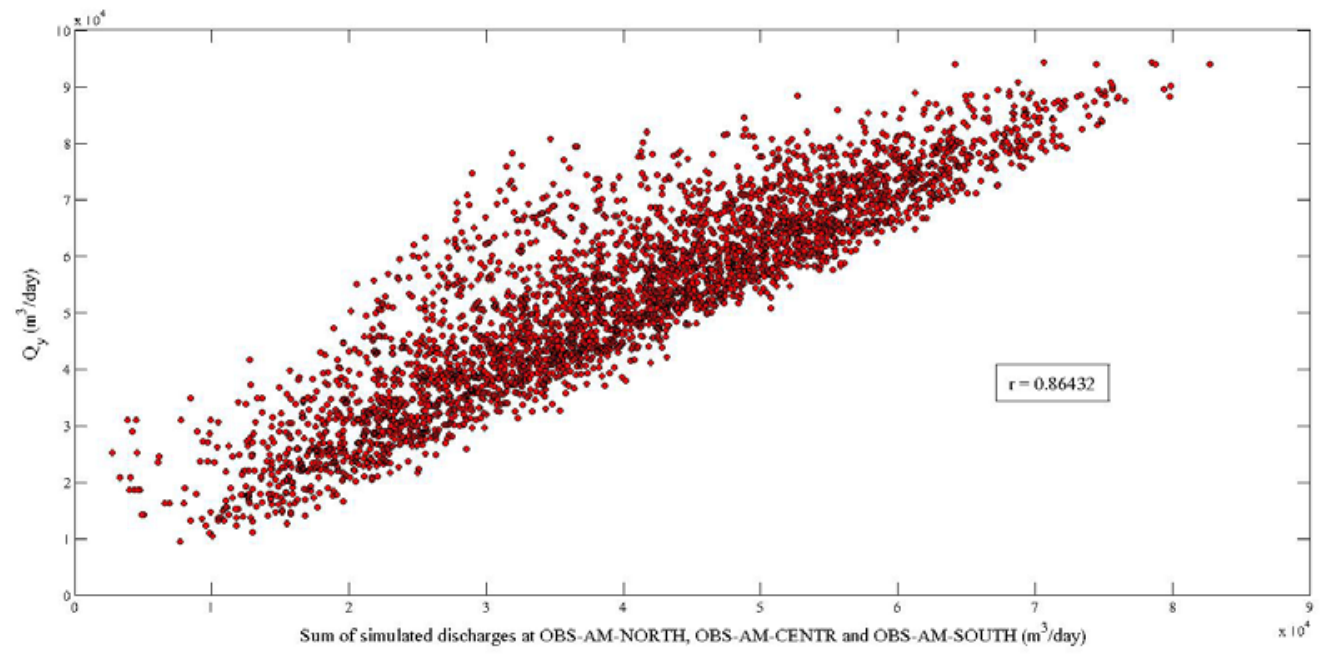

Figure 23. The relationship between the $\mathrm{Q}_{\mathrm{y}}$ estimate and summed spring discharges in Ash Meadows based on 2,000 realizations of model G3R2.

To better understand the relationship between the $\mathrm{Q}_{\mathrm{y}}$ estimate and goodness-of-fit, Figure 23 plots the relationships between $\mathrm{Q}_{\mathrm{y}}$ estimate and the SSWR of drain flows (discharge), constant-head boundary flows, and heads. Figure 24a shows a positive correlation (with a correlation coefficient of 0.67) between the SSWR of constant-head boundary flows and $\mathrm{Q}_{\mathrm{y}}$, indicating that an improved goodness-of-fit to the boundary flows gives a smaller $\mathrm{Q}_{\mathrm{y}}$ estimate. In other words, the observed boundary flows are supportive to a smaller $\mathrm{Q}_{\mathrm{y}}$ estimate. The correlation between the SSWR of drain flows and the $\mathrm{Q}_{\mathrm{y}}$ estimate is negative (Figure 24b), indicating that decrease of the $\mathrm{Q}_{\mathrm{y}}$ estimate deteriorates goodness-of-fit to the discharge observations. In this sense, the discharge observations do not support a smaller $\mathrm{Q}_{\mathrm{y}}$ estimate. Therefore, in order to achieve a smaller $\mathrm{Q}_{\mathrm{y}}$ estimate the goodness-of-fit to discharge observations must be sacrificed. This is believed to be the reason for the large difference of the drain flows between the calibrated model and realization 1768. Figure 24c indicates that the goodness-of-fit to head is not related to the $\mathrm{Q}_{\mathrm{y}}$ estimate. 

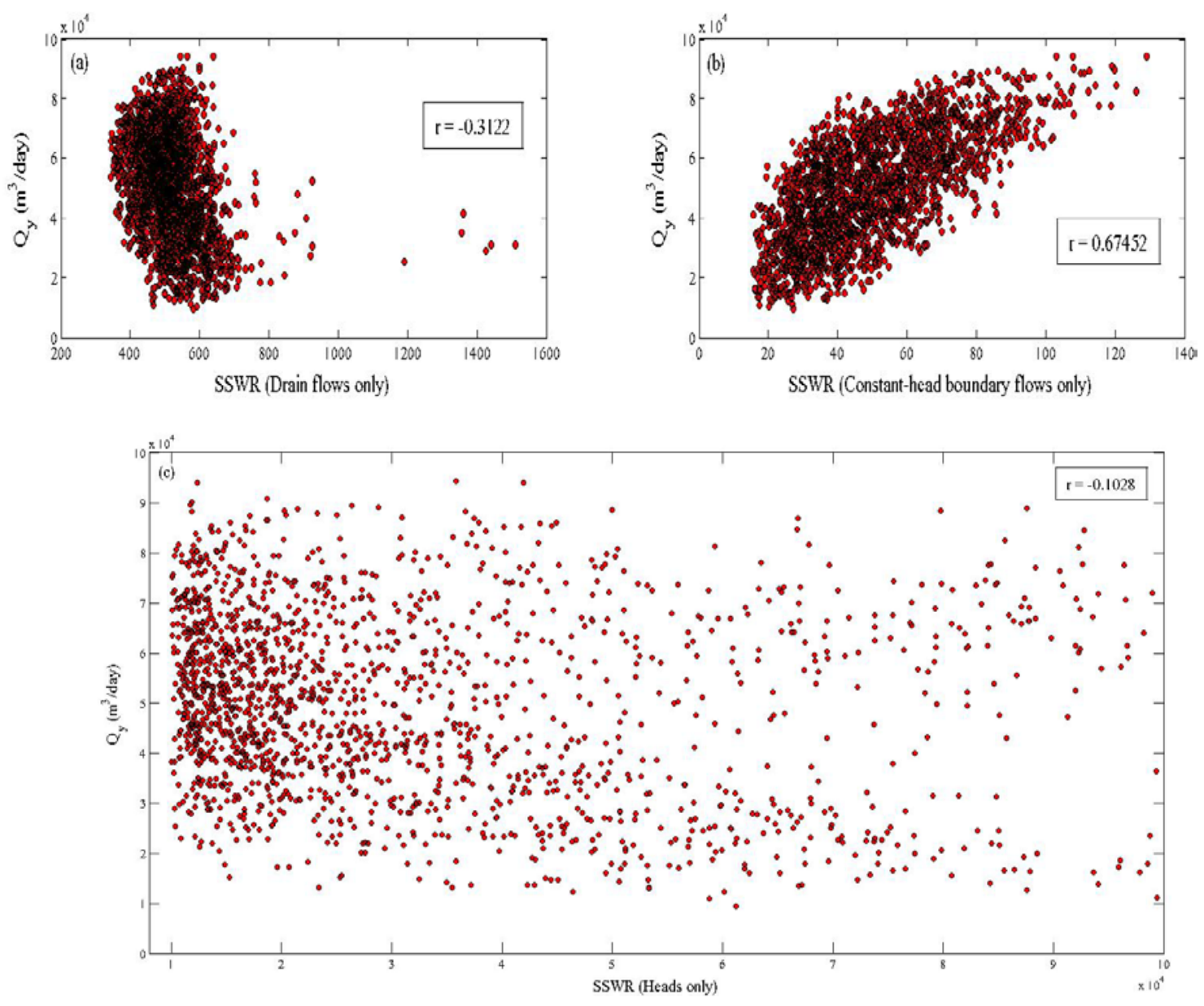

Figure 24. The relationships between three kinds of SSWRs and $\mathrm{Q}_{\mathrm{y}}$. Despite significant changes in simulated constant-head boundary flows and discharges, the differences are considered to be reasonable because the simulation results, as discussed above, are reasonable and realization 1768 provides simulated constant-head boundary flows, especially on the Stone Cabin-Railroad boundary segment, that are closer to the estimated values. Owing to relatively small weights assigned to these observations, however, these changes do not significantly affect the SSWR. This may be the reason that calibrating the DVRFS model cannot yield the expected flow rates $\left(25,000 \mathrm{~m}^{3} /\right.$ day) into northern Yucca Flat. In other words, increasing the weights of constant-head boundary flow estimates will reduce the $\mathrm{Q}_{\mathrm{y}}$ estimation. However, as discussed above, this will also reduce the goodness-of-fit to discharge observations, which are known with more confidence than the estimates boundary flow.

\subsection{Assessment of Relative Model Performance}

Model G3R2 is considered the most representative of the flow system because the simulated constant-head boundary flows of this model most closely match the estimated values. As shown in Table 15, G3R2 has the smallest SSWR value for boundary flow, although the value is close to that of G2R2. The top two largest SSWR values are for models G2R5 and G3R5. More importantly, as shown in Table 15, for observations C_GRDN0603, C_STNC0700, C_CLAY0800 and C_SILU0100 (marked in red), the flow directions 
simulated by these two models are opposite to the estimates. This is not surprising if one examines the water budget. Based on observations of discharge listed in Table 8 and constant-head boundary flow listed in Table 9, the outflow rates through discharge and constant-head boundaries are 328,546 $\mathrm{m}^{3} / \mathrm{d}$ and 33,174 $\mathrm{m}^{3} / \mathrm{d}$, respectively, and the inflow rate through the constant-head boundary is $55,513 \mathrm{~m}^{3} / \mathrm{d}$. The difference between outflow and inflow is $306,207 \mathrm{~m}^{3} / \mathrm{d}$. Considering that the flow system is treated as steady state, this difference should be compensated for by recharge to maintain mass balance. However, the recharge estimate of $\mathrm{R} 5$ is $361,075 \mathrm{~m}^{3} / \mathrm{d}$, about $15 \%$ larger than $306,207 \mathrm{~m}^{3} / \mathrm{d}$. Since the recharge value of $\mathrm{R} 5$ is fixed during the calibration (there are no recharge multipliers associated with $\mathrm{R} 5$ like those used for $\mathrm{R} 2$ to convert precipitation into recharge), the excessive water has to be forced to flow out of the system through the constant-head boundary to maintain mass balance. This explains the flow directions opposite to those observed. Therefore, the two models associated with R5 are not selected, although they yield lower values of $\mathrm{Q}_{\mathrm{y}}$ and SSWR. Furthermore, although models G2R2 and G3R2 have similar values of $\mathrm{Q}_{\mathrm{y}}$ and SSWR, G3R2 is selected for its lower SSWR value for boundary flows, especially the goodness-of-fit to the flow estimate at the Stone Cabin-Railroad boundary segment (observation C_STNC0700), considering that the flow through this segment is important to $\mathrm{Q}_{\mathrm{y}}$.

Table 15. Observations and simulated values of constant-head boundary flows for all six models.

\begin{tabular}{lrrrrrrr}
\hline \multicolumn{1}{c}{ Observation name } & Observation & \multicolumn{1}{c}{ G1R2 } & G1R5 & \multicolumn{1}{c}{ G2R2 } & G2R5 & \multicolumn{1}{c}{ G3R2 } & \multicolumn{1}{c}{ G3R5 } \\
\hline C_LASV0303 & -3633 & -2989 & -8152 & -2165 & -7319 & -2081 & -7561 \\
C_SHPR0401 & -4410 & -2203 & -2552 & -2281 & -3709 & -2001 & -3569 \\
C_SHPR0402 & -15305 & -24207 & -33660 & -22419 & -42755 & -20134 & -43702 \\
C_SHPR0403 & -4959 & -6107 & -9687 & -5113 & -11459 & -4665 & -12323 \\
C_SHPR0404 & 5927 & 4637 & 9111 & 4221 & 14225 & 3632 & 15839 \\
C_PAHR0501 & 1827 & 2480 & 3074 & 2299 & 5440 & 2047 & 5765 \\
C_PAHR0502 & -2346 & -1657 & -2255 & -14 & -999 & -341 & -930 \\
C_PAHR0505 & -2521 & -10207 & -12398 & -7245 & -13393 & -7149 & -12370 \\
C_GRDN0603 & 2334 & 1873 & -5176 & 645 & -9064 & 653 & -7239 \\
C_STNC0700 & 12476 & 62155 & 28548 & 72061 & -17039 & 64116 & 3382 \\
C_CLAY0800 & 667 & -1019 & -1796 & 1381 & -4275 & 1639 & -2691 \\
C_EURS0900 & 15100 & 4495 & 24499 & 938 & 16413 & 491 & 24818 \\
C_PANA1100 & 15000 & 16095 & 16560 & 23289 & 6906 & 23771 & 10514 \\
C_OWLS1203 & 1682 & 3593 & 4383 & 4474 & 2941 & 4559 & 3339 \\
C_SILU0100 & 500 & -2060 & -3363 & 82 & -2400 & 343 & -2456 \\
SSWR (constant-head & & 68.96 & 125.82 & 42.12 & 205.78 & 37.19 & 140.51 \\
boundary flows only) & & & & & & & \\
\hline
\end{tabular}

\subsection{Limitations of the DVRFS-based Models for Simulation of $\mathbf{Q}_{\mathbf{y}}$}

The analysis described up to this point is based on alternative models formulated by integrating three geological interpretations (G1, G2, and G3) and two recharge estimations (R2 and R5) into the DVRFS modeling framework. Although the six alternative models differ from each other and from the DVRFS model, they may be subject to structural limitations of the DVRFS model with respect to estimating the inter-basin flow into northern Yucca Flat $\left(\mathrm{Q}_{\mathrm{y}}\right)$. The limitations are documented in this section so that they can be useful for future investigation using the DVRFS model. 
The first limitation is the inherent conflict between the discharge observations and the large inter-basin flow into northern Yucca Flat, because, as discussed in Section 3.5, the observed discharge, particularly at springs in Ash Meadows, supports large inter-basin flow. In order to simultaneous reduce the inter-basin flow and simulate the observed discharge, flow from the north needs to be routed around northern Yucca Flat and maintained into the Ash Meadows area. This however does not appear to be feasible within the current HFM of the DVRFS model, although alternative HFMs in northern Yucca Flat are considered in this study. Reducing the extent, continuity, and/or hydraulic conductivity of the lower carbonate aquifer north of Yucca Flat may be solutions if they can be supported by subsurface data.

The second limitation resides in the large uncertainty associated with constant-head boundary flow, especially that of the Stone Cabin-Railroad segment (C-SCNT0700). Given that within the DVRFS modeling framework two lower carbonate units (K221_LCA and K422LNEVSU) extend from northern Yucca Flat to the northern part of the domain (Figures 7 and 8), boundary flow from segment C-SCNT0700 is critical to flow into northern Yucca Flat. While use of the estimated boundary flow helps calibration in various ways (Poeter and Hill, 1997), large uncertainties in boundary flow actually pose a challenge to accurate estimation of the inter-basin flow, and reduction of this uncertainty is necessary. However, addressing this uncertainty requires additional information that the alternative models alone cannot provide. In the next section, we present a preliminary test performed to illustrate the effects of reducing uncertainty on model calibration and estimation of inter-basin flow.

The third limitation is that internal flow is not used as a calibration target. Given the strong correlation between inter-basin flow and discharge rate shown in Section 3.5, including reliable estimates of regional inter-basin flows may better constrain the flow system. This may be feasible given regional flow estimates (Harrill et al., 1988) and results of isotope mixing models (Carroll et al., 2008).

The last limitation is that when constructing the objective function the head observations are not properly handled. As discussed in Section 3.5, the hydraulic head observations are not as useful as boundary flow and discharge for calibration of the flow system. However, the number of head observations is overwhelmingly larger than that of boundary flows and discharges, which may affect calibrated parameter values and thus estimation of inter-basin flow, though relationship of head to flow is less direct. The solution may be to decluster head observations or to assign lower weight to the head component in the objective function so that observations of boundary flow and discharge can play more significant roles during the calibration. To our knowledge, this has not been done in the DVRFS modeling and other modeling at NNSS.

\subsection{Preliminary Investigation of Effects of Boundary Flow on Estimation of $\mathbf{Q}_{\mathbf{y}}$}

To address the second limitation discussed in Section 3.7 regarding the large uncertainty in the estimated perimeter boundary flow, a preliminary test is conducted that artificially increases the weight associated with the estimated flow through the Stone CabinRailroad segment (C-SCNT0700). In the DVRFS model, the estimated flow is $12,500 \mathrm{~m}^{3} / \mathrm{d}$ and the square root of the weight is $8.33 \times 10^{-5}$. In this test, the square root value is increased to $3.16 \times 10^{-2}$, corresponding to a weight of $1.0 \times 10^{-3}$. Given that the square root of the weight is the inverse of the standard deviation of measurement error, this change is equivalent to reducing the standard deviation of the flow estimate from 12,000 to 32, a change of almost three orders of magnitude. Other than the revised weight of the 
C-SCNT0700 observation, all other components of the model remain unchanged. Model G3R2 is recalibrated using MODFLOW-2000 with calibration results and the corresponding $\mathrm{Q}_{\mathrm{y}}$ estimate analyzed below.

Calibration with the revised C-SCNT0700 weight suffers from numerical difficulty in convergence. At the time of this writing, complete convergence has not been achieved; changes of certain parameter values during calibration are too large and the calibration is automatically terminated by MODFLOW. The analysis below is based on an iteration in which the parameter values are considered to be reasonable. Despite the problems with calibration, the final results are not expected to be significantly different from those shown below.

Table 16 lists the SSWR and $\mathrm{Q}_{\mathrm{y}}$ estimate of the calibration with the original and revised C-STNT0700 observation weights. For the selected iteration of model calibration, the overall SSWR is significantly reduced from the original value of 10,767 to 6,654 and the $\mathrm{Q}_{\mathrm{y}}$ estimate is reduced from $57,252 \mathrm{~m}^{3} / \mathrm{d}$ to $30,012 \mathrm{~m}^{3} / \mathrm{d}$. The lower SSWR is mainly a result of reductions in the SSWR value of head observations, from 10,255 to 5,788. The SSWR of discharge however increases from 463 to 595, which is not surprising due to the conflict between decreasing $\mathrm{Q}_{\mathrm{y}}$ and deterioration of the goodness-of-fit to discharge. The SSWR of constant-head boundary flow increases from 49 to 270, and the reason will be explained below.

Table 16. Summary statistics for measures of goodness-of-fit for model G3R2.

\begin{tabular}{ccc}
\hline & Original weight & Revised weight \\
\hline Total SSWR of 760 observations & 10,767 & 6,654 \\
SSWR of 700 hydraulic heads & 10,252 & 5,788 \\
SSWR of 45 discharges & 463 & 595 \\
SSWR of 15 constant-head boundary flows & 49 & 270 \\
Qy & 57,252 & 30,012 \\
\hline
\end{tabular}

For the constant-head flow at C-SCNT0700, the new simulated value is $13,000 \mathrm{~m}^{3} / \mathrm{d}$; nearly the estimated value of $12,500 \mathrm{~m}^{3} / \mathrm{d}$ and dramatically lower than the original simulated value of $79,700 \mathrm{~m}^{3} / \mathrm{d}$. Although the simulated flow approximates the estimated flow, the weighted residual changes from -4.3 to -15.7 as a result of the increased weight.

In the manner of Figure 17, Figure 25 plots the simulated hydraulic head and weighted head residuals of revised model G3R2. In the southern part of the domain, the head contours of the revised model (Figure 25) show a pattern similar to the head contours of the original model (Figure 17). However, in the northern part of the domain, the head contours of the revised model are more irregular. This irregularity, especially the localized areas exhibiting high heads, may be related to non-convergence of the calibration. The generally higher simulated heads in the north also correspond to reductions in calibrated values of several $\mathrm{K}$ parameters in the same area and are believed to contribute to a reduction in simulated boundary flow at C-SCNT0700 from $79,700 \mathrm{~m}^{3} / \mathrm{d}$ in the original calibration to $13,000 \mathrm{~m}^{3} / \mathrm{d}$ in the revised calibration. 
The reduction in the SSWR of head observations from 10,252 in the original calibration to 5,788 in the revised calibration can be explained by comparing the weighted residuals of Figures 17 and 25. In the original calibration, the maximum and minimum weighted residuals are 52.8 and -15.6, respectively; in the revised calibration the corresponding values are 19.1 and -16.7. The reduction is most apparent in the northern part of the domain, where large positive weighted residuals (red squares) become either smaller or negative (black squares).

Despite the reduction in head residuals in the revised calibration, improved head simulation does not suggest that the flow system is better represented. Figure 26(a) plots the weighted observations and simulations of heads in the original and revised calibrations. The plot shows that overall the revised calibration does not improve over the original calibration. Although this is partially a result of the large scale used for the plot, it is not surprising that head observations are not sufficient to constrain the flow system.

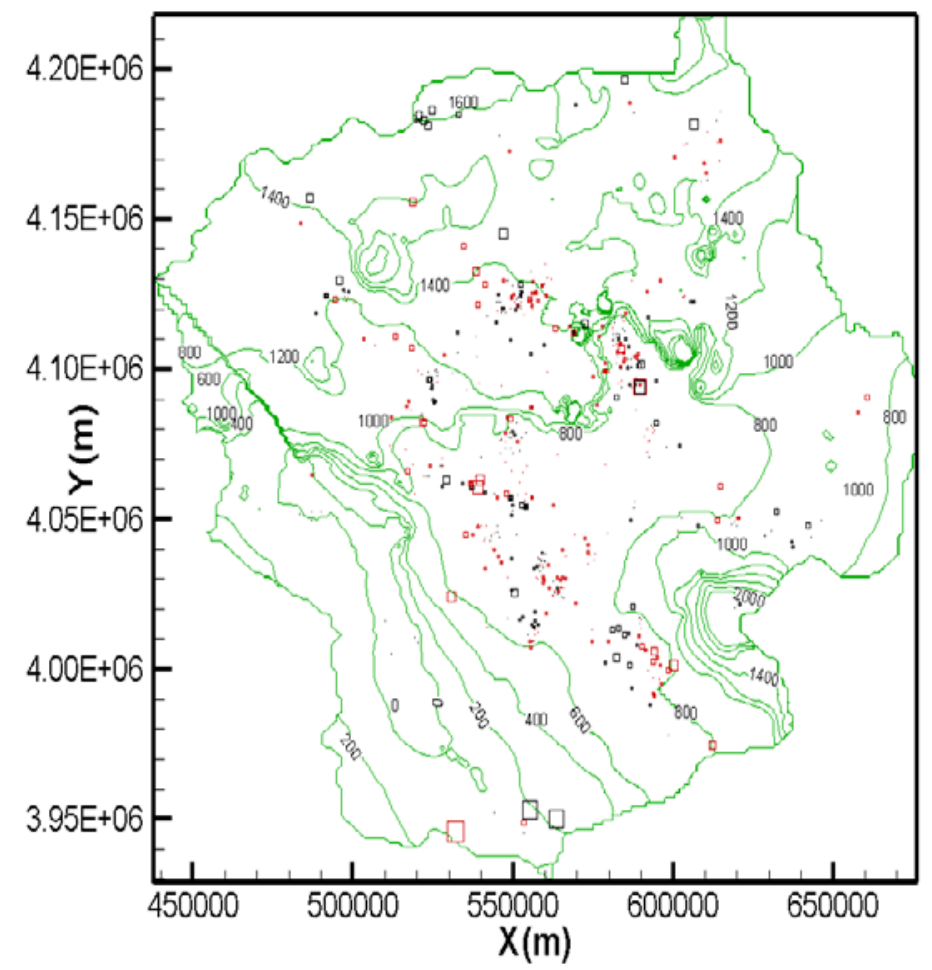

Figure 25. Distribution of weighted head residuals and the contours of hydraulic head in layer 1 of model G3R2. The red and black squares represent positive and negative residuals, respectively. Symbol size is scaled to the magnitude of the weighted residuals. The results are based on the calibration using the revised weight of boundary flow observation C-SCNT0700. 
(a)

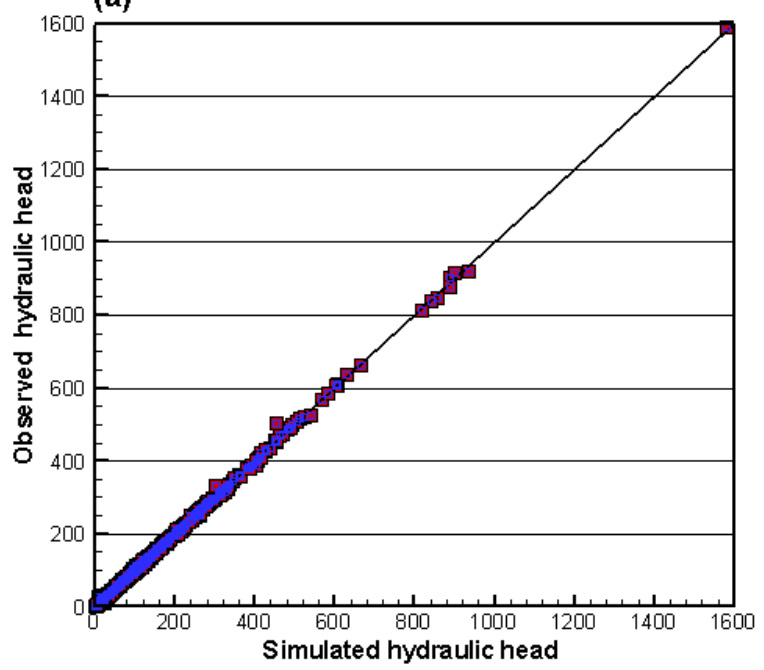

(b)

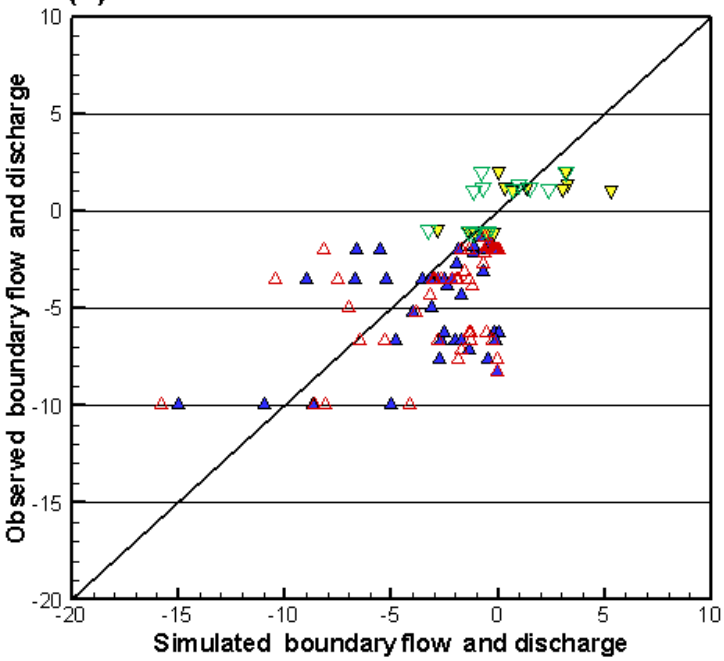

Figure 26. Weighted observed value and weighted simulated values in model G3R2 for (a) hydraulic head (filled red square for original calibration and open blue square for revised calibration) and (b) discharge (filled blue triangle for original calibration and open red triangle for revised calibration) and constant-head boundary flow (filled yellow gradient for original calibration and open green gradient for revised calibration).

The increase in the SSWR of discharge and constant-head boundary flow indicates that increasing the weight of flow observation C_STNC0700 deteriorates the simulation of discharge in the flow system. As shown in Figure 26(b), many of the discharge observations are underestimated in the revised calibration as indicated by the shift left and away from the 1:1 line for the revised calibration (open red triangles) as compared to the original calibration (filled blue triangles). This is confirmed by the values listed in Table 17. For example, the simulated discharge at OBS-SARCO-NE and OBS-SARCO-SW in the revised calibration are about half of those in the original calibration (however, it is interesting to note that simulated discharge values in most spring areas in Ash Meadows [OBS-AM-] are actually improved in the revised calibration). Similar behavior is observed for boundary flow in the revised calibration. For example, a systematic shift left and away from the 1:1 line for simulated boundary flows in the revised calibration is shown in Figure 26(b), indicating that the simulated flows are lower in the revised model. The simulated flows listed in Table 18 show that, despite the improvement at the C_STNC0700 segment, the simulation at most boundary segments is worse in the revised calibration. In particular, at segments C_GRDN0603, C_EURS0900, and C_SILU0100, the flow directions in the revised simulation are reversed from the observed directions. This suggests that the simulated flow system in the revised calibration is no more reasonable than in the original model, assuming that the estimated flow directions are physically reasonable. 
Table 17. Observed discharge values $\left(\mathrm{m}^{3} / \mathrm{d}\right)$ and corresponding simulated values using the original and revised weight for the Stone Cabin-Railroad boundary segment in model G3R2.

\begin{tabular}{|c|c|c|c|}
\hline Observation name & Observations & Original Simulations & Revised Simulations \\
\hline OBS-AM-NORTH & -18337 & -3467 & -4480 \\
\hline OBS-AM-CENTR & -23193 & -7089 & -9770 \\
\hline OBS-AM-SOUTH & -9484 & -3824 & -6920 \\
\hline OBS-AM-AMFLT & -5660 & -1313 & -2910 \\
\hline OBS-AM-CARSL & -468 & -92 & -45.7 \\
\hline OBS-AM-UPDRN & -3230 & -1311 & -634 \\
\hline OBS-OV-COFFR & -4390 & -3333 & -3230 \\
\hline OBS-OV-SPRDL & -8898 & -13359 & -14000 \\
\hline OBS-OV-OASIS & -3629 & -3165 & -3130 \\
\hline OBS-OV-BEATY & -3394 & -1208 & -829 \\
\hline OBS-TC-TECOP & -12097 & -59 & -76.8 \\
\hline OBS-TC-AMCAN & -3360 & -203 & -31.2 \\
\hline OBS-TC-SPERY & -1328 & -280 & -84.8 \\
\hline OBS-TC-CHRNC & -1766 & -39 & 0 \\
\hline OBS-TC-RESTS & -2512 & -73 & -216 \\
\hline OBS-SHOSH-N & -2235 & 0 & -455 \\
\hline OBS-SHOSH-S & -4780 & -69 & -208 \\
\hline OBS-STEWRT-V & -996 & -409 & -222 \\
\hline OBS-STEWRT-P & -2383 & -653 & -426 \\
\hline OBS-SARCO-NE & -30958 & -15911 & -8490 \\
\hline OBS-SARCO-SW & -12174 & -7226 & -3800 \\
\hline OBS-SARCO-CH & -1530 & -259 & -399 \\
\hline OBS-FRANKWEL & -1150 & -207 & -129 \\
\hline OBS-FRNKLK-N & -2350 & -1442 & -763 \\
\hline OBS-FRNKLK-S & -741 & 0 & -101 \\
\hline OBS-FRNKLK-E & -428 & -257 & -200 \\
\hline OBS-CHICAGOV & -1462 & -1042 & -356 \\
\hline OBS-INDIANSP & -2240 & -1124 & -931 \\
\hline OBS-GRAPE-SP & -2450 & -1516 & -3440 \\
\hline OBS-GRAPE-SC & -1035 & -319 & -707 \\
\hline OBS-DV-SARAT & -8311 & -7013 & -4290 \\
\hline OBS-DV-CONFI & -3236 & -8146 & -9470 \\
\hline OBS-DV-MORMN & -13356 & -19617 & -28100 \\
\hline OBS-DV-BADWT & -20098 & -15758 & -10800 \\
\hline OBS-DV-MIDDL & -6625 & -12475 & -4940 \\
\hline OBS-DV-FRNFN & -11522 & -8120 & -4320 \\
\hline OBS-DV-COTTN & -10224 & -10194 & -8580 \\
\hline OBS-DV-MESQU & -29002 & -25995 & -24800 \\
\hline OBS-DV-WESTF & -18223 & -10978 & -11000 \\
\hline OBS-DV-TRVRT & -4633 & -5079 & -3760 \\
\hline OBS-DV-TEXAS & -1220 & -316 & -979 \\
\hline OBS-DV-NEVAR & -1884 & -1368 & -1830 \\
\hline OBS-PENOYERV & -12833 & -35760 & -333 \\
\hline OBS-PAH-BENT & -17900 & -16727 & -15600 \\
\hline O-PAH-MANS & -821 & -2718 & -3360 \\
\hline
\end{tabular}


Table 18. Estimated (used as observations in calibration) and simulated values of constant-head boundary flow using the original and revised weight for the Stone Cabin-Railroad boundary segment in model G3R2.

\begin{tabular}{cccc}
\hline Observation name & Observation & Original Calibration & Revised Calibration \\
\hline C_LASV0303 & -3633 & -2190 & -1580 \\
C_SHPR0401 & -4410 & -2041 & -2010 \\
C_SHPR0402 & -15305 & -20871 & -20700 \\
C_SHPR0403 & -4959 & -4951 & -5020 \\
C_SHPR0404 & 5927 & 4163 & 4000 \\
C_PAHR0501 & 1827 & 2482 & 2250 \\
C_PAHR0502 & -2346 & 87 & -1190 \\
C_PAHR0505 & -2521 & -6629 & -8150 \\
C_GRDN0603 & 2334 & 928 & -1420 \\
C_STNC0700 & 12476 & 79680 & 13000 \\
C_CLAY0800 & 667 & 1492 & 488 \\
C_EURS0900 & 15100 & 503 & -5780 \\
C_PANA1100 & 15000 & 23774 & 24100 \\
C_OWLS1203 & 1682 & 4555 & 3580 \\
C_SILU0100 & 500 & 312 & -553 \\
\hline
\end{tabular}

Comparing Figures 27(a-b) and Figures 18(a-b) shows that in the northern Yucca Flat area the reduction in $\mathrm{Q}_{\mathrm{y}}$ in the new calibration as compared to the original G3R2 calibration is larger at cross section $\mathrm{J}=63$ than at $\mathrm{J}=101$. At both cross-sections, the reduction in flow occurs over the entire section, not just in localized areas. When examining the cross sections of the entire domain, as shown in Figures 27(c-d) and Figure 19(a-b), it is evident that the reduction in $\mathrm{Q}_{\mathrm{y}}$ is not limited to the northern Yucca Flat area, but occurs across the entire domain. This response is expected since inflow through the Stone Cabin-Railroad segment feeds both the Pahute Mesa-Oasis Valley and Ash Meadows groundwater basins in the DVRFS model (Faunt et al., 2004).

To summarize this limited test, increasing the observation weight of the Stone CabinRailroad boundary segment and recalibrating the G3R2 model reduces simulated $\mathrm{Q}_{\mathrm{y}}$ to a value of 30,012 $\mathrm{m}^{3} / \mathrm{d}$ and improves the overall goodness-of-fit of hydraulic head, but deteriorates the goodness-of-fit of discharge and constant-head boundary flow. Also, simulated flow directions at several boundary segments are reversed from their estimated directions. In the revised calibration, simulated $\mathrm{Q}_{\mathrm{y}}$ is reduced not only in northern Yucca Flat, but also across the entire domain as a result of reduced flow through the northern boundary and reduced values of hydraulic conductivity in the northern domain. Related to this, simulated discharge values are decreased and the fits to discharge observations are diminished. Considering all of these results, the revised flow model is not regarded as being more reasonable than the original. Despite the reduced boundary flow and recalibration, the simulated value of $\mathrm{Q}_{\mathrm{y}}$ in the revised G3R2 model remains higher than the 22,988 $\mathrm{m}^{3} / \mathrm{d}$ value simulated by realization 1768 selected from the Monte Carlo simulations described in Section 3.3. If a sensitivity analysis and Monte Carlo simulations were performed on the revised G3R2 model, as was done for the original model described above, it may be possible to obtain a set of model parameters that further reduce $\mathrm{Q}_{\mathrm{y}}$. However, this is not considered appropriate at this time because a systematic study of the DVRFS modeling framework is 
required first; increasing the weight of the Stone Cabin-Railroad perimeter boundary segment (and other perimeter boundary segments) does not alone appear to be sufficient to simulate a lower value of $\mathrm{Q}_{\mathrm{y}}$.
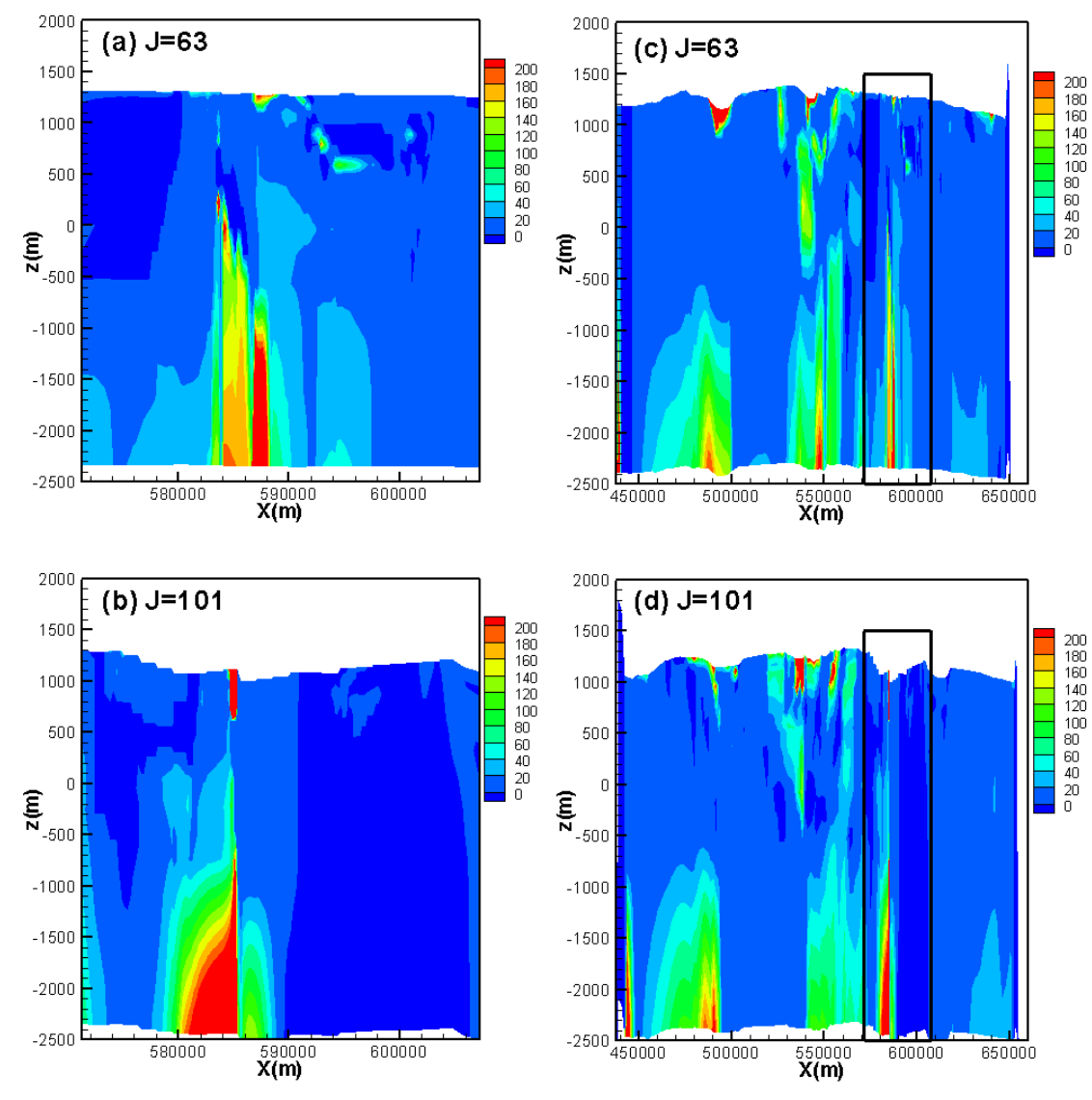

Figure 27. Contours of $\mathrm{Q}_{\mathrm{y}}$ in northern Yucca Flat for model G3R2 at (a) cross section $\mathrm{J}=63$ and (b) cross section $\mathrm{J}=101$, and across the entire model domain at (c) cross section $\mathrm{J}=63$ and (d) cross section $\mathrm{J}=101$ in the new calibration. The northern Yucca Flat area is marked with the black box in (c) and (d). 
THIS PAGE INTENTIONALLY LEFT BLANK 


\section{SUMMARY AND CONCLUSIONS}

Estimates of interbasin flow into northern Yucca Flat $\left(\mathrm{Q}_{\mathrm{y}}\right)$ vary dramatically using the methods of water balance and numerical modeling, with most estimates suggesting lower flow than simulated by the 2007 Climax Mine sub-CAU model. Two sources of uncertainty within the DVRFS modeling framework are considered in this study: uncertainty in the conceptual groundwater models and uncertainty in the parameters of individual models. At the level of model uncertainty, and using the DVRFS as the modeling framework, a total of six models are considered that reflect uncertainty in conceptualizing the recharge process and in constructing the hydrostratigraphic framework in northern Yucca Flat. For each model, uncertainty in the parameters critical to the $\mathrm{Q}_{\mathrm{y}}$ estimate is considered. A parameter-center study indicates that minimizing SSWR may cause an increase in $\mathrm{Q}_{\mathrm{y}}$ and that a small to moderate change in SSWR may correspond to a large change in $\mathrm{Q}_{\mathrm{y}}$.

Within the context of uncertainty analysis, possible values of $\mathrm{Q}_{\mathrm{y}}$ are simulated using Monte Carlo simulation with consideration of parametric uncertainty. Among the MC realizations, the optimum $\mathrm{Q}_{\mathrm{y}}$ is selected based on the following two criteria: (1) the optimum $\mathrm{Q}_{\mathrm{y}}$ estimate should be close to or smaller than $25,000 \mathrm{~m}^{3} / \mathrm{d}$ obtained in a previous UGTA study (IT Corporation, 1996b), which is considered reasonable among existing estimates; (2) among the realizations that satisfy the previous criterion, the realization of optimum $\mathrm{Q}_{\mathrm{y}}$ estimate should have the smallest SSWR. Importantly, this analysis is conducted within the constraints of existing conceptual models of hydrostratigraphic framework in northern Yucca Flat and recharge throughout the DVRFS. This goal is achieved using the following modeling procedure. First, six alternatives of the Climax sub-CAU model are converted to steady-state conditions and calibrated using the parameter estimation function of MODFLOW so that model simulations agree with corresponding field observations. The number of calibrated parameters is about 50 for each of the six models. As observed in the 2007 sub-CAU modeling, Qy estimates from the calibrated numerical models are significantly larger than those of previous studies using other approaches. Nonetheless, the model calibration results provide the basis necessary for subsequent sensitivity and uncertainty analyses. In particular, the parameter ranges used for the sensitivity and uncertainty analysis are determined as $(0.01 \hat{\theta}, 2 \hat{\theta})$, where $\hat{\theta}$ are the calibrated parameter values. A uniform distribution within the ranges is assumed for each parameter, and the parameter distributions are assumed to be independent. To avoid the computational burden associated with the large number of calibrated parameters in the sub-CAU model, the parameters most critical to $\mathrm{Q}_{\mathrm{y}}$ are identified using the Morris method, a global method for screening, which identifies six to nine critical parameters, depending on models. These parameters are critical because they are located up- and down-gradient of northern Yucca Flat and their magnitudes and ranges are larger than other parameters. MC simulations are subsequently conducted for the critical parameters and 2,000 model runs of each model are executed. Parametric uncertainty is large for individual models and dramatically different for different model combinations, indicative of significant model uncertainty.

Given the constraint that $Q_{y}$ be less than $25,000 \mathrm{~m}^{3} / \mathrm{d}$, a value selected based on the results of independent studies, the realization with the lowest SSWR is selected for each of the six models. Examination of the water budgets and goodness-of-fit between simulations and observations indicate that the simulation results for the six selected realizations are 
reasonable, although the goodness-of-fit deteriorates in comparison with the calibrated models. For the six combinations of $\mathrm{Q}_{\mathrm{y}}$ and SSWR selected for the six models, model G3R2 is considered the most reasonable because it provides the best fit to the estimates of constanthead boundary flow. Despite lower values of $\mathrm{Q}_{\mathrm{y}}$ and SSWR, models G2R5 and G3R5 are not selected because simulated flow directions through several of the outer perimeter boundary segments are opposite to the estimated directions.

The major factor contributing to lower $\mathrm{Q}_{\mathrm{y}}$ in the selected realizations as compared to the calibrated models is the reduced simulated inflow through the constant-head boundary, especially in the Stone Cabin-Railroad segment. The second factor is the increased simulated discharge for drain OBS-PENOYERV up-gradient of northern Yucca Flat. Both the decrease in boundary flow and increase in drain discharge are related to parametric uncertainty. The third factor, and the least important one, is the redistribution of flow around the northern Yucca Flat area. Note that these conclusions are drawn within the DVRFS modeling framework, and in particular, given the constant-head boundaries and HFM configuration outside the northern Yucca Flat area.

Given the importance of flow through the Stone Cabin-Railroad boundary segment to flow simulated into northern Yucca Flat, a simple test of this aspect of the G3R2 model was performed by increasing the observation weight of this boundary segment (which in turn reduces the flow through this segment to a value closer to the estimated value) and recalibrating the model. Though the results show that simulated $\mathrm{Q}_{\mathrm{y}}$ can be reduced from the value simulated in the original calibrated model, goodness-of-fit of discharge and constanthead boundary flow declined and flow directions through several boundary segments are reversed. This test indicates that reducing northern boundary flow does not alone appear to be sufficient to simulate a lower value of $\mathrm{Q}_{\mathrm{y}}$ and that a more comprehensive analysis of the DVRFS model framework would be necessary in order to address whether other components of the model can be revised to improve model fit and to reduce simulated flow into northern Yucca Flat to conceptualized values.

Estimates of inter-basin flow occurring through all HSUs present along flow paths into northern Yucca Flat that range from 19,000 to $25,000 \mathrm{~m}^{3} / \mathrm{d}$ can be realistically simulated by the Climax Mine sub-CAU flow model, despite being far lower than estimates simulated by the calibrated model. These models are more consistent than the 2007 sub-CAU model in terms of matching estimated inflow along the northern DVRFS model boundaries and matching measured spring discharge in Ash Meadows. Nonetheless, relatively few realizations of the multiple conceptual models simulate flows less than $25,000 \mathrm{~m}^{3} / \mathrm{d}$, and none simulate flow as low as the Winograd and Thordarson (1975) estimate of $1,180 \mathrm{~m}^{3} / \mathrm{d}$. Further reductions may only be possible by substantial modifications to other aspects of the model such as reducing the extent, continuity, or hydraulic conductivity of the lower carbonate aquifer north of Yucca Flat, increasing the weights of boundary flow observations, or revising selected boundary flow estimates. However, consideration must be given to the challenges inherent to estimating subsurface flow volumes where direct measurement of inflow to northern Yucca Flat is not possible and large uncertainties remain in the conceptualization of the system. 


\section{REFERENCES}

Adams, B.M., K.R. Dalbey, M.S. Eldred, D.M. Gay, L.P. Swiler, W.J. Bohnhoff, J.P. Eddy, K. Haskell, P.D. Hough, 2009. DAKOTA, A Multilevel Parallel Objective-Oriented Framework for Design Optimization, Parameter Estimation, Uncertainty Quantification, and Sensitivity Analysis, Version 5.0 User’s Manual, Sandia National Laboratories, SAND2006-6337.

Bechtel Nevada, 2006. A Hydrostratigraphic Model and Alternatives for the Groundwater Flow and Contaminant Transport Model of Corrective Action Unit 97: Yucca FlatClimax Mine, Lincoln and Nye Counties, Nevada. DOE/NV/11718-1119.

Belcher, W.R., (ed.), 2004. Death Valley Regional Ground-Water Flow System, Nevada and California - Hydrogeologic Framework and Transient Ground-Water Flow Model. U.S. Geological Survey Scientific Investigations Report 2004-5205.

Blainey, J.B., C.C. Faunt, and M.C. Hill, 2006. A Guide for Using the Transient GroundWater Flow Model of the Death Valley Regional Ground-Water Flow system, Nevada and California. USGS Open-File Report 2006-1104.

Carroll, R.W.H., G.M. Pohll, S. Earman, and R.L. Hershey, 2008. A comparison of groundwater fluxes computed with MODFLOW and a mixing model using deuterium: Application to the eastern Nevada Test Site and vicinity. Journal of Hydrology, 361, 371385.

Farnham, I.M., T.P. Rose, E.M. Kwicklis, R.L. Hershey, J.B. Paces, and W.M. Fryer, 2006. Geochemical and Isotopic Evaluation of Groundwater Movement in Corrective Action Unit 97: Yucca Flat/Climax Mine, Nevada Test Site, Nevada. Stoller-Navarro Joint Venture S-N/99205--070, Las Vegas, Nevada.

Faunt, C.C., F.A. D'Agnese, and G.M. O'Brien, 2004. Hydrology, Chapter D, In: W R Belcher (Ed.), Death Valley Regional Ground-Water Flow System, Nevada and California Hydrogeologic Framework and Transient Ground-Water Flow Model, U.S. Geological Survey, Scientific Investigations Report, 2004-5205.

Fonseca, C. and P.J. Fleming. 1993. Genetic Algorithms for Multiobjective Optimization Formulation, Discussion, Generalization. Proceedings of the fifth International Conference on Genetic Algorithms. San Mateo, CA, pp.416-423.

Halford, K.J. (U.S. Geological Survey, Carson City, NV), 2009. Letter to A. F. B. Tompson (Lawrence Livermore National Laboratory, Livermore, CA). 2009 Jan 16. 6 p.

Harrill, J.R., J.S. Gates, and J.M. Thomas, 1988. Major Ground-Water Flow Systems in the Great Basin Region of Nevada, Utah, and Adjacent States. U.S. Geological Survey Hydrologic Investigations Atlas HA-694-C.

Helton, J.C. and F.J. Davis, 2003. Latin hypercube sampling and the propagation of uncertainty in analyses of complex systems, Reliability Engineering \& System Safety, 81, 23-69. 
Hevesi, J.A., A.L. Flint, and L.E. Flint, 2003. Simulation of Net Infiltration and Potential Recharge Using a Distributed Parameter Watershed Model for the Death Valley Region, Nevada and California. Water-Resources, Investigations Report 03-4090. Sacramento, CA: U.S. Geological Survey.

Hill, M.C. and C.R. Tiedeman, 2007. Effective Methods and Guidelines for Groundwater Model Calibration, Including Analysis of Data, Sensitivities, Predictions, and Uncertainty. Hoboken, New Jersey: John Wiley and Sons.

IT Corporation, 1996a. Groundwater Flow Model Documentation Package, Volume VI in Underground Test Area Subproject, Phase I, Data Analysis Task, ITLV/10972--181.

IT Corporation, 1996b. Regional Geologic Model Data Documentation Package, Volume I in Underground Test Area Subproject, Phase I, Data Analysis Task, ITLV/10972--181.

Keating, E.H., V.V. Vesselinov, E. Kwicklis, and Z. Lu, 2003. Coupling basin- and site-scale inverse models for the Espanola aquifer, Ground Water, 41(2), 200-211.

Keating, E.H., B.A. Robinson, and V.V. Vesselinov, 2005. Development and application of numerical models to estimate fluxes through the regional aquifer beneath the Pajarito Plateau, Vadose Zone Journal, 4, 653-671.

Mckay, M.D., R.J. Beckman, W.J. Conover, 1979. A comparison of three methods for selecting values of input variables in the analysis of output from a computer code, Technometrics, 21(2): 239-245.

Morris, M.D., 1991. Factorial sampling plans for preliminary computational experiments, Technometrics, 33(2), 161-174.

Ngatchou, P., A. Zarei, and M.A. El-Sharkawi (2005), Pareto Multi Objective Optimization, 84-91, Proceedings of the 13th International Conference on Intelligent Systems Application to Power Systems.

Poeter, E.P and M.C. Hill, 1997. Inverse models: a necessary next step in ground-water modeling, Ground Water, 35(2), 250-260.

Pohlmann, K., M. Ye, D. Reeves, M. Zavarin, D. Decker, and J. Chapman, 2007. Modeling of Groundwater Flow and Radionuclide Transport at the Climax Mine sub-CAU, Nevada Test Site. Desert Research Institute, Division of Hydrologic Sciences Publication No. 45226, OE/NV/26383-06.

Rush, F.E. and D.E. Everett, 1966. Water Resources Appraisal of Little Fish Lake, Hot Creek, and Little Smoky Valleys, Nevada. Nevada Dept. of Conservation and Natural Resources Water-Resources Reconnaissance Series Report 38.

Rush, F. E., 1968. Water Resources Appraisal of Clayton Valley-Stonewall Flat Area, Nevada and California. Nevada Dept. of Conservation and Natural Resources Water-Resources Reconnaissance Series Report 45.

Saltelli, A., S. Tarantola, R. Campolongo, and M. Ratto, 2004. Sensitivity Analysis in Practice: A Guide to Assessing Scientific Models, John Wiley\& Sons, Ltd. 
Stoller-Navarro Joint Venture, 2006. Phase I Hydrologic Data for the Groundwater Flow and Contaminant Transport Model of Corrective Action Unit 97: Yucca Flat/Climax Mine, Nevada Test Site, Nye County, Nevada. S-N/99205-077, Rev. 0.

Russell, C.E. and T. Minor, 2002. Reconnaissance Estimates of Recharge Based on an Elevation-dependent Chloride Mass-balance Approach. Desert Research Institute, Division of Hydrologic Sciences Publication No. 45164.

Van Denburgh, A.S. and F.E. Rush, 1974. Water Resources Appraisal of Railroad and Penoyer Valleys, East-Central Nevada. Nevada Dept. of Conservation and Natural Resources Water-Resources Reconnaissance Series Report 60.

Vrugt, J.A., H.V. Gupta, L. A. Bastidas, W. Bouten, and S. Sorooshian. 2003. Effective and efficient algorithm for multiobjective optimization of hydrologic models, Water Resour. Res., 39(8), 1214, doi:10.1029/2002WR001746.

Winograd, I.J. and W. Thordarson, 1975. Hydrogeologic and Hydrochemical Framework, South-Central Great Basin, Nevada-California, with Special Reference to the Nevada Test Site. U.S. Geological Survey Professional Paper 712-C.

Ye, M., K.F. Pohlmann, J.B. Chapman, G.M. Pohll, and D.M. Reeves, 2010. A modelaveraging method for assessing groundwater conceptual model uncertainty. Ground Water, 48(5), 716-728. 10.1111/j.1745-6584.2009.00633.x. 
THIS PAGE INTENTIONALLY LEFT BLANK 


\section{APPENDIX A. TABLES AND FIGURES FOR MODELS G1R5, G2R2, G2R5, G3R2 AND G3R5}

Table A-1. Final parameter values for the six models after automatic calibration using MODFLOW. Parameters indicated with * are adjusted manually to address unrealistically high heads simulated in portions of the models after the automatic calibration. Values shown in red are the parameters calibrated in that individual model.

\begin{tabular}{|c|c|c|c|c|c|c|}
\hline Parameter name & G1R2 & G1R5 & G2R2 & G2R5 & G3R2 & G3R5 \\
\hline B_LVVSZ_1 & $9.00 \mathrm{E}-04$ & $9.00 \mathrm{E}-04$ & $9.00 \mathrm{E}-04$ & $9.00 \mathrm{E}-04$ & $9.00 \mathrm{E}-04$ & $9.00 \mathrm{E}-04$ \\
\hline B_HWY95 & 2.95E-04 & 2.95E-04 & 2.95E-04 & 2.95E-04 & 2.95E-04 & 2.95E-04 \\
\hline B_DVFC_FCR & $1.00 \mathrm{E}-07$ & $1.00 \mathrm{E}-07$ & 1.00E-07 & $1.00 \mathrm{E}-07$ & 1.00E-07 & 1.00E-07 \\
\hline B_LVVSZ_IS & 1.10E-08 & $1.10 \mathrm{E}-08$ & $1.10 \mathrm{E}-08$ & $1.10 \mathrm{E}-08$ & 1.10E-08 & $1.10 \mathrm{E}-08$ \\
\hline B_LVVSZ_I2 & 4.19E-08 & 4.19E-08 & 4.19E-08 & 4.19E-08 & 4.19E-08 & 4.19E-08 \\
\hline B_PAHRUMP & $9.51 E-07$ & $2.31 E-06$ & $1.00 E-14$ & 9.03E-07 & $1.00 E-14$ & $8.78 E-07$ \\
\hline B_DV_N & $1.00 E-14$ & $1.00 E-14$ & $1.00 E-14$ & $6.74 E-08$ & $1.00 E-14$ & $7.80 E-08$ \\
\hline B_SOLTARIO & $1.38 E-05$ & 3.73E-05 & 2.59E-07 & $2.80 E-05$ & $1.72 E-07$ & $6.75 E-05$ \\
\hline B_TC_LINE & $1.00 \mathrm{E}-07$ & $1.00 \mathrm{E}-07$ & $1.00 \mathrm{E}-07$ & $1.00 \mathrm{E}-07$ & $1.00 \mathrm{E}-07$ & $1.00 \mathrm{E}-07$ \\
\hline UPPER_DRN & $9.19 E+01$ & $1.11 E+02$ & $7.51 E+01$ & $9.87 E+01$ & $7.33 E+01$ & $9.98 E+01$ \\
\hline DEEP_DRN & $4.95 E+01$ & $7.06 E+01$ & $4.19 E+01$ & $4.21 E+01$ & $4.08 E+01$ & $4.49 E+01$ \\
\hline UP_PLY_DRN & $5.18 E+01$ & $7.82 E+01$ & $4.56 E+01$ & $7.79 E+01$ & $4.19 E+01$ & $9.05 E+01$ \\
\hline UP_PAH_DRN & $9.63 E+01$ & $1.08 E+02$ & $2.04 E+02$ & $1.57 E+02$ & $1.82 E+02$ & $1.53 E+02$ \\
\hline UP_DV_DRN & $1.00 \mathrm{E}+04$ & $1.00 \mathrm{E}+04$ & $1.00 \mathrm{E}+04$ & $1.00 \mathrm{E}+04$ & $1.00 \mathrm{E}+04$ & $1.00 \mathrm{E}+04$ \\
\hline UP_DVN_DRN & $8.34 E+01$ & $1.26 E+02$ & $7.03 E+01$ & $8.06 E+01$ & $7.73 E+01$ & $1.01 E+02$ \\
\hline FRNCR_DRN & $1.00 \mathrm{E}+04$ & $1.00 \mathrm{E}+04$ & $1.00 \mathrm{E}+04$ & $1.00 \mathrm{E}+04$ & $1.00 \mathrm{E}+04$ & $1.00 \mathrm{E}+04$ \\
\hline KDP_VOL & $3.09 E-03$ & $2.61 E-03$ & $2.72 E-03$ & $2.86 E-03$ & $2.70 E-03$ & $2.82 E-03$ \\
\hline KDEP_LCA & $5.00 E-04$ & $7.22 E-04$ & $3.55 E-04$ & $4.73 E-04$ & $4.06 E-04$ & $5.03 E-04$ \\
\hline KDEP_VFVL & $1.23 \mathrm{E}-02$ & 1.23E-02 & $1.23 \mathrm{E}-02$ & 1.23E-02 & $1.23 \mathrm{E}-02$ & $1.23 \mathrm{E}-02$ \\
\hline KDEP_VSUU & 4.35E-03 & 4.35E-03 & 4.35E-03 & 4.35E-03 & 4.35E-03 & 4.35E-03 \\
\hline KDEP_NO & $1.00 \mathrm{E}-07$ & $1.00 \mathrm{E}-07$ & $1.00 \mathrm{E}-07$ & $1.00 \mathrm{E}-07$ & $1.00 \mathrm{E}-07$ & $1.00 \mathrm{E}-07$ \\
\hline KDP_LCANO & $1.72 E-04$ & $2.37 E-04$ & $3.06 E-04$ & $2.74 E-04$ & $3.38 E-04$ & $3.41 E-04$ \\
\hline KDP_LCAT1 & $1.05 E-03$ & $9.14 E-04$ & $1.22 E-03$ & $1.17 E-03$ & $1.17 E-03$ & $1.09 E-03$ \\
\hline KDEP_VSUL & $1.20 \mathrm{E}-04$ & $1.20 \mathrm{E}-04$ & $1.20 \mathrm{E}-04$ & $1.20 \mathrm{E}-04$ & $1.20 \mathrm{E}-04$ & $1.20 \mathrm{E}-04$ \\
\hline KDEP_UCCU* & $2.20 E-03$ & $1.50 E-03$ & $2.20 E-03$ & $2.20 \mathrm{E}-03$ & $2.20 E-03$ & $2.20 \mathrm{E}-03$ \\
\hline KDEP_XL & $1.32 E-03$ & $1.35 E-03$ & $6.37 E-04$ & $1.27 E-03$ & $5.52 E-04$ & $1.20 E-03$ \\
\hline K1_VANI & $1.27 \mathrm{E}+00$ & $1.27 \mathrm{E}+00$ & $1.27 \mathrm{E}+00$ & $1.27 \mathrm{E}+00$ & $1.27 \mathrm{E}+00$ & $1.27 \mathrm{E}+00$ \\
\hline K11_ICU & $2.46 \mathrm{E}-03$ & 2.46E-03 & $4.06 E-03$ & $2.34 E-03$ & $4.55 E-03$ & $1.48 E-03$ \\
\hline K11C_XILCU* & 7.19E-03 & $5.84 E-03$ & $1.94 E-03$ & $1.94 \mathrm{E}-03$ & $1.94 E-03$ & $1.94 \mathrm{E}-03$ \\
\hline K1LCCU_XCU* & $7.26 E-03$ & $6.79 E-03$ & $4.08 E-03$ & 4.08E-03 & $4.08 E-03$ & $4.08 \mathrm{E}-03$ \\
\hline K11DV_XCU & $2.08 E-01$ & $4.99 E-01$ & $5.97 E-02$ & $5.89 E-01$ & $5.06 E-02$ & $4.69 E-01$ \\
\hline K12223LCCU & $1.13 E-03$ & $1.64 E-03$ & $6.99 E-04$ & $2.15 E-03$ & $7.05 E-04$ & $2.00 E-03$ \\
\hline K122fgLCCU & $6.00 \mathrm{E}-05$ & 6.00E-05 & $6.00 \mathrm{E}-05$ & $6.00 \mathrm{E}-05$ & $6.00 \mathrm{E}-05$ & $6.00 \mathrm{E}-05$ \\
\hline K122esLCCU & $6.07 E-02$ & $9.43 E-02$ & $5.35 E-02$ & $1.79 E-02$ & $4.31 E-02$ & $3.41 E-02$ \\
\hline K1221UCCU* & 3.88E-02 & 3.88E-02 & $3.88 E-02$ & 3.88E-02 & $3.88 E-02$ & 3.88E-02 \\
\hline K2CARBVANI & $1.00 \mathrm{E}+00$ & $1.00 \mathrm{E}+00$ & $3.94 E+00$ & 3.30E-01 & $3.03 E+00$ & $2.32 E-01$ \\
\hline K221_LCA & $6.09 \mathrm{E}+00$ & $6.09 \mathrm{E}+00$ & $2.94 E+00$ & $5.68 E-01$ & $3.56 E+00$ & $1.01 E+00$ \\
\hline K232_LCA & 1.00E-03 & $1.00 \mathrm{E}-03$ & 1.00E-03 & 1.00E-03 & 1.00E-03 & $1.00 \mathrm{E}-03$ \\
\hline K241SM_LCA & $1.97 E-03$ & $5.64 E-03$ & 3.18E-03 & $6.00 E-03$ & $3.06 E-03$ & $7.16 E-03$ \\
\hline K241LCA_T1 & $4.86 E-01$ & 6.99E-01 & $5.19 E-01$ & $8.75 E-01$ & $4.59 E-01$ & $8.96 E-01$ \\
\hline K241SMWLCA & $3.51 E-01$ & $1.09 E+00$ & $9.11 E-02$ & $8.46 E-01$ & 5.69E-02 & $8.43 E-01$ \\
\hline K2_DV_LCA & $3.00 \mathrm{E}+00$ & $3.00 \mathrm{E}+00$ & $3.00 \mathrm{E}+00$ & $3.00 \mathrm{E}+00$ & $3.00 \mathrm{E}+00$ & $3.00 \mathrm{E}+00$ \\
\hline K2412_LCA & $7.39 E-02$ & $5.22 E-01$ & $2.52 E-02$ & $2.37 E-01$ & $2.64 E-02$ & $3.94 E-01$ \\
\hline
\end{tabular}


Table A-1. Final parameter values for the six models after automatic calibration using MODFLOW. Parameters indicated with * are adjusted manually to address unrealistically high heads simulated in portions of the models after the automatic calibration. Values shown in red are the parameters calibrated in that individual model (continued).

\begin{tabular}{|c|c|c|c|c|c|c|}
\hline Parameter name & G1R2 & G1R5 & G2R2 & G2R5 & G3R2 & G3R5 \\
\hline K2412fLCA & $3.26 E+00$ & $3.38 E+00$ & $5.93 E+00$ & $5.97 E+00$ & $5.28 E+00$ & $4.84 E+00$ \\
\hline K242G_LCA & $4.98 E-01$ & $1.35 E+00$ & $7.31 E-02$ & $4.50 E-01$ & $1.88 E-01$ & $1.82 E+00$ \\
\hline K242YN_LCA & 1.17E-04 & 1.17E-04 & 1.17E-04 & 1.17E-04 & 1.17E-04 & 1.17E-04 \\
\hline K242A_LCA & $2.37 E+01$ & $5.06 E+01$ & $1.23 E+01$ & $1.08 E+01$ & $1.48 E+01$ & $1.54 E+01$ \\
\hline K2SHPLCA & 6.51E-02 & $6.51 \mathrm{E}-02$ & $6.51 \mathrm{E}-02$ & 6.51E-02 & $6.51 \mathrm{E}-02$ & $6.51 \mathrm{E}-02$ \\
\hline K2YMLCA & $2.74 E+00$ & $4.96 E+00$ & $1.22 E+00$ & $2.79 E+00$ & $1.45 E+00$ & $5.13 E+00$ \\
\hline K2421_LCA & $4.22 E-02$ & $1.97 E-01$ & $3.09 E-02$ & $1.24 E-01$ & $3.14 E-02$ & $1.31 E-01$ \\
\hline K2422b_LCA & $4.60 E-02$ & $8.24 E-02$ & $1.51 E-02$ & $4.71 E-02$ & $1.78 E-02$ & $4.07 E-02$ \\
\hline K243_LCA & $4.48 E+00$ & $7.62 E+00$ & $1.04 E+01$ & $6.32 E+00$ & $1.12 E+01$ & $8.52 E+00$ \\
\hline K243_UCA* & $5.00 \mathrm{E}-03$ & $5.00 \mathrm{E}-03$ & $5.00 \mathrm{E}-03$ & $5.00 \mathrm{E}-03$ & $5.00 \mathrm{E}-03$ & $5.00 \mathrm{E}-03$ \\
\hline K243PP_LCA & $1.00 \mathrm{E}+00$ & $1.00 \mathrm{E}+00$ & $1.18 E+00$ & $1.00 \mathrm{E}+00$ & $8.44 E-01$ & $1.00 \mathrm{E}+00$ \\
\hline K243GV_LCA & $2.40 \mathrm{E}-03$ & $2.40 \mathrm{E}-03$ & $2.40 \mathrm{E}-03$ & $2.40 \mathrm{E}-03$ & $2.40 \mathrm{E}-03$ & $2.40 \mathrm{E}-03$ \\
\hline K244_LCA & $2.00 \mathrm{E}+02$ & $2.00 \mathrm{E}+02$ & $2.00 \mathrm{E}+02$ & $2.00 \mathrm{E}+02$ & $2.00 \mathrm{E}+02$ & $2.00 \mathrm{E}+02$ \\
\hline K3_VOLVANI & $3.77 E-01$ & $3.09 E+00$ & $1.68 E-01$ & $6.81 E-03$ & $1.38 E-01$ & $9.13 E-01$ \\
\hline K3_ATU & - & - & $1.60 \mathrm{E}-03$ & $1.60 \mathrm{E}-03$ & $1.60 \mathrm{E}-03$ & $1.60 \mathrm{E}-03$ \\
\hline K3_TMLVTA & - & - & $2.89 \mathrm{E}+02$ & $2.89 \mathrm{E}+02$ & $2.89 E+02$ & $2.89 \mathrm{E}+02$ \\
\hline K3_TMUVTA & - & - & $2.89 \mathrm{E}+02$ & $2.89 \mathrm{E}+02$ & $2.89 E+02$ & $2.89 \mathrm{E}+02$ \\
\hline K3C_PVA & 3.16E-01 & 3.16E-01 & 3.16E-01 & $3.20 \mathrm{E}-01$ & 3.16E-01 & $3.20 \mathrm{E}-01$ \\
\hline K3C_TM & $1.46 E-01$ & $4.23 E-01$ & $2.24 E-01$ & $6.47 E+00$ & $2.40 E-01$ & $1.14 E+00$ \\
\hline K3211TMVA & $1.07 E+01$ & $1.91 E+01$ & $1.08 E+01$ & $1.69 E+01$ & $1.01 E+01$ & $2.90 E+01$ \\
\hline K3PVA & $1.75 E+02$ & $3.71 E+02$ & $9.10 E+01$ & $1.59 E+02$ & $8.37 E+01$ & $2.58 E+02$ \\
\hline K3BRU123 & $4.36 E+00$ & $4.11 E+00$ & $3.01 E+01$ & $6.63 E+01$ & $3.29 E+01$ & $1.63 E+01$ \\
\hline K3LFU_am & 5.09E-02 & 5.09E-02 & $5.09 \mathrm{E}-02$ & 5.09E-02 & 5.09E-02 & $5.09 \mathrm{E}-02$ \\
\hline K32BR4CH13 & $3.68 E-01$ & $1.22 E+00$ & $8.37 E-02$ & $2.23 E-01$ & $6.76 E-02$ & $1.35 E+00$ \\
\hline K32CH24LF & $7.77 E-01$ & $1.34 E+00$ & $4.77 E-01$ & $1.54 E+00$ & $4.41 E-01$ & $1.40 E+00$ \\
\hline K321521_PP & $2.17 E+02$ & $3.82 E+02$ & $2.41 E+02$ & $8.34 \mathrm{E}+02$ & $2.48 E+02$ & $6.83 \mathrm{E}+02$ \\
\hline K3215BCU1 & $1.00 \mathrm{E}-02$ & $1.00 \mathrm{E}-02$ & $1.00 \mathrm{E}-02$ & $1.00 \mathrm{E}-02$ & $1.00 \mathrm{E}-02$ & $1.00 \mathrm{E}-02$ \\
\hline K3215BCU34 & $8.01 E-01$ & $1.30 E+00$ & $7.89 E-01$ & $1.04 E+00$ & $7.75 E-01$ & $1.57 E+00$ \\
\hline K3215TR & $5.60 \mathrm{E}-02$ & $5.60 \mathrm{E}-02$ & $5.60 \mathrm{E}-02$ & $5.60 \mathrm{E}-02$ & $5.60 \mathrm{E}-02$ & $5.60 \mathrm{E}-02$ \\
\hline K33_OVU & $9.90 \mathrm{E}-03$ & $9.90 \mathrm{E}-03$ & $9.90 \mathrm{E}-03$ & $9.90 \mathrm{E}-03$ & $9.90 \mathrm{E}-03$ & $9.90 \mathrm{E}-03$ \\
\hline K33_OVUsw & 4.86E-02 & 4.86E-02 & 4.86E-02 & 4.86E-02 & 4.86E-02 & $4.86 \mathrm{E}-02$ \\
\hline K4_VFVANIA & $5.00 \mathrm{E}+03$ & $5.00 \mathrm{E}+03$ & $5.00 \mathrm{E}+03$ & $5.00 \mathrm{E}+03$ & $5.00 \mathrm{E}+03$ & $5.00 \mathrm{E}+03$ \\
\hline K4_VFVANIC & $5.00 \mathrm{E}+03$ & $5.00 \mathrm{E}+03$ & $5.00 \mathrm{E}+03$ & $5.00 \mathrm{E}+03$ & $5.00 \mathrm{E}+03$ & $5.00 \mathrm{E}+03$ \\
\hline K4_VFVANVL & $2.18 \mathrm{E}+00$ & $2.18 \mathrm{E}+00$ & $3.53 E+01$ & $2.18 \mathrm{E}+00$ & $5.14 E+01$ & $2.18 \mathrm{E}+00$ \\
\hline K4_VF_AQ & $1.26 E+00$ & $1.89 E+00$ & $1.97 E+00$ & $1.78 E+00$ & $2.01 E+00$ & $2.12 E+00$ \\
\hline K4_VF_CU & $3.00 E-01$ & $8.44 E-01$ & $2.54 E-01$ & $2.77 E+00$ & $2.35 E-01$ & $2.74 E+00$ \\
\hline K4_VF_OAA & 5.92E-02 & 5.92E-02 & 5.92E-02 & 5.92E-02 & $5.92 \mathrm{E}-02$ & 5.92E-02 \\
\hline K4UP_VSUC & $9.40 \mathrm{E}-01$ & $9.40 \mathrm{E}-01$ & $7.31 E-01$ & $1.39 E-02$ & $6.53 E-01$ & $1.06 E-02$ \\
\hline K4UP_VSUP & $3.16 E+00$ & $2.05 E+00$ & $2.17 E+01$ & $1.68 E+00$ & $1.49 E+01$ & $2.18 E+00$ \\
\hline K42UP_VSU & $7.48 E+00$ & $1.53 E+01$ & $5.75 E+00$ & $8.29 E+00$ & $5.42 E+00$ & $9.99 E+00$ \\
\hline K4222P_VSU & 5.81E-01 & 5.81E-01 & 5.81E-01 & $5.80 \mathrm{E}-01$ & 5.81E-01 & $5.80 \mathrm{E}-01$ \\
\hline K42222_VSU & 5.00E-03 & 5.00E-03 & 5.00E-03 & 5.00E-03 & 5.00E-03 & 5.00E-03 \\
\hline K422GV_VSU & $2.81 E-04$ & $8.36 E-04$ & $4.01 E-03$ & $1.00 E-03$ & $4.41 E-03$ & $1.31 E-03$ \\
\hline K422DV_VSU & $1.05 E-02$ & $8.32 E-03$ & $1.21 E-02$ & $9.18 E-03$ & $1.20 E-02$ & $9.36 E-03$ \\
\hline K422GW_VSU & $2.71 E-02$ & $2.95 E-02$ & $2.41 E-02$ & $2.22 E-02$ & $2.27 E-02$ & $2.92 E-02$ \\
\hline K4222S_VSU & $8.97 E-02$ & $7.82 E-02$ & $5.49 E-02$ & $3.00 E-02$ & $4.93 E-02$ & $8.46 E-02$ \\
\hline
\end{tabular}


Table A-1. Final parameter values for the six models after automatic calibration using MODFLOW. Parameters indicated with * are adjusted manually to address unrealistically high heads simulated in portions of the models after the automatic calibration. Values shown in red are the parameters calibrated in that individual model (continued).

\begin{tabular}{lcccccc}
\hline Parameter name & G1R2 & G1R5 & G2R2 & G2R5 & G3R2 & G3R5 \\
\hline K422LNEVSU & $3.59 E-01$ & $2.54 E-01$ & $4.95 E-01$ & $1.20 E-01$ & $4.96 E-01$ & $3.50 E-01$ \\
K422LNWVSU & $2.64 E-01$ & $\mathbf{1 . 8 8 E - 0 1}$ & $\mathbf{1 . 8 9 E - 0 1}$ & $3.95 E-02$ & $\mathbf{1 . 5 8 E - 0 1}$ & $\mathbf{1 . 4 4 E - 0 1}$ \\
RCH_2 & $\mathbf{6 . 2 2 E - 0 1}$ & $1.00 \mathrm{E}+00$ & $5.69 E-01$ & $1.00 \mathrm{E}+00$ & $5.06 E-01$ & $1.00 \mathrm{E}+00$ \\
RCH_35 & $7.19 E-01$ & $1.00 \mathrm{E}+00$ & $5.71 \mathrm{E}-01$ & $1.00 \mathrm{E}+00$ & $6.24 \mathrm{E}-\mathbf{0 1}$ & $1.00 \mathrm{E}+00$ \\
RCH_467 & $1.00 \mathrm{E}+00$ & $1.00 \mathrm{E}+00$ & $1.00 \mathrm{E}+00$ & $1.00 \mathrm{E}+00$ & $1.00 \mathrm{E}+00$ & $1.00 \mathrm{E}+00$ \\
RCH_8 & $1.00 \mathrm{E}+00$ & $1.00 \mathrm{E}+00$ & $1.00 \mathrm{E}+00$ & $1.00 \mathrm{E}+00$ & $1.00 \mathrm{E}+00$ & $1.00 \mathrm{E}+00$ \\
RCH_9 & $1.00 \mathrm{E}-07$ & $1.00 \mathrm{E}-07$ & $1.00 \mathrm{E}-07$ & $1.00 \mathrm{E}-07$ & $1.00 \mathrm{E}-07$ & $1.00 \mathrm{E}-07$ \\
\hline
\end{tabular}

Table A-2. Parameter values in the six selected realizations for the six models.

\begin{tabular}{ccccccc}
\hline & G1R2 & G1R5 & G2R2 & G2R5 & G3R2 & G3R5 \\
\hline DEEP_DRN & $3.46 \mathrm{E}+00$ & $4.93 \mathrm{E}+00$ & $5.03 \mathrm{E}+00$ & $3.80 \mathrm{E}+01$ & $4.91 \mathrm{E}+00$ & $2.70 \mathrm{E}+01$ \\
UP_PLY_DRN & $7.38 \mathrm{E}+01$ & $1.11 \mathrm{E}+02$ & & & & \\
K11_ICU & & & $4.10 \mathrm{E}-03$ & $1.40 \mathrm{E}-03$ & $4.60 \mathrm{E}-03$ & $1.70 \mathrm{E}-03$ \\
K221_LCA & & & $3.20 \mathrm{E}-01$ & $7.00 \mathrm{E}-02$ & $3.80 \mathrm{E}-01$ & $5.00 \mathrm{E}-02$ \\
K241LCA_T1 & & & $4.60 \mathrm{E}-01$ & $1.52 \mathrm{E}+00$ & $4.10 \mathrm{E}-01$ & $1.43 \mathrm{E}+00$ \\
K242G_LCA & $1.50 \mathrm{E}-01$ & $4.00 \mathrm{E}-01$ & $1.20 \mathrm{E}-01$ & $4.40 \mathrm{E}-01$ & $3.00 \mathrm{E}-01$ & $1.10 \mathrm{E}+00$ \\
K242A_LCA & $2.62 \mathrm{E}+01$ & $5.58 \mathrm{E}+01$ & $1.88 \mathrm{E}+00$ & $1.61 \mathrm{E}+01$ & $2.27 \mathrm{E}+00$ & $2.77 \mathrm{E}+01$ \\
K243_LCA & $3.66 \mathrm{E}+00$ & $6.23 \mathrm{E}+00$ & $5.15 \mathrm{E}+00$ & $4.98 \mathrm{E}+00$ & $5.56 \mathrm{E}+00$ & $7.10 \mathrm{E}+00$ \\
K4222S_VSU & $4.20 \mathrm{E}-02$ & $3.70 \mathrm{E}-02$ & $8.80 \mathrm{E}-02$ & $4.20 \mathrm{E}-02$ & $7.90 \mathrm{E}-02$ & $7.90 \mathrm{E}-02$ \\
K422LNEVSU & & & $6.30 \mathrm{E}-01$ & $2.00 \mathrm{E}-02$ & $6.30 \mathrm{E}-01$ & $8.00 \mathrm{E}-02$ \\
\hline
\end{tabular}



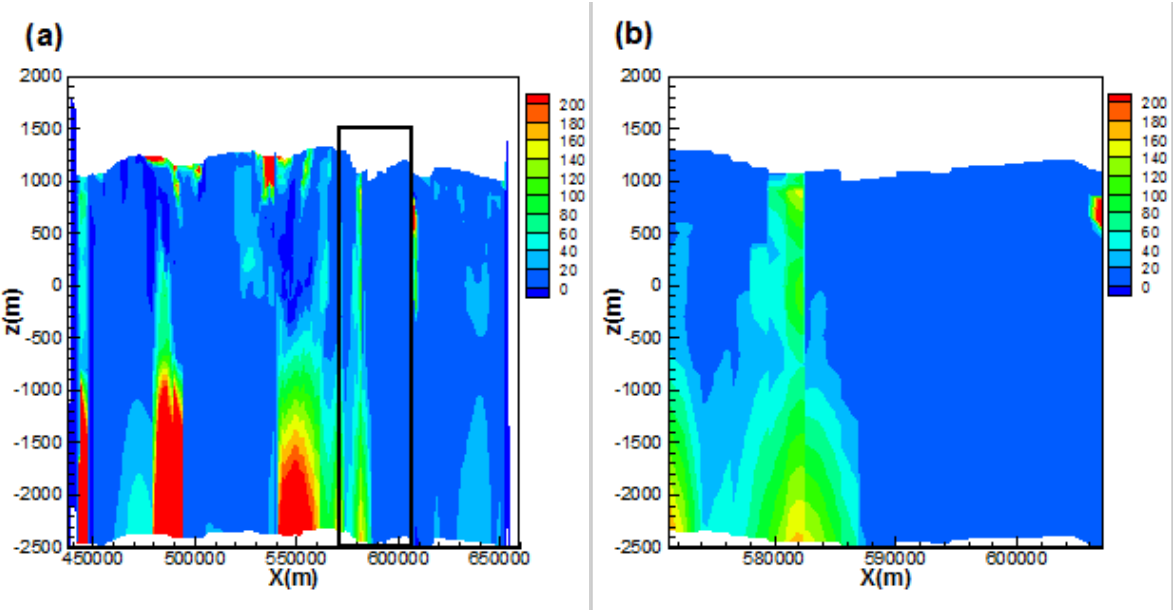

Figure A-1. Contours of $\mathrm{Q}_{\mathrm{y}}$ at the cross sectionJ =101 (a) across the entire domain and (b) in northern Yucca Flat for calibrated model G1R2. The northern Yucca Flat area is marked with the black square in (a).
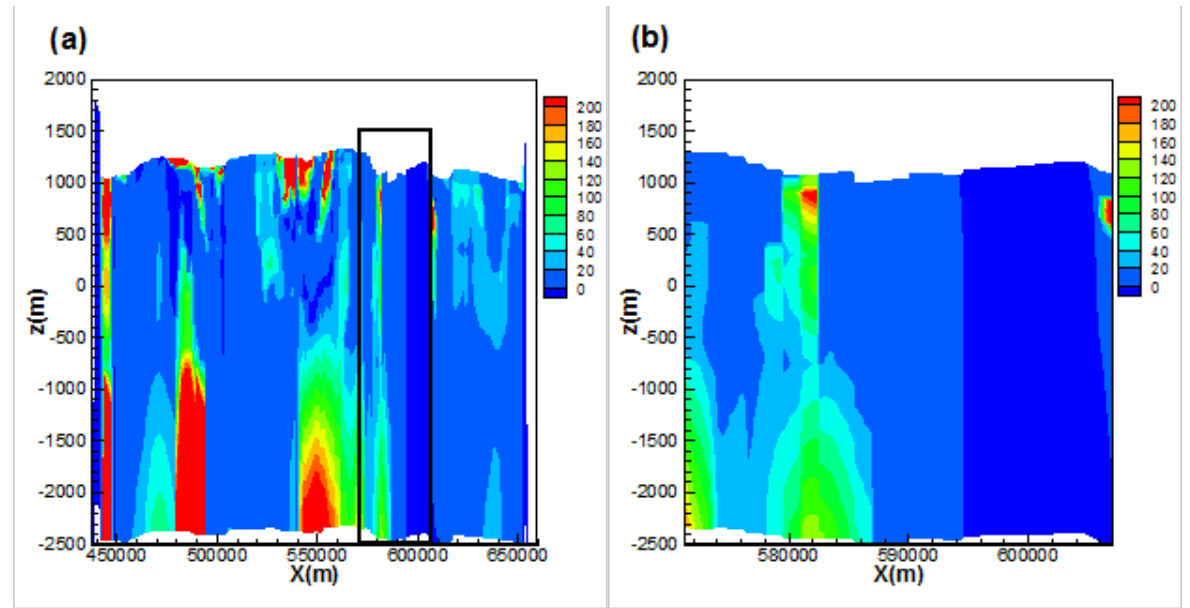

Figure A-2. Contours of $\mathrm{Q}_{\mathrm{y}}$ at the cross section $\mathrm{J}=101$ (a) across the entire domain and (b) in northern Yucca Flat for calibrated model G1R5. The northern Yucca Flat area is marked with the black square in (a). 


\section{(a)}

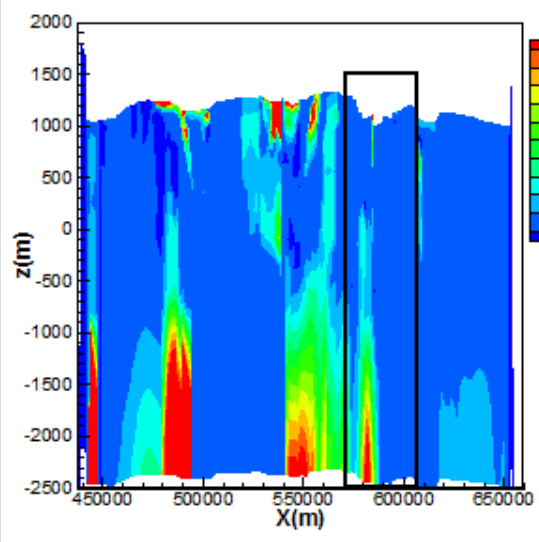

(b)

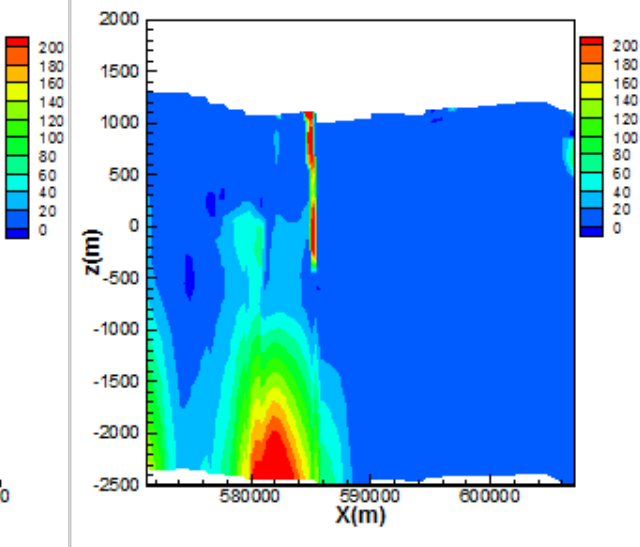

Figure A-3. Contours of $\mathrm{Q}_{\mathrm{y}}$ at the cross section $\mathrm{J}=101$ (a) for the entire domain and (b) in northern Yucca Flat for the calibrated model G2R2. The northern Yucca Flat area is marked with the black square in (a).
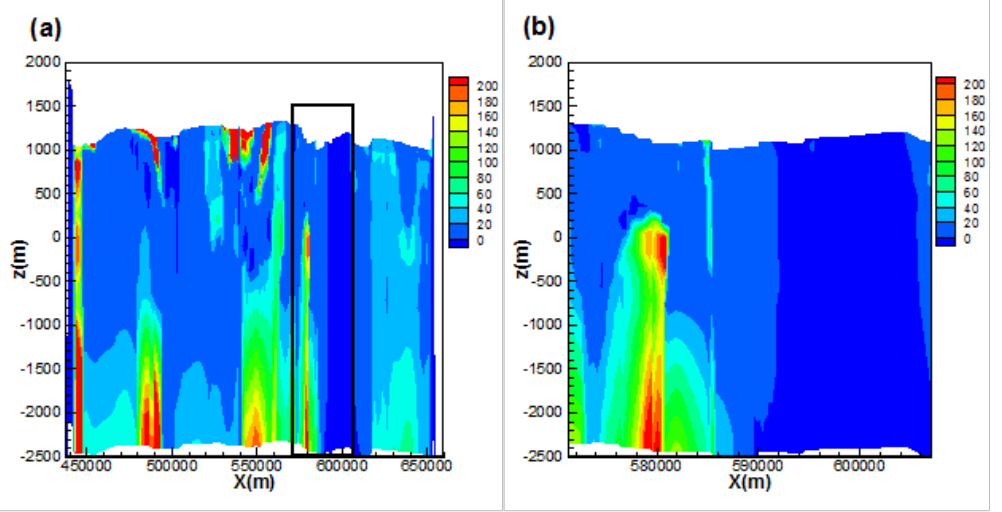

Figure A-4. Contours of $\mathrm{Q}_{\mathrm{y}}$ at the cross section $\mathrm{J}=101$ (a) for the entire domain and (b) in northern Yucca Flat for calibrated model G2R5. The northern Yucca Flat area is marked with the black square in (a).
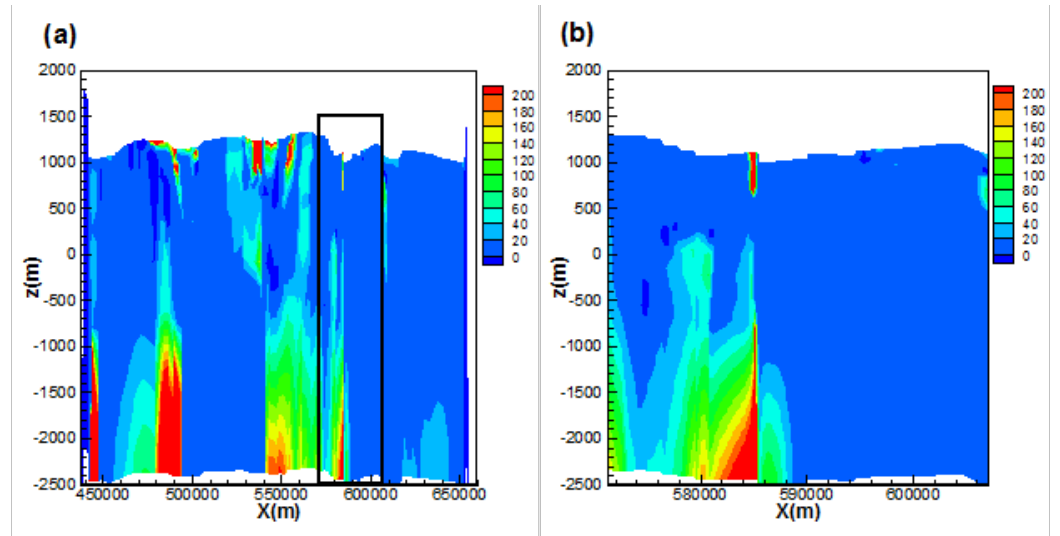

Figure A-5. Contours of $\mathrm{Q}_{\mathrm{y}}$ at the cross section $\mathrm{J}=101$ (a) for the entire domain and (b) in northern Yucca Flat for calibrated modelG3R2. The northern Yucca Flat area is marked with the black square in (a). 
(a)

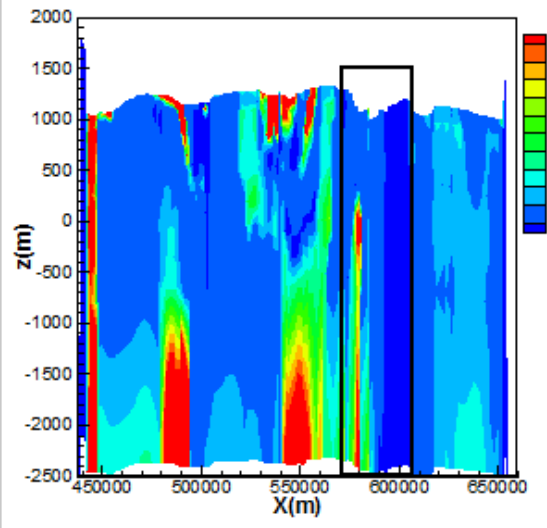

(b)

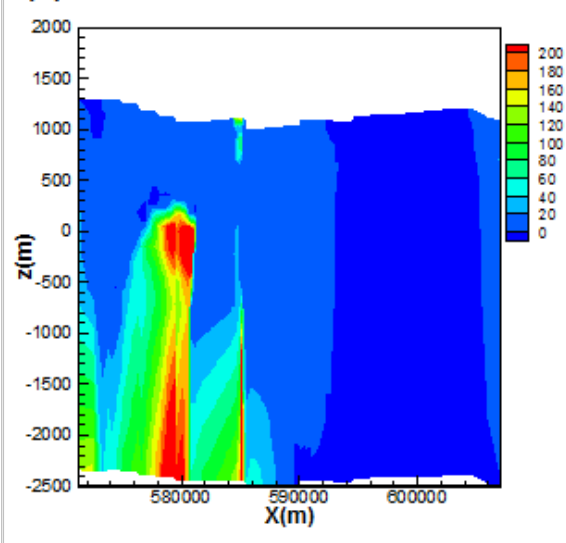

Figure A-6. Contours of $\mathrm{Q}_{\mathrm{y}}$ at the cross section $\mathrm{J}=101$ (a) for the entire domain and (b) in northern Yucca Flat for calibrated model G3R5. The northern Yucca Flat area is marked with the black square in (a).
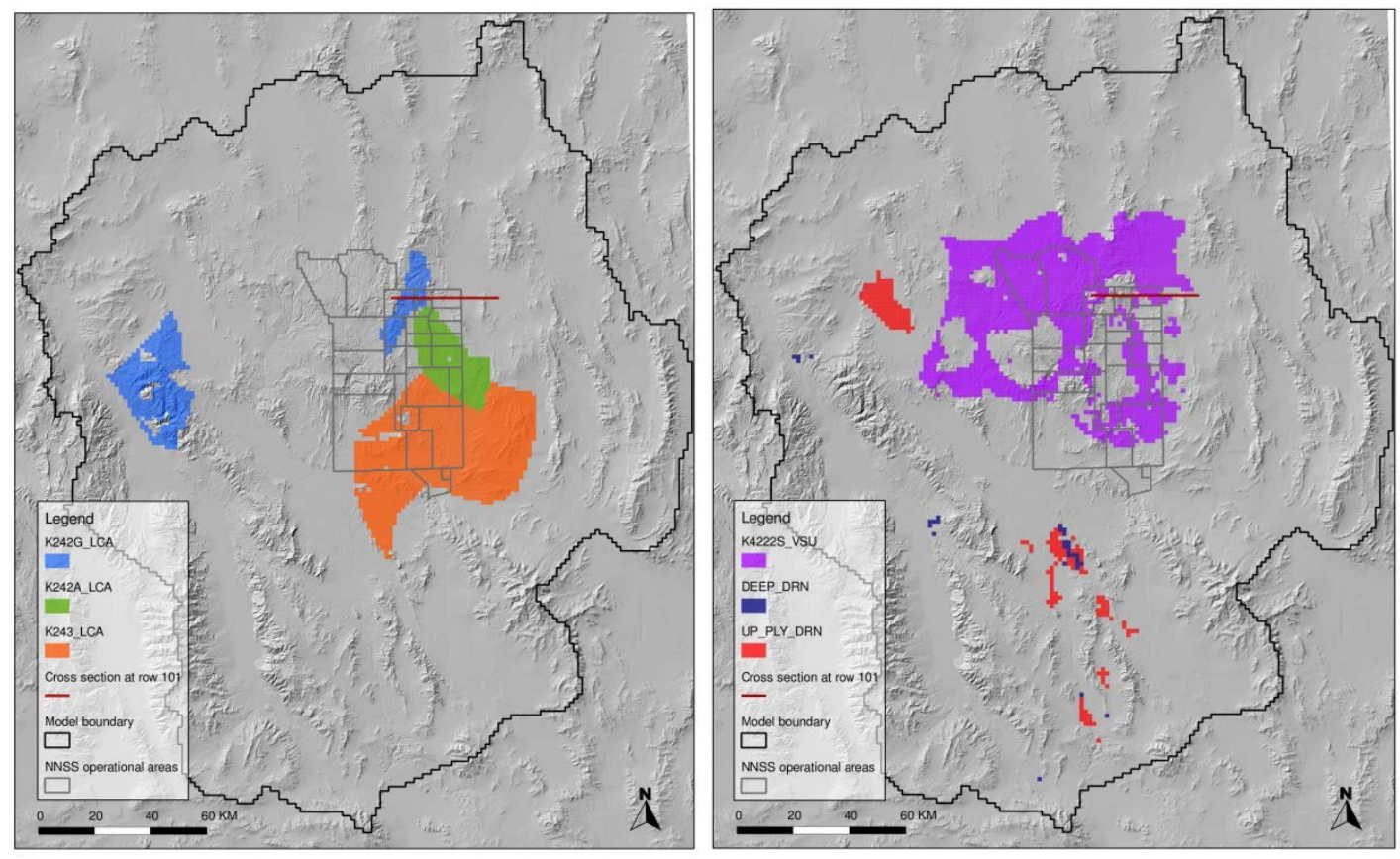

Figure A-7. Spatial distributions of hydraulic conductivity zones and drain parameters identified in the Morris analysis for model G1. The cross section through which Qy is calculated is highlighted in red. 

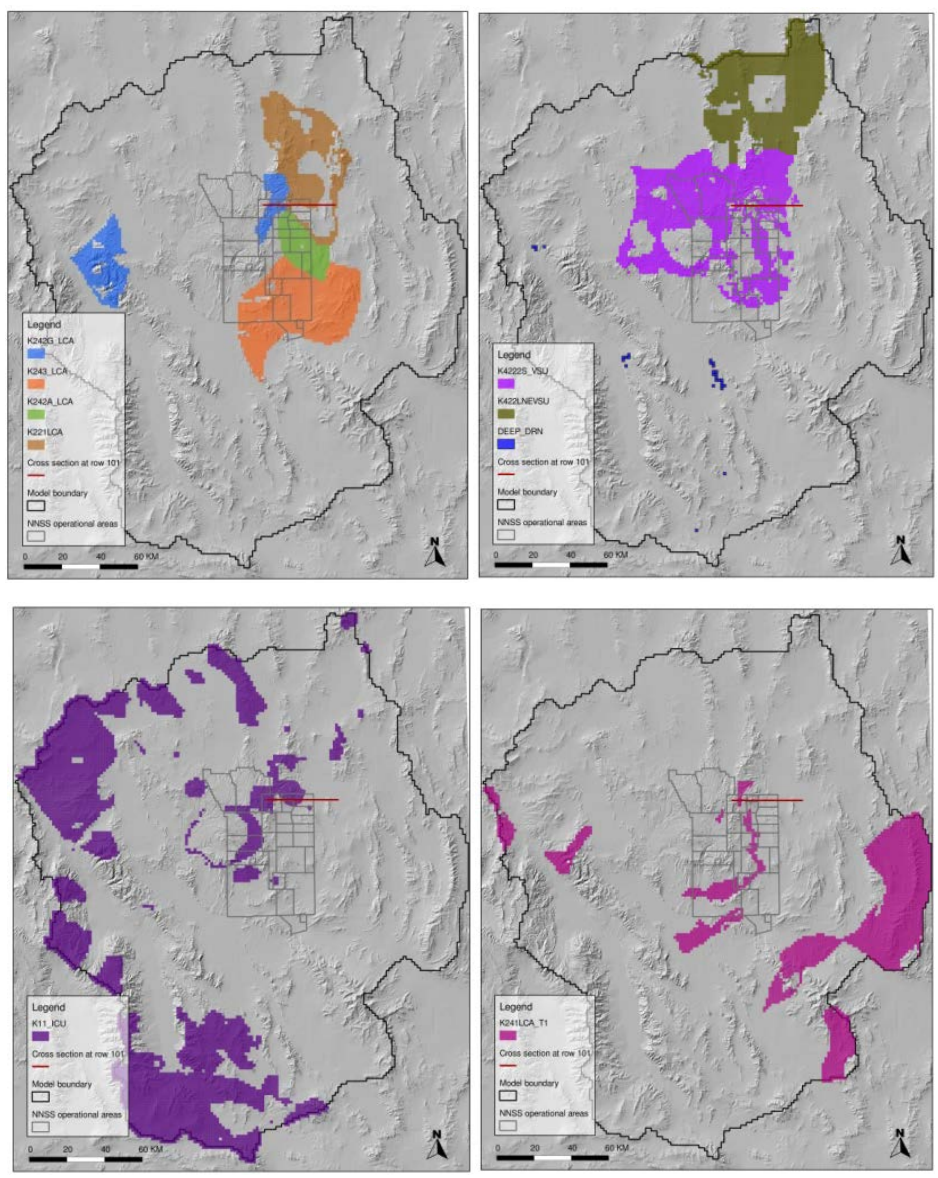

Figure A-8. Spatial distributions of hydraulic conductivity zones and drain parameters identified in the Morris analysis for model G2. The cross section through which Qy is calculated is highlighted in red.

(a)

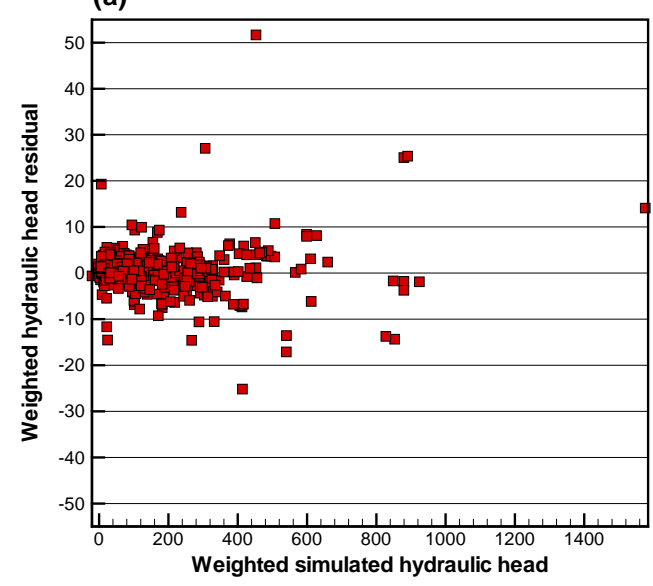

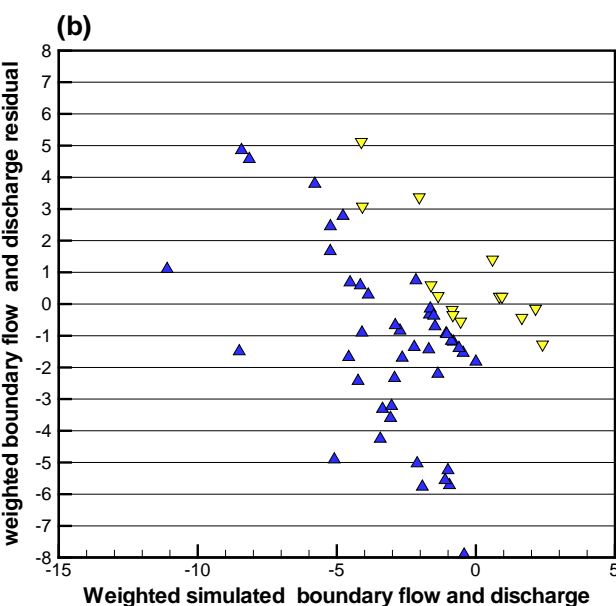

Figure A-9. Weighted residuals and weighted simulated equivalent for (a) hydraulic head and (b) discharge (blue) and constant-head boundary flow (yellow) for G1R2. 
(a)

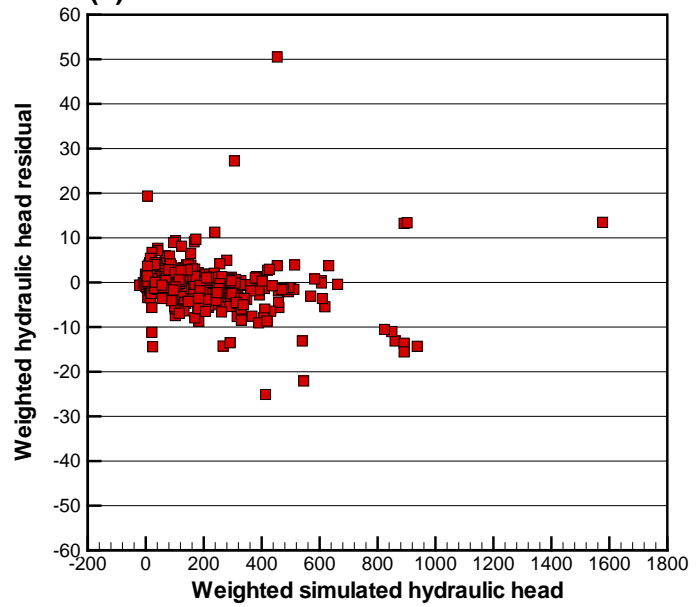

(b)

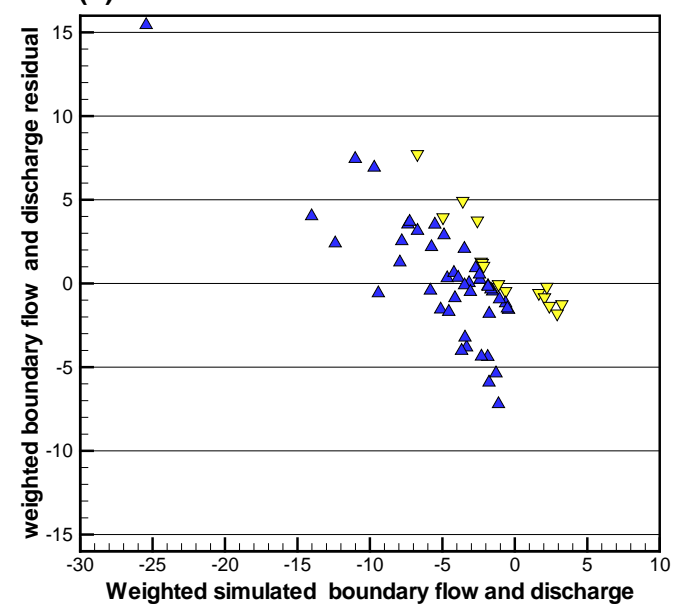

Figure A-10. Weighted residuals and weighted simulated equivalent for (a) hydraulic head and (b) discharge (blue) and constant-head boundary flow (yellow) for G1R5.

(a)

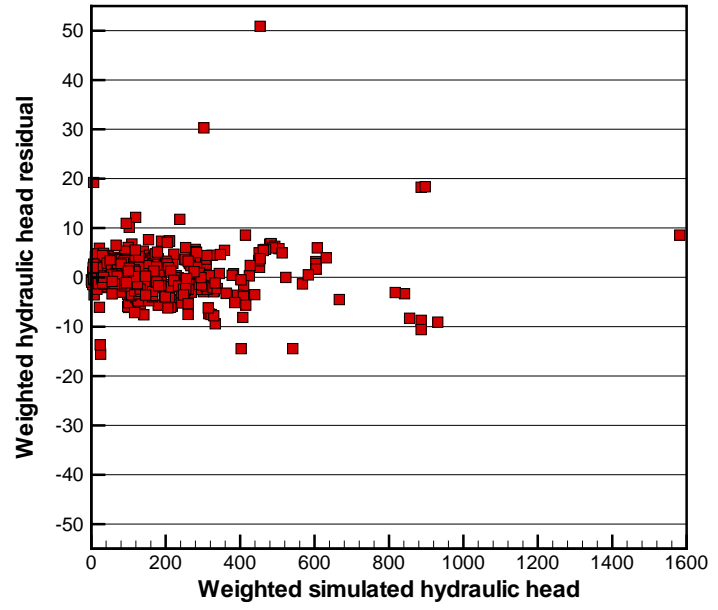

(b)

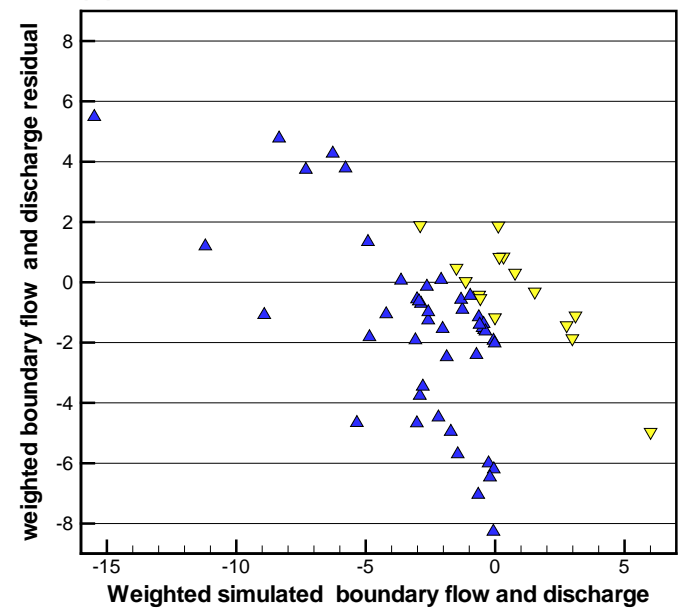

Figure A-11. Weighted residuals and weighted simulated equivalents for (a) hydraulic head and (b) discharge (blue) and constant-head boundary flow (yellow) for G2R2. 
(a)

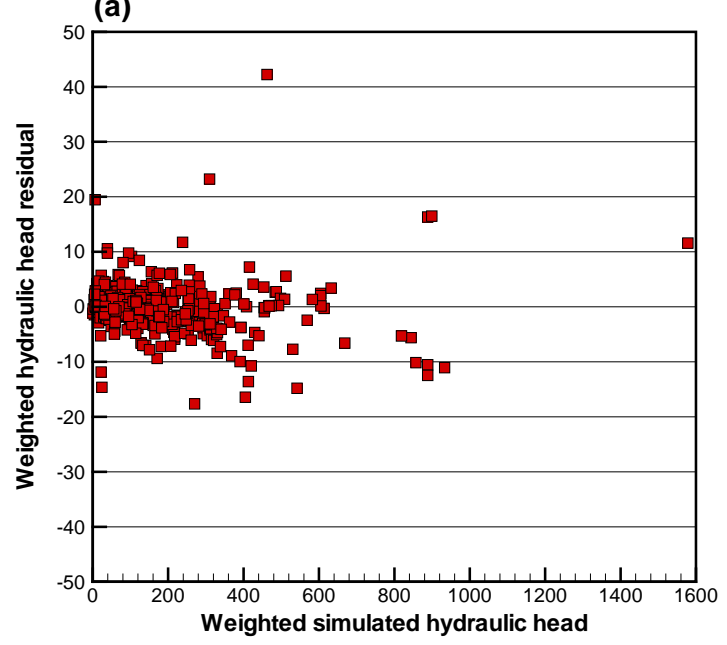

(b)

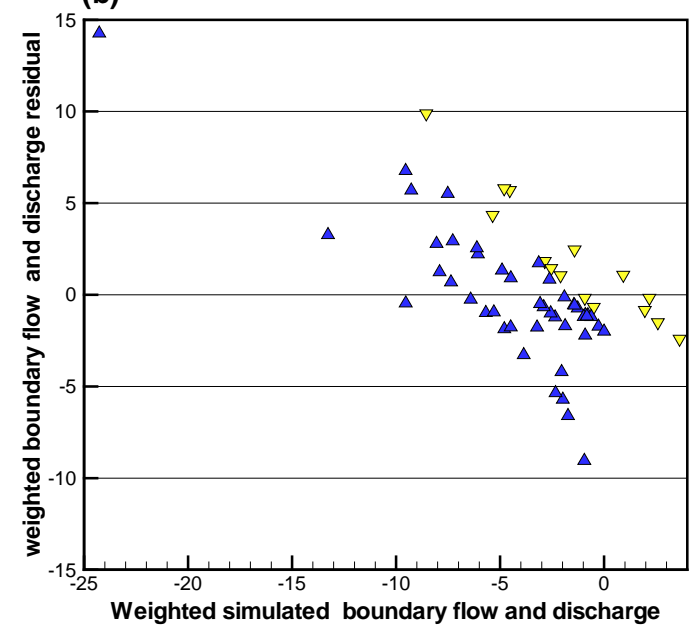

Figure A-12. Weighted residuals and weighted simulated equivalents for (a) hydraulic head and (b) discharge (blue) and constant-head boundary flow (yellow) for G2R5.

(a)

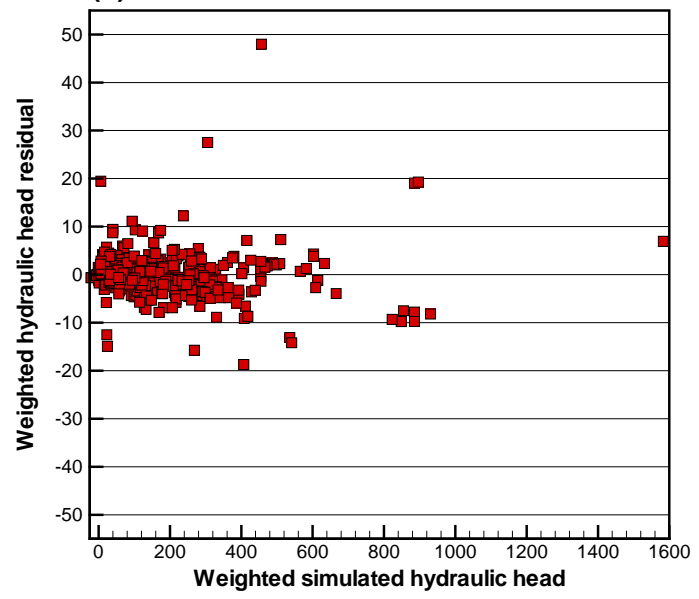

(b)

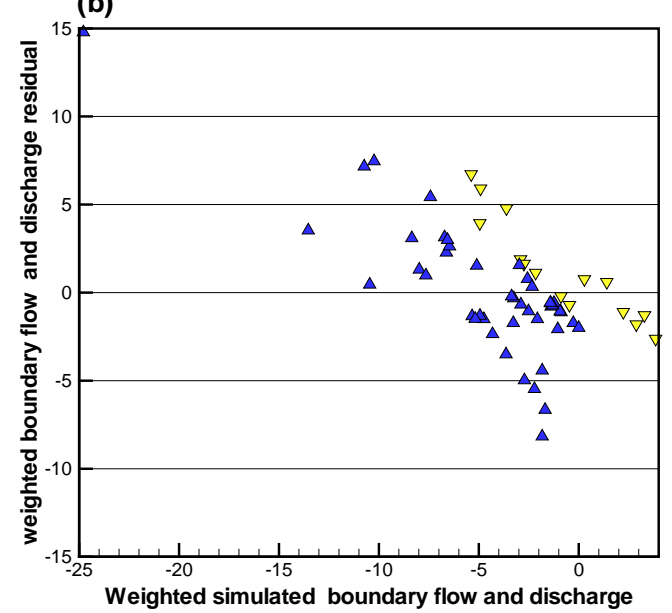

Figure A-13. Weighted residuals and weighted simulated equivalents for (a) hydraulic head and (b) discharge (blue) and constant-head boundary flow (yellow) for G3R5. 
(a)

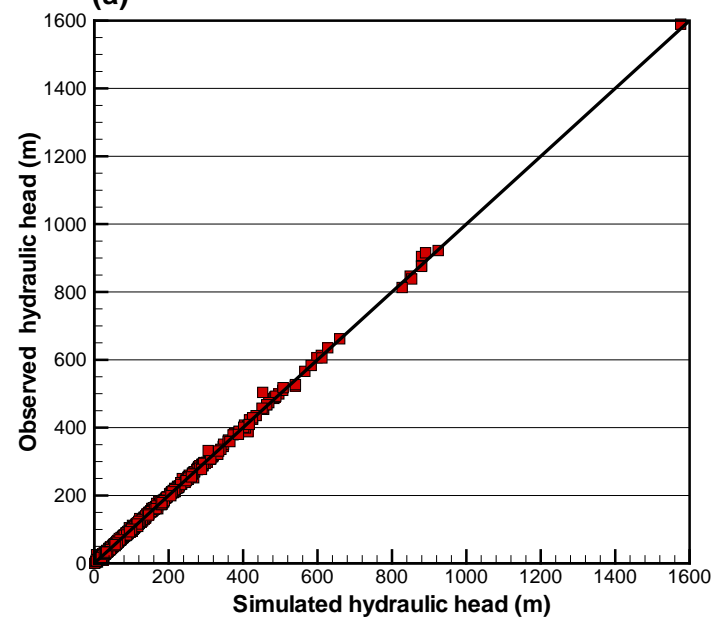

(b)

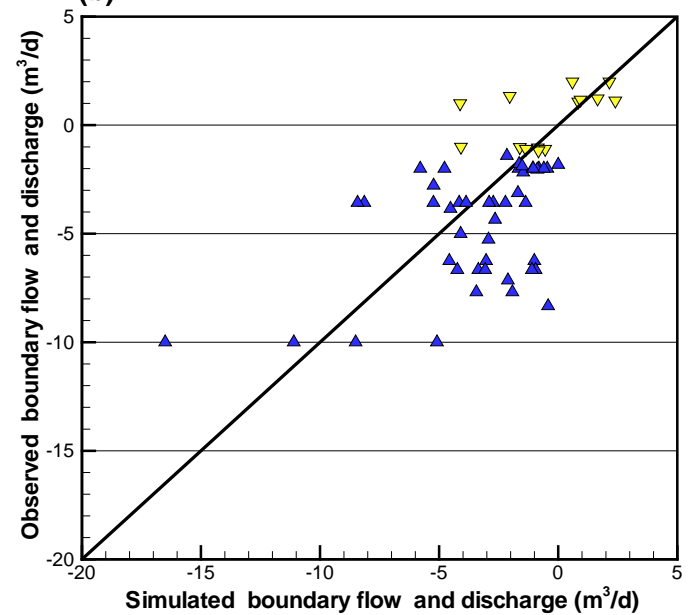

Figure A-14. Weighted observed values and weighted simulated values for (a) hydraulic head and (b) discharge (blue) and constant-head boundary flow (yellow) for G1R2.

(a)

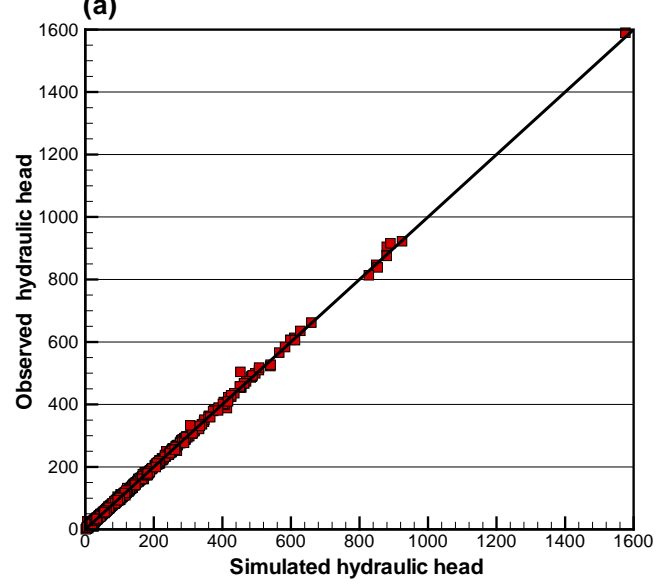

(b)

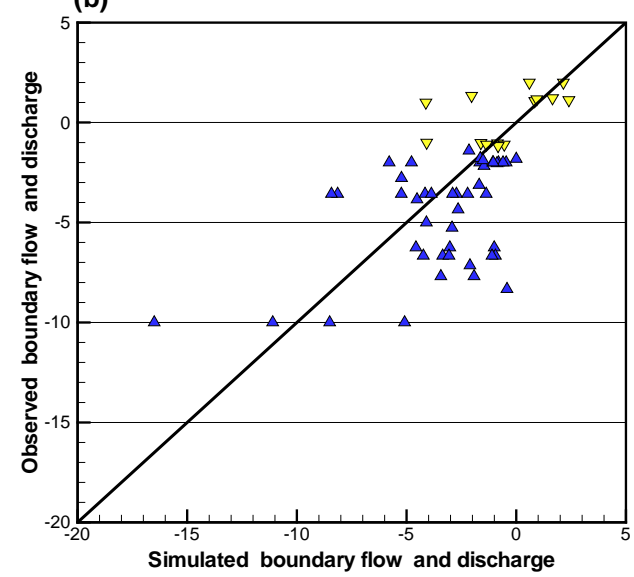

Figure A-15. Weighted observed values and weighted simulated values for (a) hydraulic head and (b) discharge (blue) and constant-head boundary flow (yellow) for G1R5. 
(a)

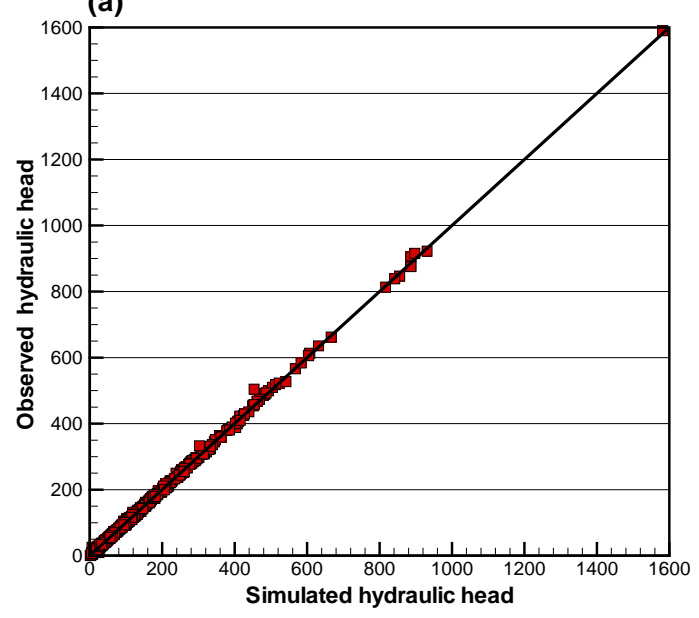

(b)

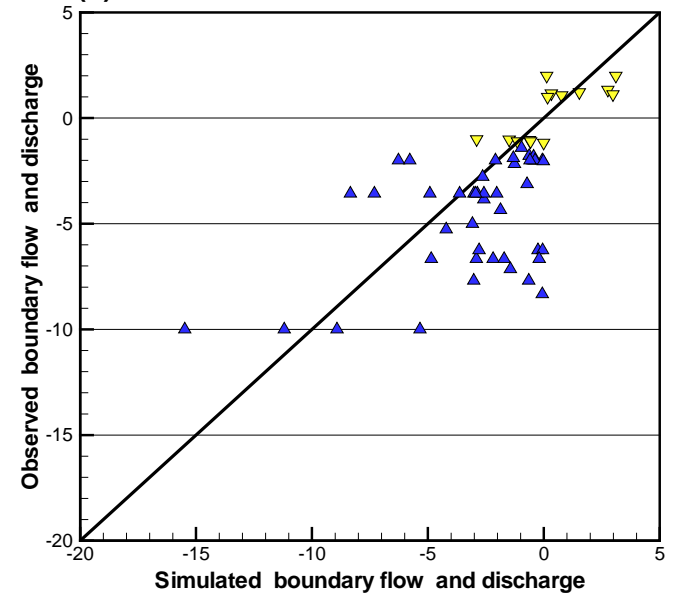

Figure A-16. Weighted observed values and weighted simulated values for (a) hydraulic head and (b) discharge (blue) and constant-head boundary flow (yellow) for G2R2.

(a)

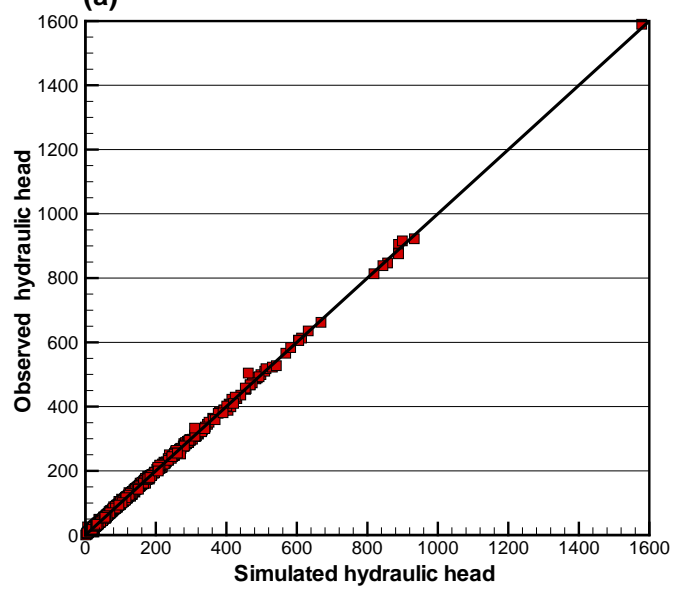

(b)

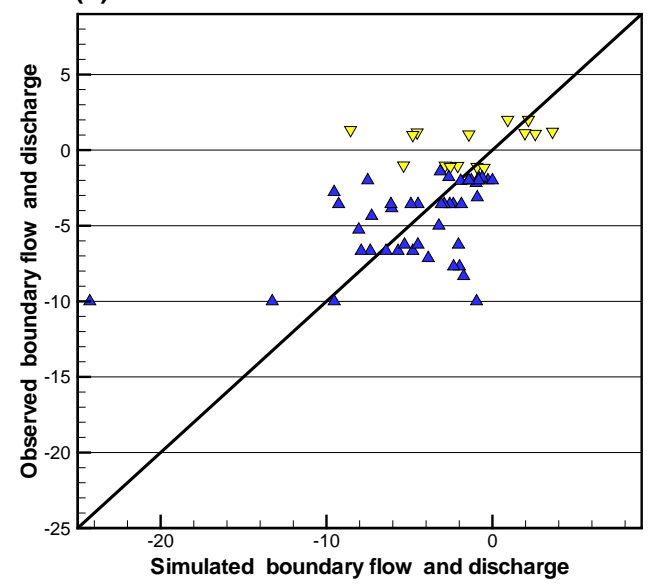

Figure A-17. Weighted observed values and weighted simulated values for (a) hydraulic head and (b) discharge (blue) and constant-head boundary flow (yellow) for G2R5. 

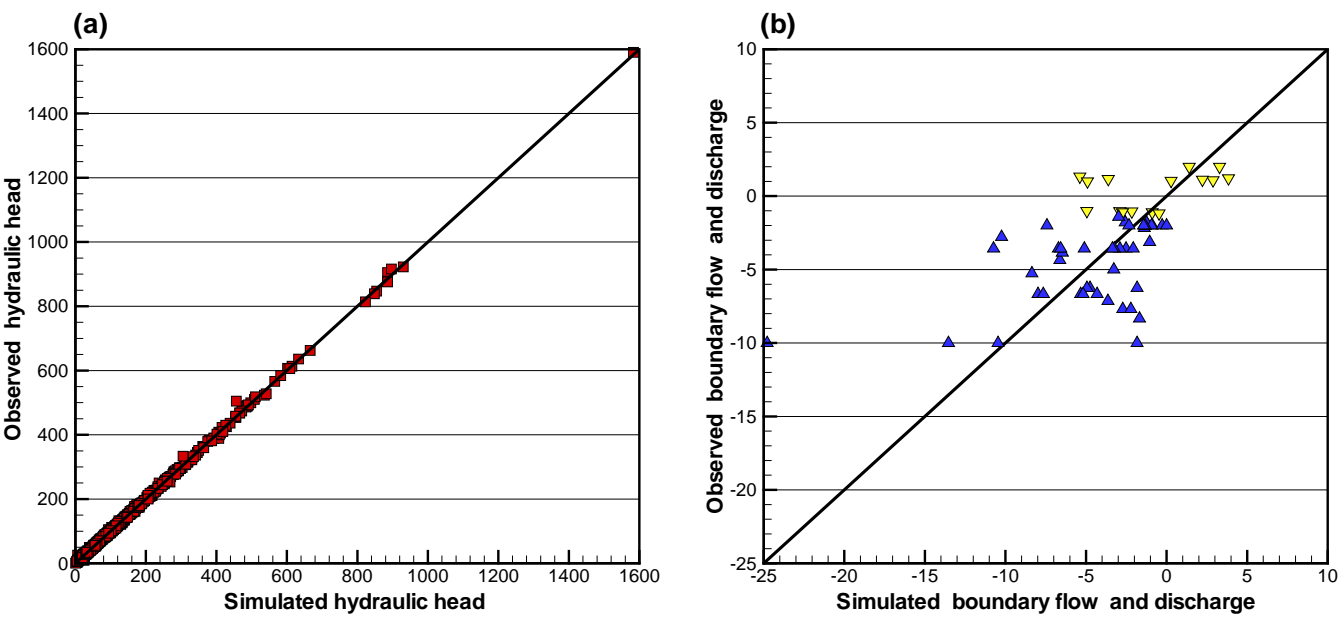

Figure A-18. Weighted observed values and weighted simulated values for (a) hydraulic head and (b) discharge (blue) and constant-head boundary flow (yellow) for G3R5.

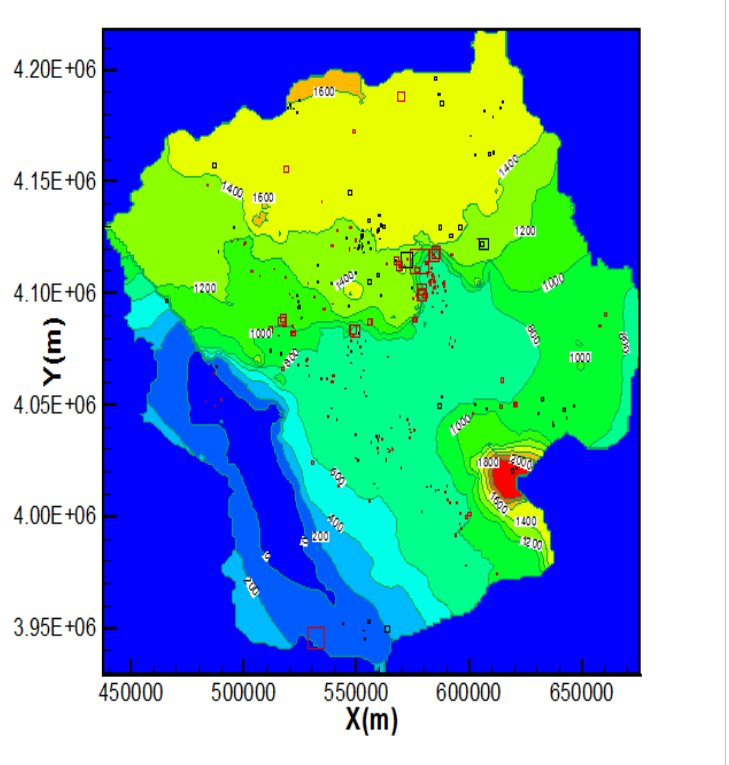

Figure A-19. Spatial distribution of unweighted head residuals and contours of hydraulic head in layer 1 of model G1R2. The red and black squares represent positive and negative residuals, respectively. Symbol size is scaled to the magnitude of the weighted residuals. 


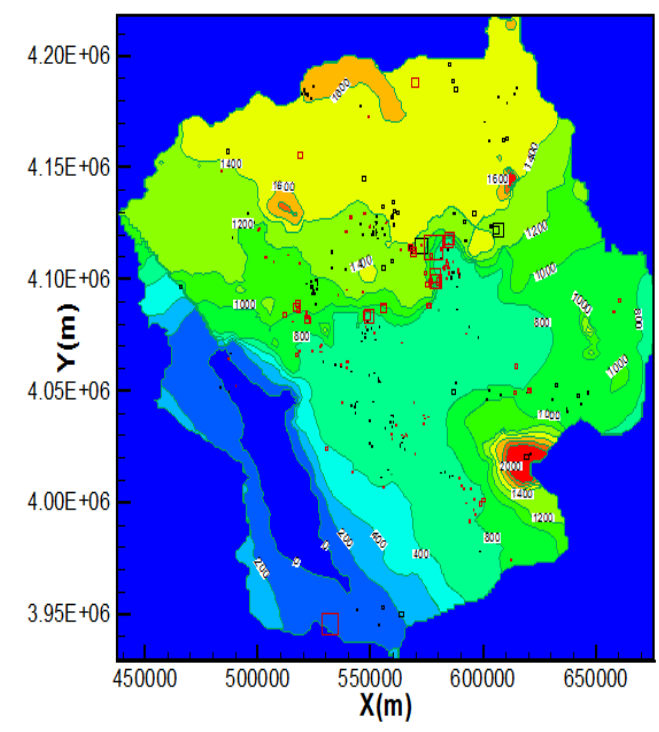

Figure A-20. Spatial distribution of unweighted head residuals and contours of hydraulic head in layer 1 of model G1R5. The red and black squares represent positive and negative residuals, respectively. Symbol size is scaled to the magnitude of the weighted residuals.

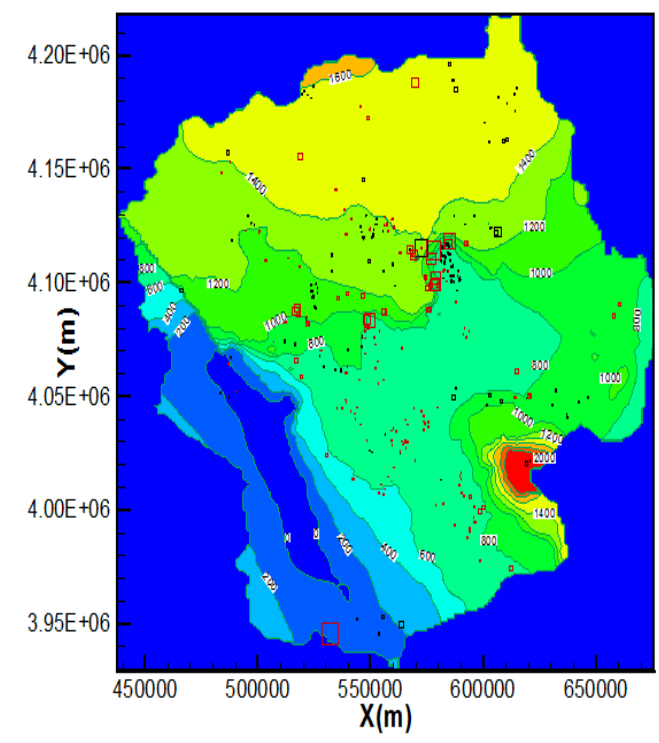

Figure A-21. Spatial distribution of unweighted head residuals and contours of hydraulic head in layer 1 of model G2R2. The red and black squares represent positive and negative residuals, respectively. Symbol size is scaled to the magnitude of the weighted residuals. 


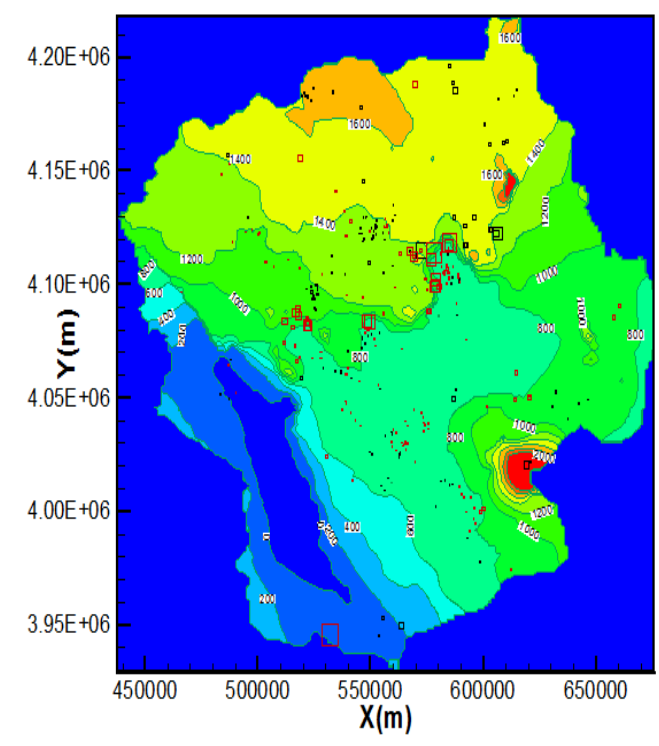

Figure A-22. Spatial distribution of unweighted head residuals and contours of hydraulic head in layer 1 of model G2R5. The red and black squares represent positive and negative residuals, respectively. symbol sizeis scaled to the magnitude of the weighted residuals.

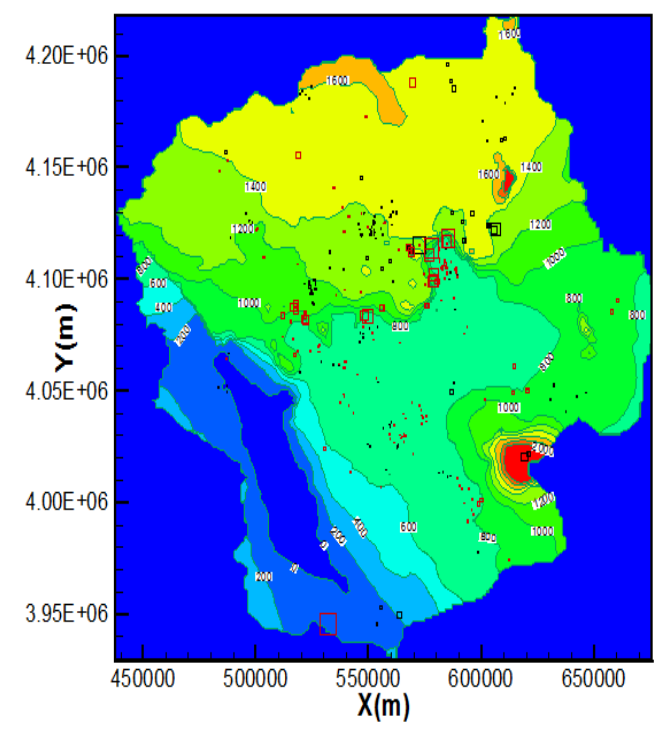

Figure A-23. Spatial distribution of unweighted head residuals and contours of hydraulic head in layer 1 of model G3R5. The red and black squares represent positive and negative residuals, respectively. Symbol size is scaled to the magnitude of the weighted residuals. 


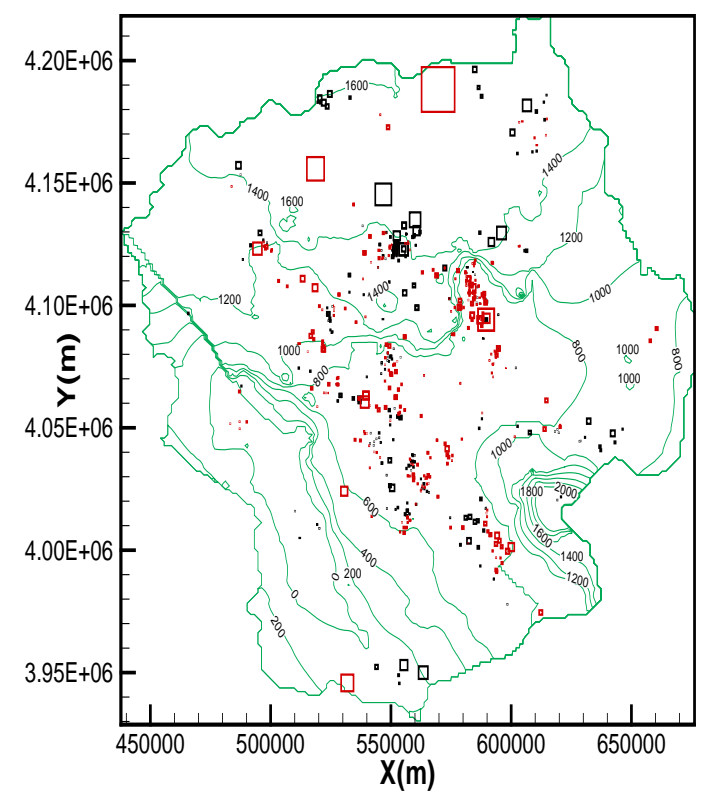

Figure A-24. Distribution of weighted head residuals and contours of hydraulic head in layer 1 of model G1R2. The red and black squares represent positive and negative residuals, respectively. Symbol size is scaled to the magnitude of the weighted residuals.

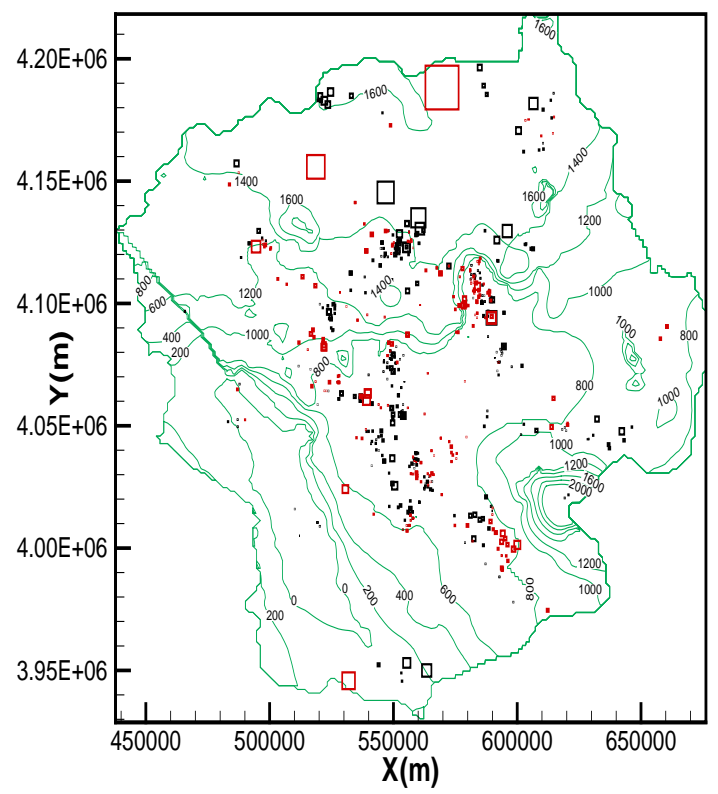

Figure A-25. Distribution of weighted head residuals and contours of hydraulic head in layer 1 of model G1R5. The red and black squares represent positive and negative residuals, respectively. Symbol size is scaled to the magnitude of the weighted residuals. 


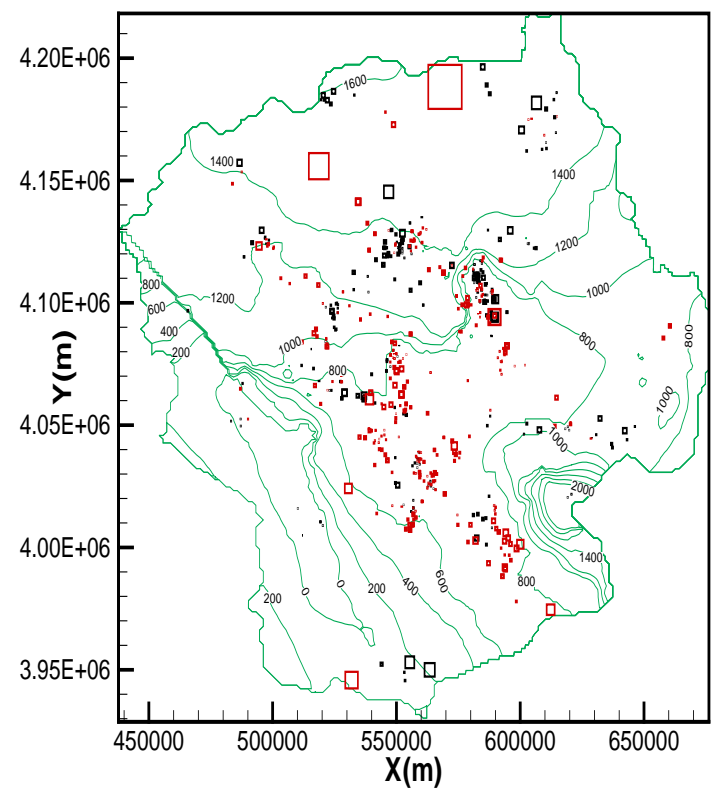

Figure A-26. Distribution of weighted head residuals and ontours of hydraulic head in layer 1 of model G2R2. The red and black squares represent positive and negative residuals, respectively. Symbol size is scaled to the magnitude of the weighted residuals.

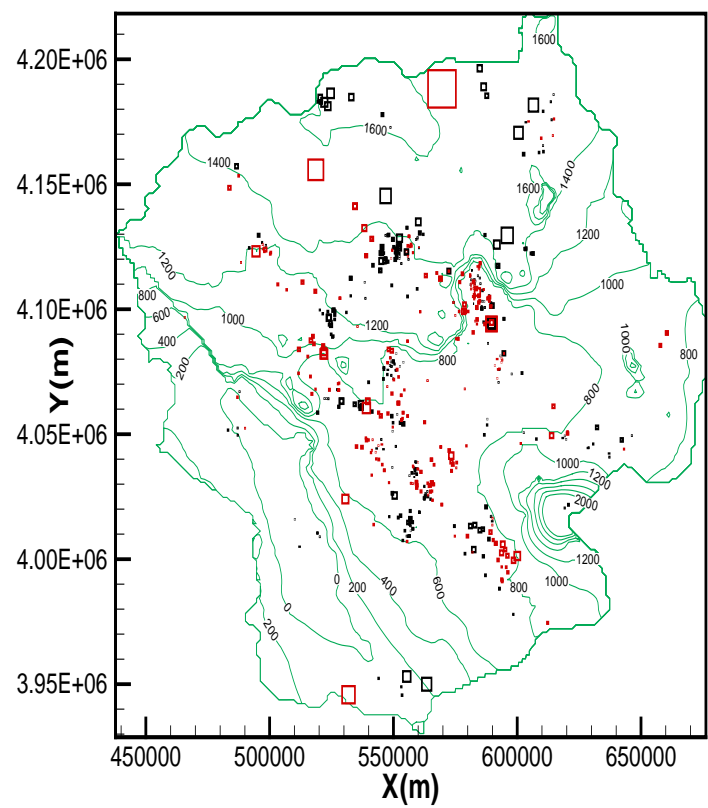

Figure A-27. Distribution of weighted head residuals and contours of hydraulic head in layer 1 of model G2R5. The red and black squares represent positive and negative residuals, respectively. Symbol size is scaled to the magnitude of the weighted residuals. 


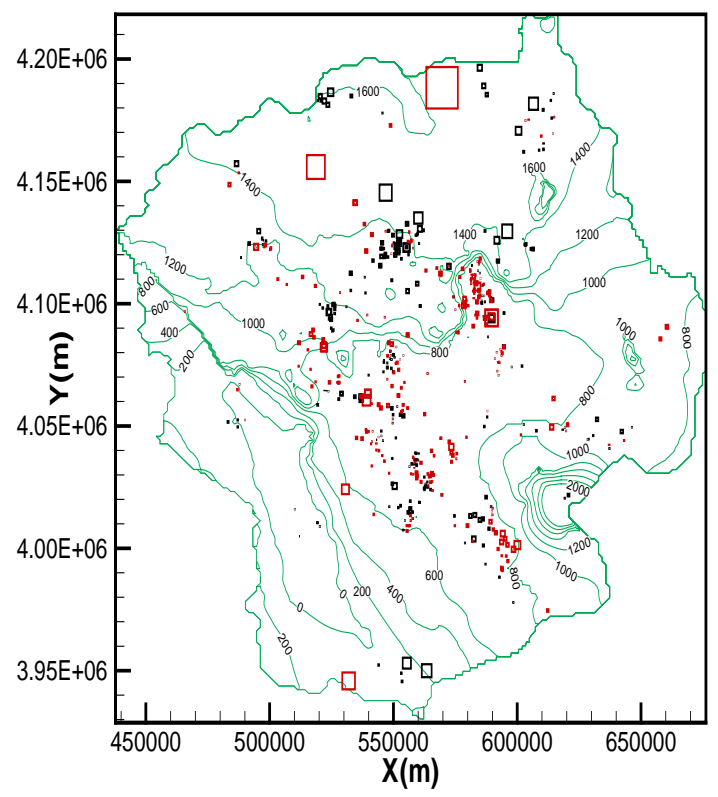

Figure A-28. Distribution of weighted head residuals and contours of hydraulic head inlayer 1 of model G3R5. The red and black squares represent positive and negative residuals, respectively. Symbol size is scaled to the magnitude of the weighted residuals. 
THIS PAGE INTENTIONALLY LEFT BLANK 


\section{APPENDIX B. CONVERSION OF THE CLIMAX SUB-CAU FLOW MODEL TO STEADY STATE CONDITIONS}

Following the guidance presented by Blainey et al. (2006), the Climax sub-CAU regional flow model was converted to steady state conditions to reduce simulation times during sensitivity analysis, calibration, and forward runs. The model used as the basis for the conversion is the calibrated forward run incorporating the USGS net infiltration recharge model and USGS hydrostratigraphic framework model. This is model G1R2 as described by Pohlmann et al. (2007).

Modifications were made to the following files:

(1) Discretization. File DIS_WT_CONFINED.txt renamed to DIS_WT_CONFINED_ss.txt. The value of NPER (number of stress periods in the simulation) was changed from 87 to 1 to specify a single stress period. NSTP (number of time steps in a stress period) changed from 6 to 1 to utilize a single time step. All lines describing transient stress periods were deleted (i.e., lines 24 through 109).

(2) Hydrogeologic Unit Flow Package. File HUF2_CONFINED.txt renamed HUF2_CONFINED_ss.txt. The value of NPHUF (number of HUF parameters) was changed from 69 to 62 to reflect the removal of the seven storage parameters. The seven storage parameters were deleted from lines 246 through 283.

(3) Sensitivity Process. File SENSITIVITY.txt renamed SENSITIVITY_ss.txt. The values of NPLIST (number of named parameters listed) and MXSEN (maximum number of parameters for which sensitivities are to be calculated) were changed from 100 to 93 to reflect the removal of the seven storage parameters. The seven storage parameters were deleted from lines 97 through 103.

(4) Name File. File name.txt. The MNW file MNW_withdrawal_1_7_20.txt was deactivated and other file names were modified to reflect their steady-state versions.

(5) Output Control. File OC.txt renamed OC_ss.txt. Removed references to stress periods after stress period 1 (lines 14 through 27) and specified printed output for stress period 1 time step 1 (line 7).

(6) Drain Observation Package. File DROB_tr.txt renamed DROB_ss.txt. Value of IREFSP (stress period to which the observation time is referenced) changed from 86 to 1 for all drain observations. Removed drain observations OB-PAH-BENT, O-PAHBENT, OBS-PAH-MANS, and OB-PAH-MANS since their time-varying discharge rates do not represent steady-state conditions. Changed value of NQDR (number of cell groups for which drain observations are listed) and NQTDR (total number of drain observations for all cell groups) from 49 to 45 . Changed value of NQCDR (greater than or equal to the total number of cells in all cell groups) from 787 to 769.

(7) Head-Observation Package. File HOBs_sstr.txt replaced by HOBs_ss.txt. Steadystate head observations were obtained as a shapefile from the DVRFS Project Data website as described in the metadata for steady-state, pre-pumped hydraulic-head observations for the DVRFS model at http://rmgsc.cr.usgs.gov/metadata/dvrfs/hobs_ss.htm. File hobs_ss.dbf was extracted 
from the archive hobs_ss.zip and converted to an OpenOffice Calc spreadsheet with the necessary columns, then exported to text file hobs_ss.dat. File hobs_ss.dat was then reformatted to create a steady-state MODFLOW HOBs input file named HOBs_ss.txt that is projected on the refined mesh of the Climax sub-CAU flow model.

A comparison of the mass balance results computed at the end of stress period 1 , time step 6 of the original transient model (G1R2) and the corresponding steady-state model is presented in Table B-1. Stress period 1 is the steady-state, pre-development stress period of the transient model. The mass balance results for the two versions of the model are identical.

Table B-1. Mass balance (flow rate in $\mathrm{m}^{3} / \mathrm{d}$ ) for the transient and steady-state versions of the Climax sub-CAU regional flow model G1R2.

\begin{tabular}{|c|c|c|c|c|}
\hline \multirow[t]{2}{*}{ Model ID } & \multicolumn{2}{|c|}{$\begin{array}{c}\text { Transient G1R2 Model } \\
\text { CRFM tr.01 }\end{array}$} & \multicolumn{2}{|c|}{$\begin{array}{c}\text { Steady-State G1R2 Model } \\
\text { CRFM ss.00 }\end{array}$} \\
\hline & Cumulative & Time Step 6 & Cumulative & Time Step 6 \\
\hline \multicolumn{5}{|l|}{$\mathbf{I N}\left(\mathrm{m}^{3} / \mathrm{d}\right)$} \\
\hline Constant head & $166,220,162$ & 455,086 & $166,220,162$ & 455,086 \\
\hline Recharge & $65,826,349$ & 180,223 & $65,826,349$ & 180,223 \\
\hline Total & $232,046,511$ & 635,309 & $232,046,511$ & 635,309 \\
\hline \multicolumn{5}{|l|}{ OUT $\left(\mathrm{m}^{3} / \mathrm{d}\right)$} \\
\hline Constant head & $112,296,515$ & 307,451 & $112,296,515$ & 307,451 \\
\hline Drains & $119,782,464$ & 327,946 & $119,782,464$ & 327,946 \\
\hline Total & $232,078,979$ & 635,397 & $232,078,979$ & 635,397 \\
\hline In - Out $\left(\mathrm{m}^{3} / \mathrm{d}\right)$ & $-32,468$ & -89 & $-32,468$ & -89 \\
\hline Percent difference & -0.01 & -0.01 & -0.01 & -0.01 \\
\hline
\end{tabular}

The sum of squares weighted residuals for the steady state model are listed in Table B2. Corresponding values for the transient model are not listed because they represent a much larger set of head, drain, and constant-head boundary observations and thus are not suitable for comparison to these values.

Table B-2. Sum of Squared Weighted Residuals for observations in the steady-state model.

\begin{tabular}{lc}
\hline Hydraulic head & 10,730 \\
Drains & 633 \\
Constant head boundary flow & 116 \\
Total & 11,479 \\
\hline
\end{tabular}

Figures B-1 and B-2 are contour maps showing heads simulated by the transient and steady-state models in layer 1 (top layer) and 16 (base layer) respectively. Heads simulated in the two models are essentially identical to each other.

From these comparisons of the mass balance results and simulated heads for the transient and steady-state models, it can be concluded that conversion to steady-state conditions did not adversely change the structure, parameterization, or observation of the model in the steady-state, pre-pumping stress period. 


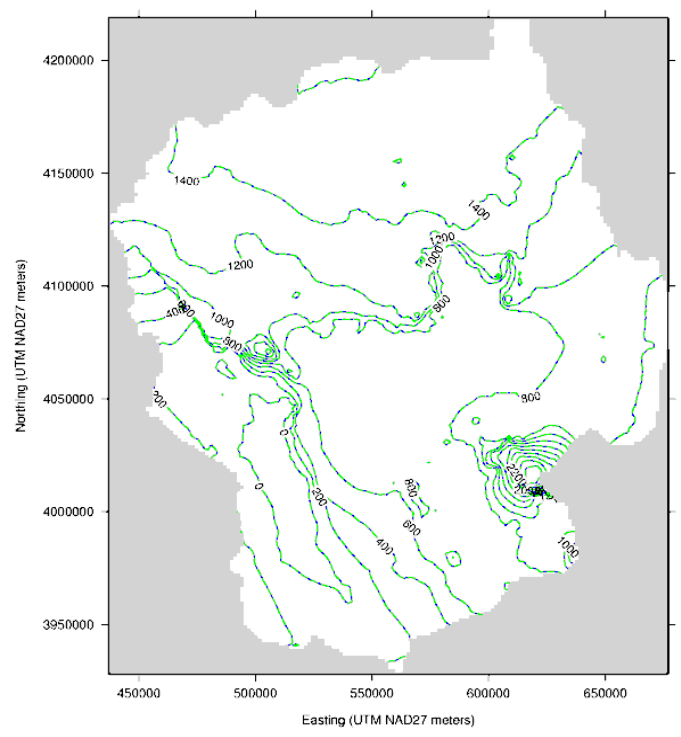

Figure B-1. Hydraulic heads simulated by the transient model (dashed green contour lines) and steady-state model (solid blue contour lines) in layer 1.

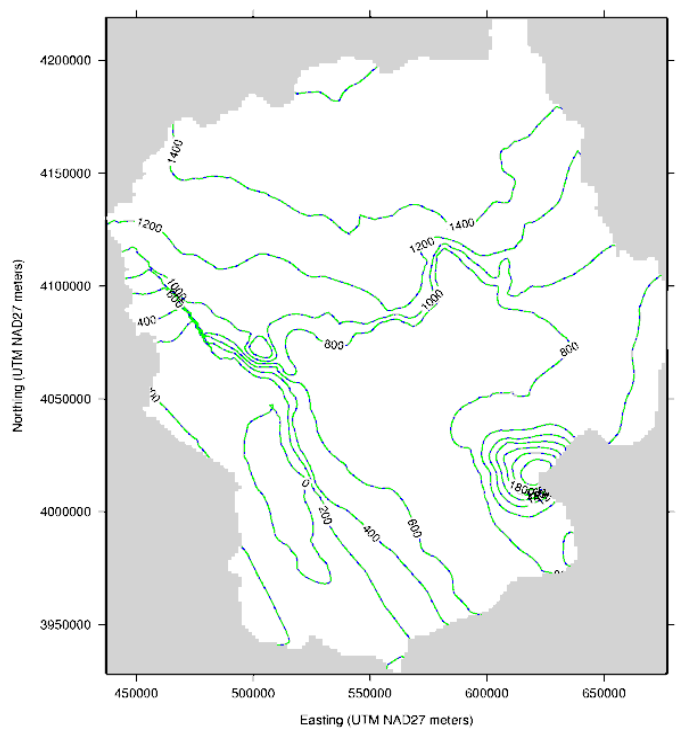

Figure B-2. Hydraulic heads simulated by the transient model (dashed green contour lines) and the steady-state model (solid blue contour lines) in layer 16. 


\section{References}

Blainey, J.B., C.C. Faunt, and M.C. Hill, 2006. A Guide for Using the Transient GroundWater Flow Model of the Death Valley Regional Ground-Water Flow system, Nevada and California. USGS Open-File Report 2006-1104.

Pohlmann, K., M. Ye, D. Reeves, M. Zavarin, D. Decker, and J. Chapman, 2007. Modeling of Groundwater Flow and Radionuclide Transport at the Climax Mine sub-CAU, Nevada Test Site. Desert Research Institute, Division of Hydrologic Sciences Publication No. 45226, DOE/NV/26383-06. 


\section{APPENDIX C. SOFTWARE}

MODFLOW-2000 (U.S. GEOLOGICAL SURVEY MODULAR FINITE-DIFFERENCE GROUND-WATER FLOW MODEL)

Version: 1.13 .00

Compiler: Intel FORTRAN Compiler for Linux, version 11.1.072

Operating system: Linux CentOS 5.5

DAKOTA (The Design Analysis Kit for Optimization and Terascale Applications)

Version: 5.0 released, subversion revision 6562

Compiler: gcc Compiler 4.1.2

Operating system: Linux CentOS 5.5

MATLAB (MathWorks)

Version: 7.8.0.347 (R2009a) 32-bit (glnx86).

Operating system: Linux CentOS 5.5

TECPLOT (Tecplot, Inc.)

Version:12.0.0.3454

Operating system: Linux CentOS 5.5

\section{Python Programming Language}

Version: 2.4.3

Compiler: GCC 4.1.2 20080704 (Red Hat 4.1.2-46)

Operating system: Linux CentOS 5.5

Quantum GIS

Version 1.5.0-Tethys

Operating System: Linux Ubuntu 10.04 LTS 